\title{
COVID-19 Pandemic: Review of Contemporary and Forthcoming Detection Tools
}

This article was published in the following Dove Press journal:

Infection and Drug Resistance

\begin{abstract}
Mumtarin Jannat Oishee $\mathbb{D}^{\prime}$
Tamanna Ali $\mathbb{D}^{\prime}$

Nowshin Jahan (D)

Shahad Saif Khandker (D)

Md Ahsanul Haq (D)

Mohib Ullah Khondoker $\mathbb{D}^{2}$

Bijon Kumar Sil (D) ${ }^{3}$

Halyna Lugova $\mathbb{D I}^{4}$

Ambigga Krishnapillai $\mathbb{D}^{4}$

Abdullahi Rabiu Abubakar (D) ${ }^{5}$

Santosh Kumar ${ }^{6}{ }^{6}$

Mainul Haque $\mathbb{D}^{7}$

Mohd Raeed Jamiruddin (I) $^{8}$

Nihad Adnan (D) ${ }^{9}$

'Gonoshasthaya-RNA Molecular Diagnostic and Research Center, Dhaka, Bangladesh;

${ }^{2}$ Gonoshasthaya Samaj Vittik Medical

College, Dhaka, I344, Bangladesh; ${ }^{3}$ Gono

Bishwabidyalay, Dhaka, 1344, Bangladesh;

${ }^{4}$ Faculty of Medicine and Defence Health,

National Defence University of Malaysia,

Kuala Lumpur, Malaysia; ${ }^{5}$ Department of

Pharmacology and Therapeutics, Faculty of

Pharmaceutical Sciences, Bayero University,

Kano, 700233, Kano, Nigeria; ${ }^{6}$ Department

of Periodontology and Implantology,

Karnavati University, Gandhinagar, 382422,

India; ${ }^{7}$ The Unit of Pharmacology, Faculty of

Medicine and Defence Health Universiti

Pertahanan, Nasional Malaysia (National

Defence University of Malaysia), Kuala

Lumpur, Malaysia; ${ }^{8}$ Department of Pharmacy,

BRAC University, Dhaka, 12/2, Bangladesh;

${ }^{9}$ Department of Microbiology, Jahangirnagar

University, Dhaka, I342, Bangladesh
\end{abstract}

Correspondence: Mainul Haque

The Unit of Pharmacology, Faculty of

Medicine and Defence Health, Universiti

Pertahanan, Nasional Malaysia (National

Defence University of Malaysia), Kem

Perdana Sungai Besi, Kuala Lumpur,

57000 , Malaysia

Tel +60109265543

Email runurono@gmail.com
Abstract: Recent severe acute respiratory syndrome 2 (SARS-CoV-2) known as COVID19 , presents a deadly challenge to the global healthcare system of developing and developed countries, exposing the limitations of health facilities preparedness for emerging infectious disease pandemic. Opportune detection, confinement, and early treatment of infected cases present the first step in combating COVID-19. In this review, we elaborate on various COVID-19 diagnostic tools that are available or under investigation. Consequently, cell culture, followed by an indirect fluorescent antibody, is one of the most accurate methods for detecting SARS-CoV-2 infection. However, restrictions imposed by the regulatory authorities prevented its general use and implementation. Diagnosis via radiologic imaging and reverse transcriptase PCR assay is frequently employed, considered as standard procedures, whereas isothermal amplification methods are currently on the verge of clinical introduction. Notably, techniques such as CRISPR-Cas and microfluidics have added new dimensions to the SARS-CoV-2 diagnosis. Furthermore, commonly used immunoassays such as enzyme-linked immunosorbent assay (ELISA), lateral flow immunoassay (LFIA), neutralization assay, and the chemiluminescent assay can also be used for early detection and surveillance of SARS-CoV-2 infection. Finally, advancement in the next generation sequencing (NGS) and metagenomic analysis are smoothing the viral detection further in this global challenge.

Keywords: SARS-CoV-2, COVID-19, severe acute syndrome, diagnostic, detection-tools, immunoassay, amplification, gene-sequencing, cell-culture, microscopy

\section{Introduction}

The outbreak of unknown severe pneumonia, first reported in December 2019 in Wuhan city of China, has turned into a global pandemic and a rapidly emerging crisis. $^{1}$ A novel strain of coronavirus, similar to the acute SARS-CoV of 2002-2003, was responsible for the current pandemic (COVID-19). Henceforth, it was named Severe Acute Respiratory Syndrome Coronavirus-2 (SARS-CoV-2), ${ }^{2-4}$ there is no universally approved treatment protocol is available other than symptomatic treatment, although FDA recently provided emergency use authorization to Remdesivir. ${ }^{5}$ Concerted effort globally paves the way into vaccine development. Currently, FDA has approved Pfizer-BioNTech COVID-19 Vaccine and Moderna COVID-19 vaccine for emergency use authorization. ${ }^{6-8}$ Following FDA approval, other countries have also approved the vaccine for mass roll-out. ${ }^{9-11}$

Early diagnosis is of prime importance for disease containment and reducing transmission by quick isolation of patients and supporting critical treatment. 
Real-Time Reverse Transcriptase Polymerase Chain Reaction (rRT-PCR) has been the most widely implemented SARS-CoV-2 diagnostic tool. ${ }^{12}$ An increasing urge for point-of-care tests predisposes the availability of several other diagnostic tools and techniques. Point of care tests are generally updated technologies that include both the rapid and laboratory-free diagnosis, which plausibly would meet the urgency of the ongoing situation. $^{13}$ A recently published review paper on COVID-19 diagnostics by Yüce et al focused on the principles of available molecular and serological diagnostic tests along with explaining Emergency Use Authorization-issued commercial test kits while another evaluated the two mainstream of diagnostics - molecular and serology in the light of only FDA approved kits. $^{14,15}$ Moreover, review on the suitable sampling site or solely on the principles of diagnostics have also been published. ${ }^{16,17}$ However, a comprehensive review covering all the available in-use and potential technologies for SARS-CoV-2 detection along with their strengths and drawbacks as well as suitable sampling sites is required to fill the gap. Our current review is intended to elaborate the missing piece pertaining to all the up-to-date FDA-approved kits and discuss the emerging technologies with the potentials as supporting diagnostic tools.

\section{Methodology}

A thorough search was performed using online databases such as Google Scholar, PubMed, ScienceDirect independently, using such keywords as "COVID-19", "SARS-CoV-2", "Novel coronavirus", "n-CoV", "Diagnosis", "Diagnostic" without any year restriction. Further, required information were also collected from authentic websites (ie, WHO, FDA, etc.). Only English literature was included. References were managed using EndNote software (Version X7).

\section{Diagnostic and Detection Methods}

The deployment of different diagnostic tests (Figure 1) varies depending on resource facilities, the urgency in obtaining results, and the type of methods available. Presently available test procedures are categorized in Table 1.

\section{Cell Culture and Microscopy}

Cell culture, followed by microscopic technique, has been instrumental in pathogen identification and detection of

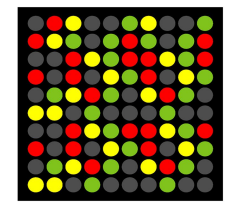

Microarray

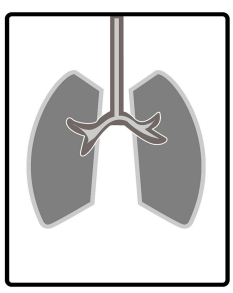

X-ray/ CT

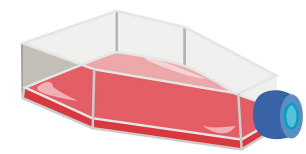

Cell Culture

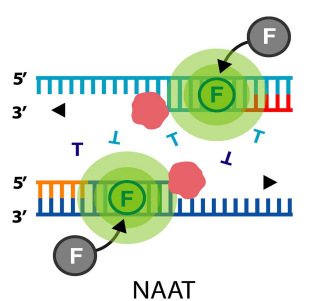

NAAT

COVID-19 DIAGNOSTICS

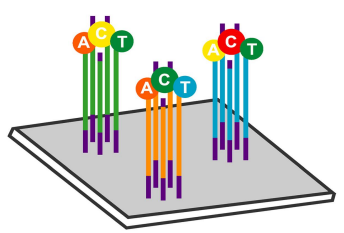

NGS Sequencing

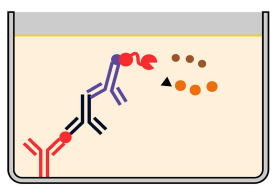

ELISA
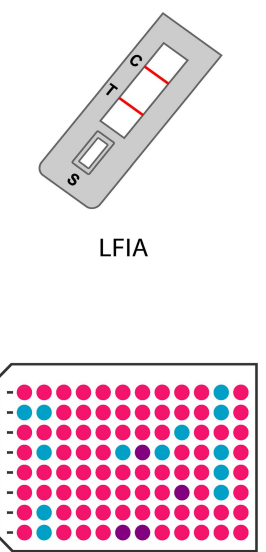

Neutralizing Assay

Figure I Graphical representation of various diagnostic assays of COVID-19.

Abbreviations: NAAT, nucleic acid amplification test; ELISA, enzyme-linked immunosorbent assay; CT, computed tomography; LFIA, lateral flow immunochromatographic assays; NGS, next-generation sequencing. 
Table I Present COVID-19 Test Procedures

\begin{tabular}{|c|c|}
\hline Mode of Detection & Detection Methods \\
\hline Culture-based detection & - Virus propagation in cell lines \\
\hline Radiology based technology & $\begin{array}{l}\text { - X-Ray } \\
\text { - Chest Computed Tomography }\end{array}$ \\
\hline Molecular technology & $\begin{array}{l}\text { - } \text { Real-Time RT-PCR } \\
\text { - Isothermal amplification } \\
\text { - CRISPR-Cas technology } \\
\text { - Lab-on-chip }\end{array}$ \\
\hline Immunoassay technology & $\begin{array}{l}\text { - ELISA } \\
\text { - Neutralization assay } \\
\text { - Chemiluminescent assay } \\
\text { - Lateral Flow Assay } \\
\text { - Dip-stick }\end{array}$ \\
\hline $\begin{array}{l}\text { Technology under } \\
\text { development }\end{array}$ & $\begin{array}{l}\text { - } \text { Aptamer } \\
\text { - Molecular imprinting technology } \\
\text { (MIT) } \\
\text { - Microarray } \\
\text { - Biosensors } \\
\text { - MALDI-TOF profiling }\end{array}$ \\
\hline Sequencing technologies & $\begin{array}{l}\text { - Sanger-sequencing } \\
\text { - Next-generation sequencing } \\
\text { - Nanopore sequencing }\end{array}$ \\
\hline
\end{tabular}

emerging diseases. ${ }^{18-21}$ In the ongoing SARS-CoV-2 pandemic, these techniques are used for both diagnostics and research purposes. ${ }^{22-27}$ In this approach, following the initial identification by sequencing, the novel virus's identity is confirmed through immunofluorescence microscopy using a cross-reactive viral antibody. Also, electron microscopy reveals its typical coronavirus-like morphology. ${ }^{28,29}$ Microscopy and cell culture have also provided insights into its structural organization, cell tropism, pathogenesis, transmissibility and replication, and host-virus interaction. ${ }^{23,30,31}$ However, WHO dictates that such culture and propagation of SARS-CoV-2 be carried out in biosafety level 3 laboratories only, making its wider use unrealistic in public and commercial settings. ${ }^{32}$

\section{Radiology-Based Detection}

Multiple studies are advocating radiologic imaging such as chest radiograph (CXR), chest ultrasound (US), lung ultrasound (LUS), and particularly chest computed tomography (chest CT) as complementary and, in some cases, as standard diagnosis method of COVID-19. ${ }^{33-47}$ Patients who developed COVID-19 pneumonia shared similar lung abnormalities. ${ }^{48}$ Peripheral ground-glass opacities, multiple bilateral consolidation, crazy paving patterns, and reticular pattern are standard features found in chest CT of pneumonia patients. ${ }^{41}$ Although China's health commission has defined radiologic features as a significant criterion for COVID-19 diagnosis, the scientific community remains uncertain. $^{39,49}$ A meta-analysis of chest CT's diagnostic accuracy for COVID-19 detection reported that it has an overall high sensitivity, especially in difficult epidemic situations. ${ }^{38} \mathrm{Li}$ and Xia said that CT-based findings could identify COVID-19 earlier than laboratory results with a $3.8 \%$ misdiagnosis rate. ${ }^{40}$ The limitations of CT to be taken into consideration are: (i) CT features of COVID-19 patients can overlap with other infections including SARS-CoV, MERS-CoV, influenza, and H1N1, thus limiting its capacity in distinguishing between COVID-19 and other pneumonia, (ii) Typical CT manifestation of COVID19 patients are only found in the later stage and mostly absent in earlier phase or asymptomatic patients, (iii) most of the studies supporting CT are based in China which warrants the need for more evidence-based studies in other regions. ${ }^{49}$ Also, the success of the technique depends on the experience of radiologists. Conversely, the American College of Radiology (ARC) does not recommend CT to be used as a first-line test or for screening to diagnose COVID19 , and if used, should only be in cases where the patient has already been hospitalized with symptoms and clinical signs for $\mathrm{CT}^{50}$

\section{Nucleic Acid Amplification Tests}

Generally, lack of understanding regarding the clinical manifestations, symptoms, and epidemiological features of SARS-CoV-2 hinders the containment and management efforts for the COVID-19 infection. However, such efforts can be better realized with a rapid, and accurate diagnosis. Molecular diagnosis by nucleic acid amplification of the virus paves the way. Specific probes and primers designed and updated with the enrichment of sequence data render nucleic acid amplification test (NAAT) an ideal mode of diagnosis. These tests supplement the demanding situation, including Real-Time Reverse Transcriptase Polymerase Chain Reaction (rRT-PCR), isothermal amplification methods, and CRISPR-Cas based detection system. ${ }^{51-53}$

In addition to diagnose SARS-CoV-2 virus, FDA recently authorized emergency use tests. One of them is Abbott Diagnostics' ID NOW COVID-19, which detects the $R d R p$ gene from nasal or nasopharyngeal swab $(95 \%$ sensitivity and $100 \%$ specificity). FDA also approved TaqPath COVID-19 Combo kit (ThermoFisher-Applied 
Biosystems), Smart Detect SARS-CoV-2 rRT-PCR Kit (InBios International, Inc.), Biomeme SARS-CoV-2 RealTime rRT-PCR Test (Biomeme, Inc) which detect Orflab, $E, N$, and $S$ gene (mentioned in Table 2). Besides several diagnostic kits like US Food and Drug Administration (USFDA) certified Sherlock Biosciences's CRISPR SARS-CoV-2 Rapid Diagnostic kit as the first CRISPRbased assay which is a combined approach done by using RT-PCR, CRISPR-based assay. Atila BioSystems Inc., on the other hand, has developed FDA approved iAMP COVID-19 detection kit, using isothermal amplification technology (Table 2).

\section{Real-Time RT-PCR}

Viral RNA is initially reverse transcribed into short cDNA using RNA-dependent DNA polymerase ( $R d D p)$, which is facilitated by appropriate primer specific for viral RNA genome sequences. ${ }^{54}$ Real-time PCR technology allows monitoring the ongoing DNA amplification in real-time, yielding quantitative measurement of PCR amplicons; Amplification process repeats for around 40-45 cycles to detect viral DNA by using specific DNA probe tagged with a fluorophore and a quencher (TaqMan assays) or sequence nonspecific fluorogenic dye (SYBR Green). ${ }^{55-57}$ While performing Real-Time RT-PCR, the total reaction is carried out in a single tube starting from cDNA synthesis to PCR amplification, referred to as a one-step procedure. Another way is a two-step procedure where cDNA synthesis and amplification are performed in separate tubes. Though the two-step procedure provides greater sensitivity, flexibility, and the advantage of multiple cDNA usage, the one-step approach is the preferred method for SARS-CoV-2 detection in diagnostic settings. ${ }^{58}$ The technique is not tedious, involves less sample handling, thereby lowering the possibilities of cross-contamination between reverse transcription and PCR steps. ${ }^{59,60}$

For SARS-CoV-2 detection, several genomic regions are being used as targets for PCR amplification. This includes nucleocapsid $(\mathrm{N})$, envelope (E), spike (S), genes, RNA-dependent RNA polymerase (RdRP), ORF1ab, or ORF8 regions. ${ }^{61,62}$ For SARS-CoV-2 detection, several in-house and commercial assays have been developed based on either of these genes. Some manufacturers or authors suggest identifying one gene as a screening step and another gene detection as a confirmatory test. ${ }^{62,63}$ On the contrary, three or more genes are suggested to be examined by others, requiring all genes to be detected for being optimistic. ${ }^{64-66}$ For example, researchers at the University of Hong Kong retained $N$ gene identification as a screening procedure and ORF1ab detection as a confirmatory test. ${ }^{67}$ The National Institute of Infectious Diseases of Japan recommends nested RT-PCR test targeting ORFla, $S$ gene, and $N$ gene. ${ }^{68}$

Real Time-PCR by nasopharyngeal and respiratory samples is considered the gold standard for the qualitative detection of SARS-CoV-2 infection. ${ }^{67}$ Several studies suggested that SARS-CoV-2 viral nucleic acid can be detectable at several locations, including sputum, nasopharyngeal swab, bronchial aspirates, bronchoalveolar lavage fluid (BAL), blood, anal swab, and urine. ${ }^{12,69,70} \mathrm{In}$ a study of 4800 cases in a single hospital in China, bronchoalveolar lavage fluid showed the highest rate of detection (100\%) for the ORFlab gene of SARS-CoV-2, followed by nasal and pharyngeal swabs samples (38.25\%) and the sputum (49.12\% positive rate) ${ }^{71}$ However, another study conducted on sputum samples and nasopharyngeal swab samples collected from sixty-three subjects on the same day revealed that representatives from nasopharyngeal swab were distinct from sputum samples, which yielded some-false negatives. This may be because of specimen type and processing. ${ }^{72}$ In addition to low viral count in the nasal and pharyngeal swab, variable and inherently unstable rRT-PCR test results make it difficult to diagnose SARS-CoV-2. ${ }^{73}$ One of the most extensive head-to-head comparisons of nasopharyngeal (NP) and oropharyngeal/nares $(\mathrm{OP} / \mathrm{Na})$ swab for the detecting SARS-CoV-2 demonstrated that OP/Na sampling is a suitable alternative for COVID-19 detection in symptomatic ambulatory patients. ${ }^{74}$ When the oral swab is negative during the late infection, identifying the virus in blood and anal swab may be an alternative strategy. ${ }^{75}$ Wang et al detected SARS-CoV2 in multiple sites' specimens and found lower respiratory tract specimens positive in most cases. ${ }^{16} \mathrm{~A}$ recent meta-analysis of 11 studies encompassing 3442 respiratory specimens reveals sputum testing having higher sensitivity for SARS-Cov-2 detection than the other respiratory sites. ${ }^{76}$ Recently, saliva samples have also been claimed as a reliable tool for diagnosis by realtime rRT-PCR. ${ }^{77}$ Furthermore, patients with mild COVID19 symptoms may result in false-negative for nasopharyngeal samples. ${ }^{78}$ The existence of SARS-CoV-2 at multiple sites necessitates specimen collection from different body locations at different stages of infection for diagnosis by rRT-PCR. ${ }^{16,70}$ Suggested sampling sites and several studies' findings on suitable specimens for rRT-PCR are mentioned in Table 3. 


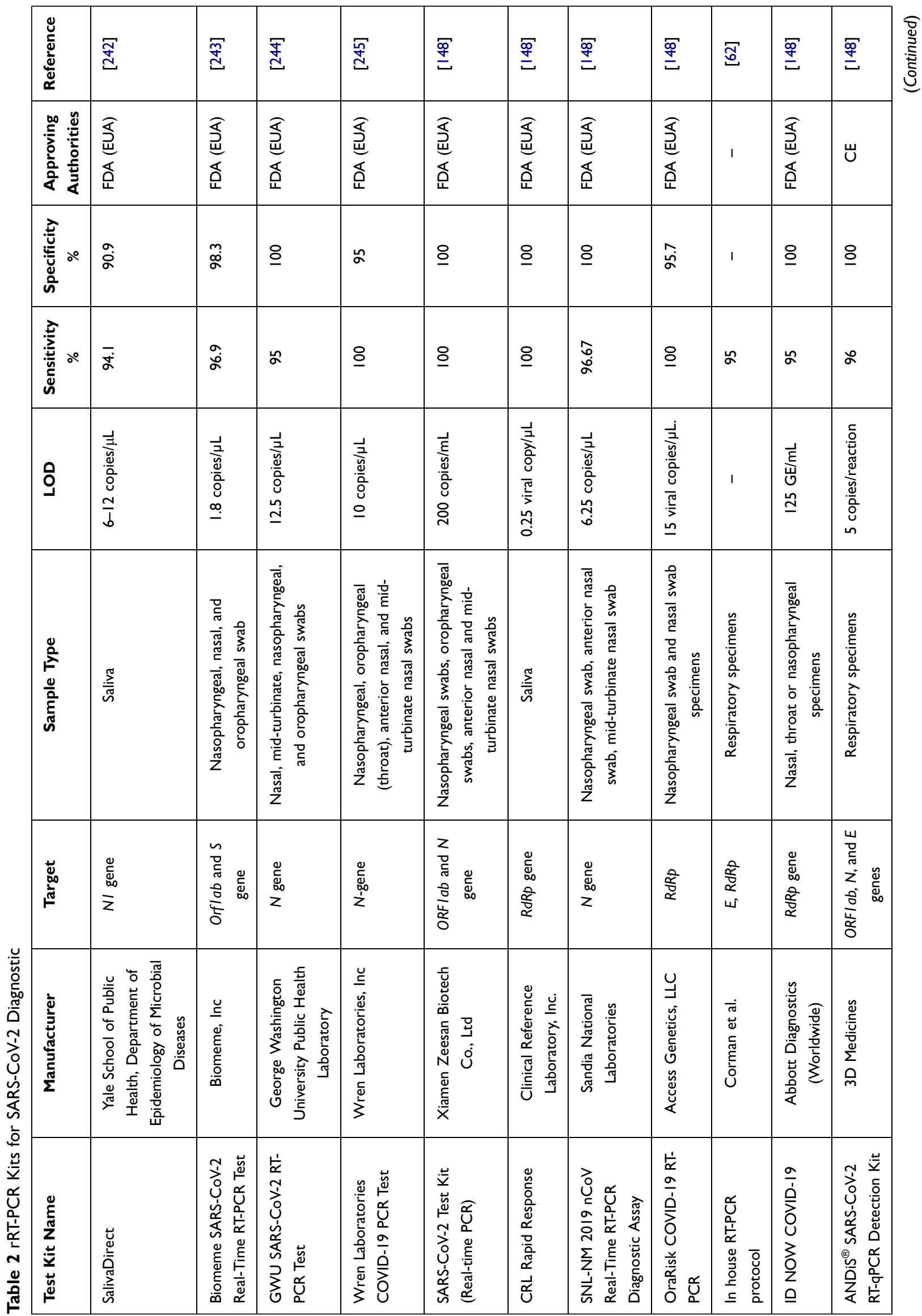




\begin{tabular}{|c|c|c|c|c|c|c|c|c|c|c|}
\hline 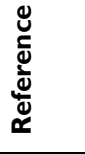 & 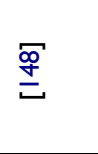 & $\stackrel{\text { og }}{v}$ & $\stackrel{\text { go }}{\underline{v}}$ & $\stackrel{\text { og }}{v}$ & $\stackrel{\text { og }}{v}$ & 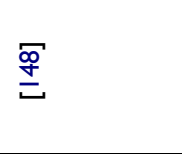 & 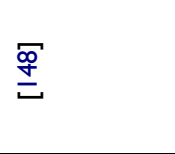 & 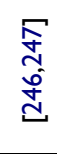 & $\stackrel{\text { 品 }}{\mathbf{d}}$ & $\underset{\sigma}{\stackrel{\sigma}{d}}$ \\
\hline 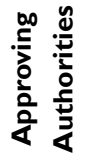 & U & U & 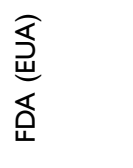 & 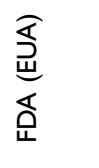 & 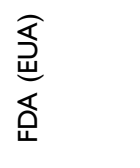 & 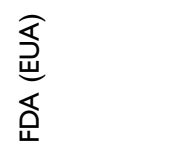 & 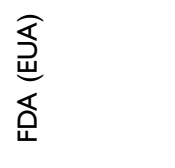 & 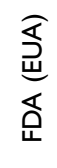 & 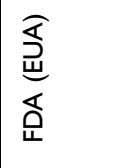 & 1 \\
\hline 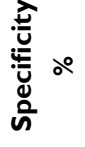 & ๙ & 으 & 으 & 으 & $\begin{array}{l}\triangle \\
\wedge 1\end{array}$ & 으 & 으 & 으 & 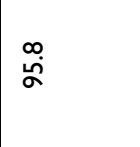 & fं \\
\hline 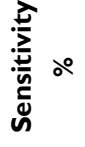 & హ & 으 & 으 & 으 & $\stackrel{\sim}{\wedge}$ & 으 & 으 & $\stackrel{2}{\circ}$ & นn & $\frac{m}{\sigma}$ \\
\hline oి & 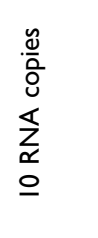 & 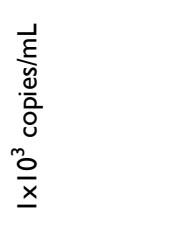 & 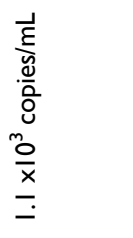 & 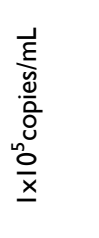 & 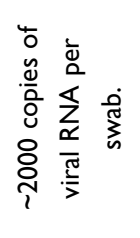 & 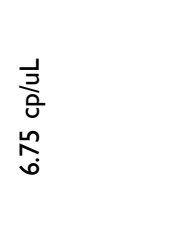 & 1 & 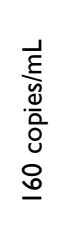 & 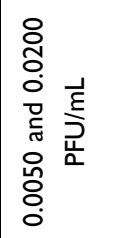 & 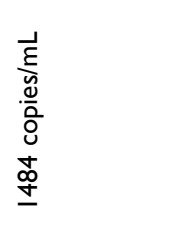 \\
\hline 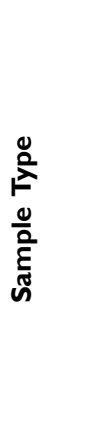 & 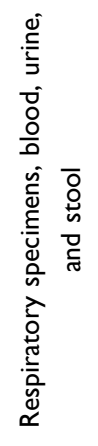 & 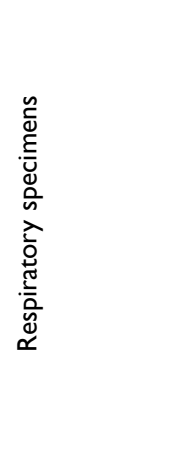 & 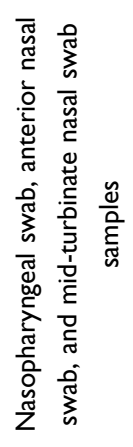 & 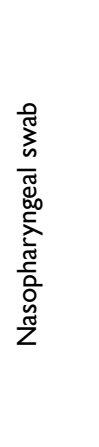 & 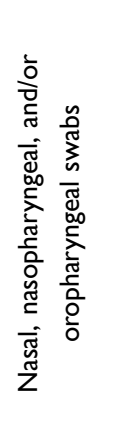 & 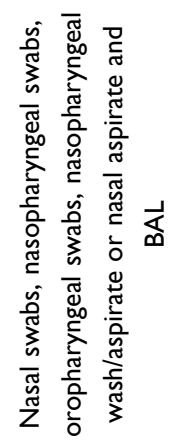 & 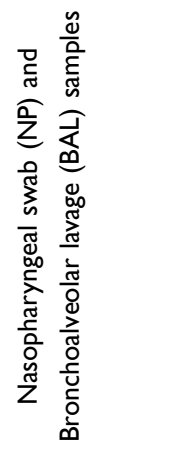 & 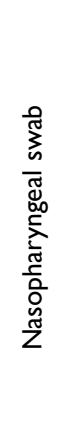 & 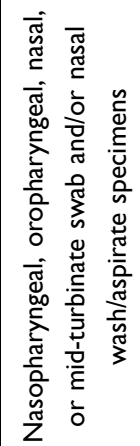 & 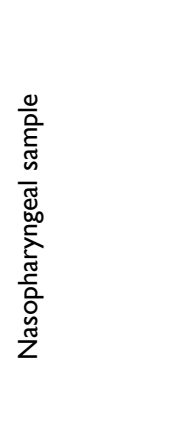 \\
\hline 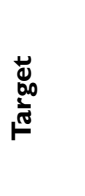 & 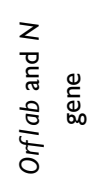 & 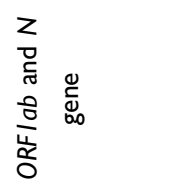 & 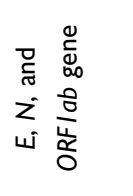 & 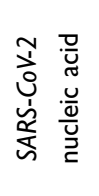 & 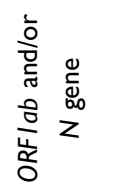 & 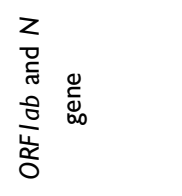 & 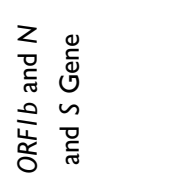 & 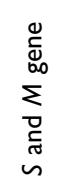 & $\begin{array}{l}w \\
w \\
0 \\
\tilde{c} \\
\tilde{z}\end{array}$ & 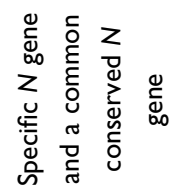 \\
\hline 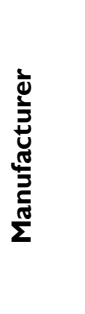 & $\begin{array}{l}\overleftarrow{s} \\
\dot{5} \\
\frac{5}{x} \\
\frac{x}{\infty} \\
\frac{0}{\infty}\end{array}$ & 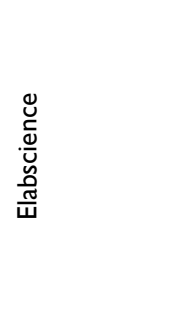 & 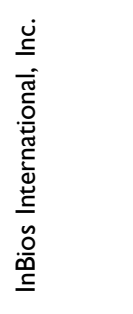 & 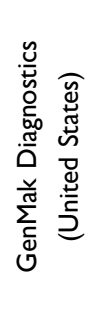 & 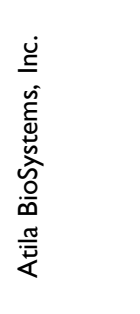 & 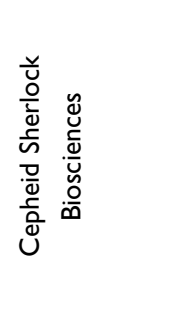 & 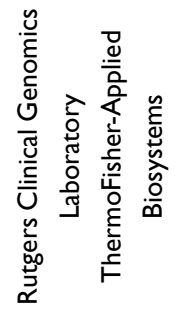 & 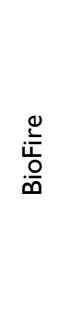 & 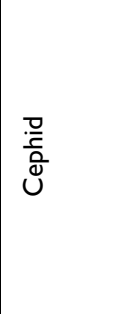 & 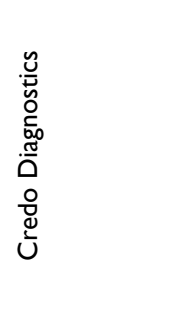 \\
\hline 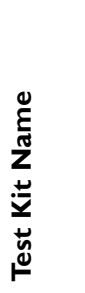 & 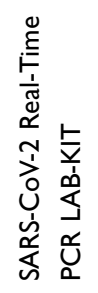 & 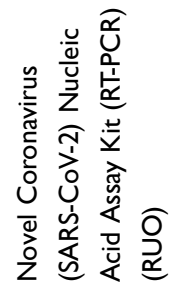 & 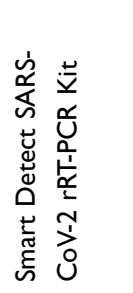 & 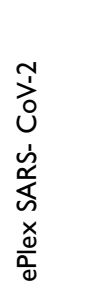 & 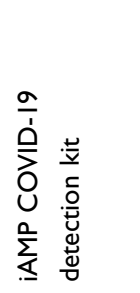 & 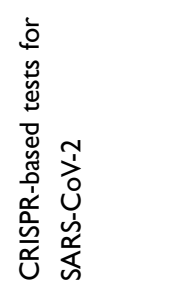 & 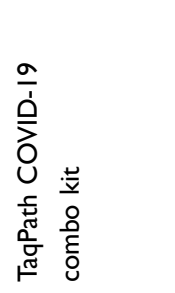 & $\begin{array}{l}\bar{i} \\
\frac{i}{\alpha} \\
0 \\
\stackrel{\underline{i}}{o} \\
\stackrel{o}{\infty}\end{array}$ & 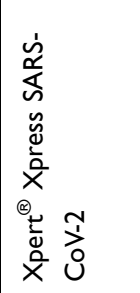 & 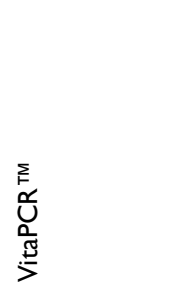 \\
\hline
\end{tabular}




\begin{tabular}{|c|c|c|c|c|c|c|c|c|c|c|c|}
\hline 品 & $\overline{\bar{\beth}}$ & 좀 & 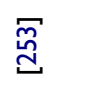 & 岧 & 氛 & 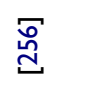 & 胥 & $\stackrel{\infty}{\stackrel{\infty}{ٌ ~}}$ & 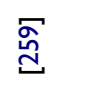 & 灾 & $\overline{\bar{d}}$ \\
\hline 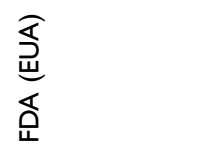 & $\begin{array}{l}\text { 胥 } \\
\text { 奀 }\end{array}$ & $\begin{array}{l}\text { 预 } \\
\text { 吕 }\end{array}$ & 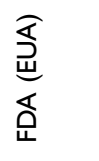 & 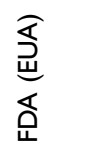 & $\begin{array}{l}\text { 胥 } \\
\text { 否 }\end{array}$ & 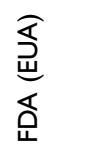 & 1 & 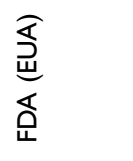 & $\begin{array}{l}\text { 盃 } \\
\text { 各 }\end{array}$ & 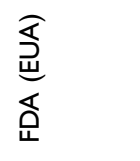 & 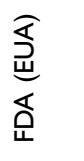 \\
\hline 으 & 으 & 으 & 으 & 으 & 으 & 으 & 으 & 으 & 으 & $\begin{array}{l}\stackrel{\circ}{\circ} \\
\infty \\
\infty\end{array}$ & 으 \\
\hline$\hat{\sigma}$ & 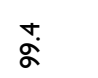 & 으 & 으 & 으 & $\stackrel{2}{\alpha}$ & థొ & 으 & 으 & 으 & \begin{tabular}{l}
$\stackrel{ \pm}{m}$ \\
\multirow{J}{*}{}
\end{tabular} & 으 \\
\hline 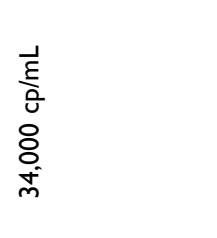 & 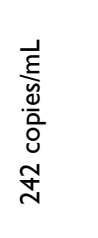 & 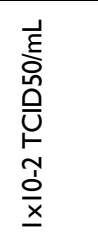 & $\begin{array}{l}\frac{1}{\frac{\partial}{2}} \\
\frac{0}{0} \\
\frac{\omega}{m}\end{array}$ & 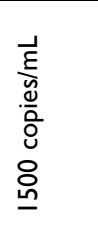 & 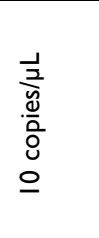 & 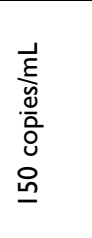 & 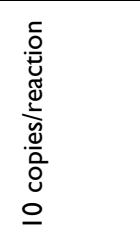 & 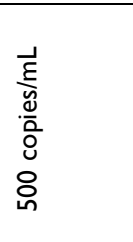 & 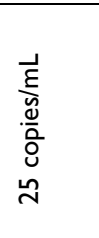 & 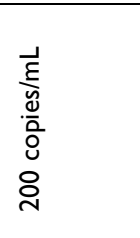 & $\begin{array}{l}\frac{1}{2} \\
\text { à } \\
\text { un. }\end{array}$ \\
\hline 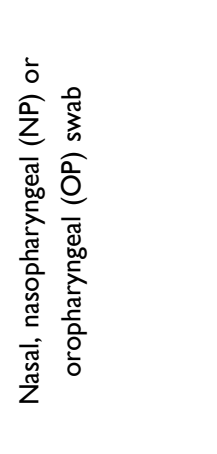 & 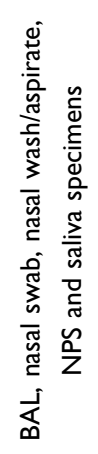 & 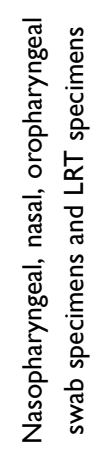 & 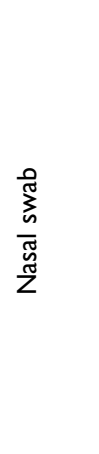 & 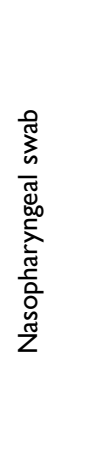 & 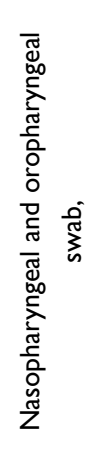 & 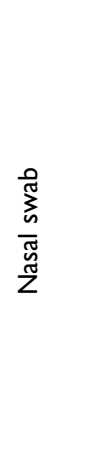 & 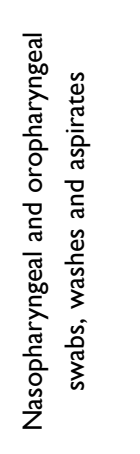 & 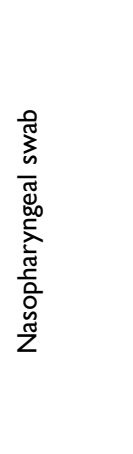 & 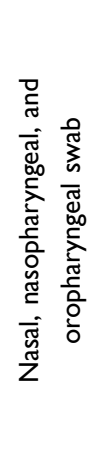 & 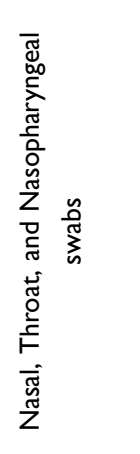 & 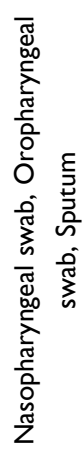 \\
\hline 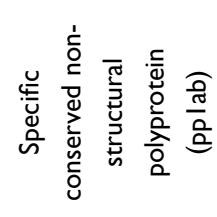 & 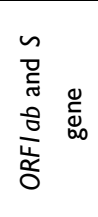 & 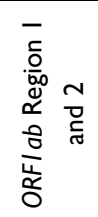 & 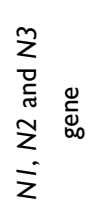 & 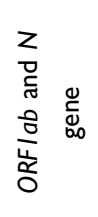 & 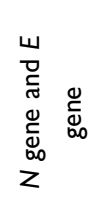 & 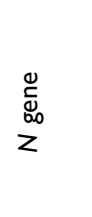 & 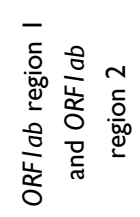 & 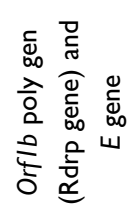 & 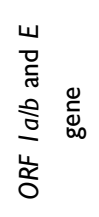 & 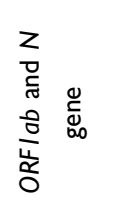 & 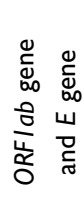 \\
\hline $\begin{array}{l}\overline{\bar{v}} \\
\overline{\bar{z}} \\
\bar{\partial}\end{array}$ & 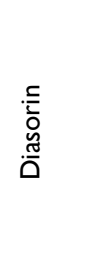 & $\begin{array}{l}\frac{\mathrm{U}}{\mathrm{b}} \\
\frac{\mathrm{O}}{\mathrm{O}} \\
\mathrm{T}\end{array}$ & $\begin{array}{l}0 \\
0 \\
0 \\
0 \\
0\end{array}$ & 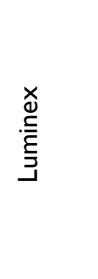 & 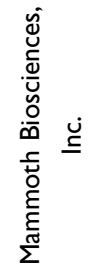 & 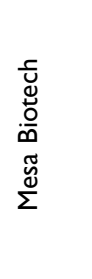 & 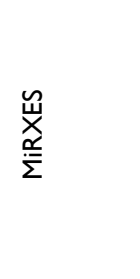 & $\begin{array}{l}\overline{\mathscr{d}} \\
\tilde{d} \\
\tilde{\sigma}\end{array}$ & 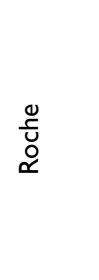 & 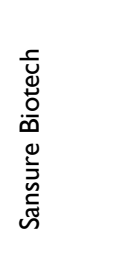 & 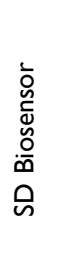 \\
\hline 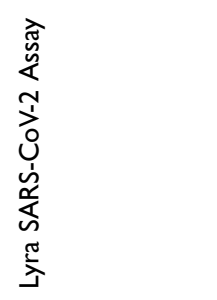 & 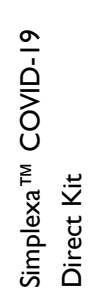 & 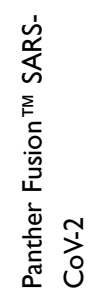 & 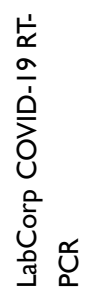 & 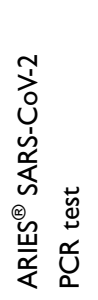 & 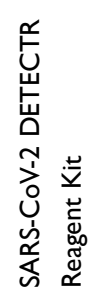 & 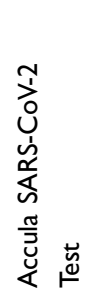 & 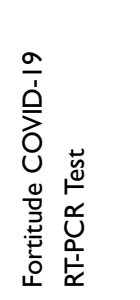 & 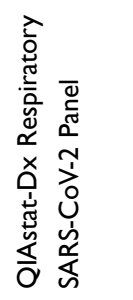 & 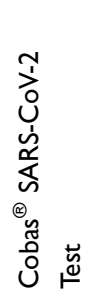 & 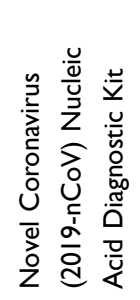 & 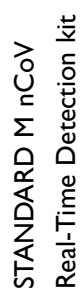 \\
\hline
\end{tabular}




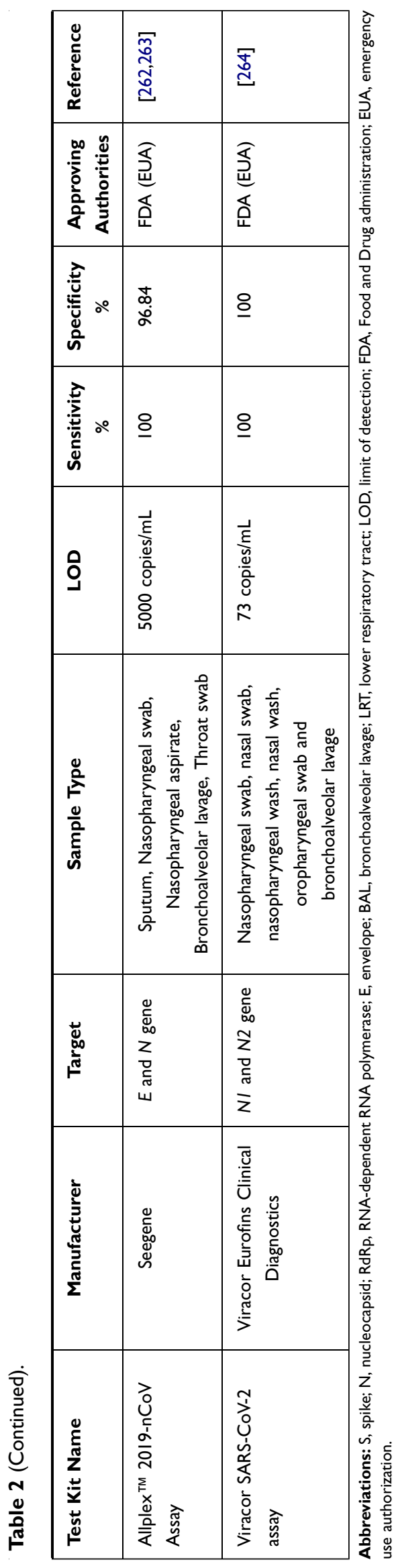

The rRT-PCR testing for COVID-19 holds various advantages. Its sensitivity and specificity are a method of choice in the early stages of infection. It provides valuable information during the acute phase of the disease when a person has not yet seroconverted. False-negative results, low stability, tedious working procedures, and lack of trained personnel and proper facilities are some of the limitations inherent with the rRT-PCR detection technique.${ }^{79}$ Furthermore, test accuracy is affected by different variables such as specimen collection site, sampling time point, procedure, and viral load, ie, LOD (Limit of Detection) of tests. These reasons result in decreased rRT-PCR sensitivity by $20 \%$ to $70 \%{ }^{71,80-83}$ The highest sensitivity, ie, lowest false-negative rate $(20 \%)$, is observed if the test is done on day eight after exposure, which approximates to 3 days after symptom onset, as depicted in Figure 2. ${ }^{82}$ Co-detection of other respiratory coronaviruses and low stability of RNA may account for false-negative results, too. ${ }^{78,84}$

Furthermore, the detection of multiple loci and differences in reagents' sensitivity to different genetic regions thwart the tests' accuracy and consistency. ${ }^{85,86}$ However, more research needs to be addressed to attain an accurate portrait of sensitivity and specificity. To overcome the limitations, manufacturers are now improvising current rRT-PCR test procedures with increased fidelity, as mentioned in Table 2. Considering all the factors, the US Food and Drug Administration (FDA) has deduced that negative real-time RT-PCR test result does not necessarily substantiate the absence of SARS-CoV-2 infection and shall not be the only factor in patient management decisions. ${ }^{87,88}$ Re-testing should be taken into consideration in consultation with public health authorities. ${ }^{89}$

\section{Isothermal Amplification Technologies}

Molecular diagnosis in the laboratory settings by conventional PCR methods needs to be swapped with Point-OfCare (POC) tests to increase test frequency and eliminate prolonged turn-around time. Such a test facilitates rapid, robust detection onsite in a cost-effective and user-friendly manner. One such promising molecular point-of-care test method includes Isothermal Nucleic Acid Amplification Techniques. ${ }^{90,91}$

\section{LAMP}

Isothermal amplification methods allow the circumvention of the need for sophisticated thermal cyclic equipment, costly reagents and facilities, and time-consuming steps of real-time RT-PCR. Reverse transcription 
Table 3 Recommended Plausible Sampling Sites by Several Studies for Real-Time RT-PCR

\begin{tabular}{|c|c|c|c|}
\hline Sampling Sites & $\begin{array}{l}\text { Sample Size/Study } \\
\text { Participants }\end{array}$ & Findings & Reference \\
\hline Sputum and nasopharyngeal swab & 8274 patients & $\begin{array}{c}\text { Nasopharyngeal swab samples with the more precise } \\
\text { result than sputum }\end{array}$ & [72] \\
\hline Pharyngeal swabs & 610 patients & $\begin{array}{l}\text { The variable and potentially unstable result from } \\
\text { Pharyngeal swabs }\end{array}$ & [73] \\
\hline $\begin{array}{l}\text { Oral swabs, anal swabs, and blood } \\
\text { samples }\end{array}$ & 178 subjects & $\begin{array}{c}\text { Blood and Anal swab positive when oral swab negative at } \\
\text { the later stage of infection }\end{array}$ & [75] \\
\hline $\begin{array}{l}\text { Nasopharyngeal swabs, sputum, blood, } \\
\text { feces, and anal swabs }\end{array}$ & 132 patients & $\begin{array}{l}\text { Rate of positive in sputum higher at an early stage, the } \\
\text { digestive tract nucleic acid (fecal/anal swab) is found at a } \\
\text { later stage of infection }\end{array}$ & [236] \\
\hline Nasal swab, throat swab, sputum & 76 patients & $\begin{array}{l}\text { Sputum induction suggested being more helpful than } \\
\text { throat swabs in convalescent patients }\end{array}$ & [237] \\
\hline $\begin{array}{l}\text { Bronchoalveolar lavage fluid, Pharyngeal } \\
\text { swabs, blood, sputum, feces, urine, and } \\
\text { nasal samples }\end{array}$ & $\begin{array}{l}1070 \text { specimens from } 205 \\
\text { patients }\end{array}$ & $\begin{array}{l}\text { Bronchoalveolar lavage fluid specimens with the highest } \\
\text { sensitivity }\end{array}$ & [16] \\
\hline $\begin{array}{l}\text { Urine, blood, anal swabs, and } \\
\text { oropharyngeal swabs }\end{array}$ & 74 patients & $\begin{array}{l}\text { Sample collection from multiple sites suggested by the } \\
\text { author. }\end{array}$ & [70] \\
\hline Sputum, throat swab, urine, and stool & 82 patients & $\begin{array}{l}\text { Viral load in sputum higher than throat swab, load in anal } \\
\text { swab less than respiratory samples. }\end{array}$ & [12] \\
\hline $\begin{array}{l}\text { Nasopharyngeal swabs, oropharyngeal } \\
\text { swabs, and sputum }\end{array}$ & $\begin{array}{l}291 \text { specimens from } 43 \\
\text { patients }\end{array}$ & $\begin{array}{l}\text { Sputum with the highest detection of SARS-CoV-2, } \\
\text { Nasopharyngeal swabs, and oropharyngeal swabs with } \\
\text { similar yield }\end{array}$ & [238] \\
\hline Saliva & 200 specimens & $\begin{array}{l}\text { Saliva pooling as a plausible alternative method in } \\
\text { ambulatory patients in a low prevalence setting. }\end{array}$ & [239] \\
\hline $\begin{array}{l}\text { Gargle lavage, Nasopharyngeal, and } \\
\text { oropharyngeal swab }\end{array}$ & 50 patients & Gargle lavage can be a viable alternative for swab sample & [240] \\
\hline $\begin{array}{l}\text { Upper respiratory tract samples, lower } \\
\text { respiratory tract samples, blood, and } \\
\text { others }\end{array}$ & $\begin{array}{l}\text { II } 3 \text { studies with a median } \\
\text { sample size of } 15 \text { patients } \\
\text { in all studies }\end{array}$ & $\begin{array}{l}\text { Viral load in sputum higher than the other upper } \\
\text { respiratory tract sample at the early stage of infection }\end{array}$ & [24I] \\
\hline
\end{tabular}

Loop-mediated isothermal amplification (RT-LAMP) is one such alternative rapid nucleic acid amplification method that can amplify DNA in 13-20 minutes by using DNA polymerase strand displacement activity at fixed temperature of $60-65^{\circ} \mathrm{C}$ while employing $4-8$ specially designed primers. ${ }^{92-95}$ Furthermore, reaction endpoint can be visually observed via photometry, where the turbidity is caused by precipitation of magnesium pyrophosphate or fluorescent dye. ${ }^{96-98}$ The advantage of detecting RNA directly from unpurified samples while being a rapid, robust, and relatively simple test has made it a method of choice for diagnosis of SARS-CoV-2. ${ }^{99-103}$ In one study, primers specific for nucleocapsid genes were found to detect 100 copies of RNA per reaction and were regarded as most sensitive. RT-LAMP test reported by Zhang et al virtually determined viral RNA at levels of approximately 4.8 copies per $\mu \mathrm{L}$, which was comparable with rRT-PCR. ${ }^{104}$ Recently, a novel real-time RT-LAMP assay has been developed with colorimetric versions performed in a single tube. The assay shows high sensitivity, a LOD of 118.6 copies/reaction, and reasonable specificity regarding common respiratory viruses. ${ }^{93}$ Direct swab-toRT-LAMP assay has also been developed faster and convenient, with less sensitivity and robustness. ${ }^{105}$ Multiplex RT-LAMP coupled with lateral flow biosensor has been devised, exhibiting 100\% sensitivity and specificity 


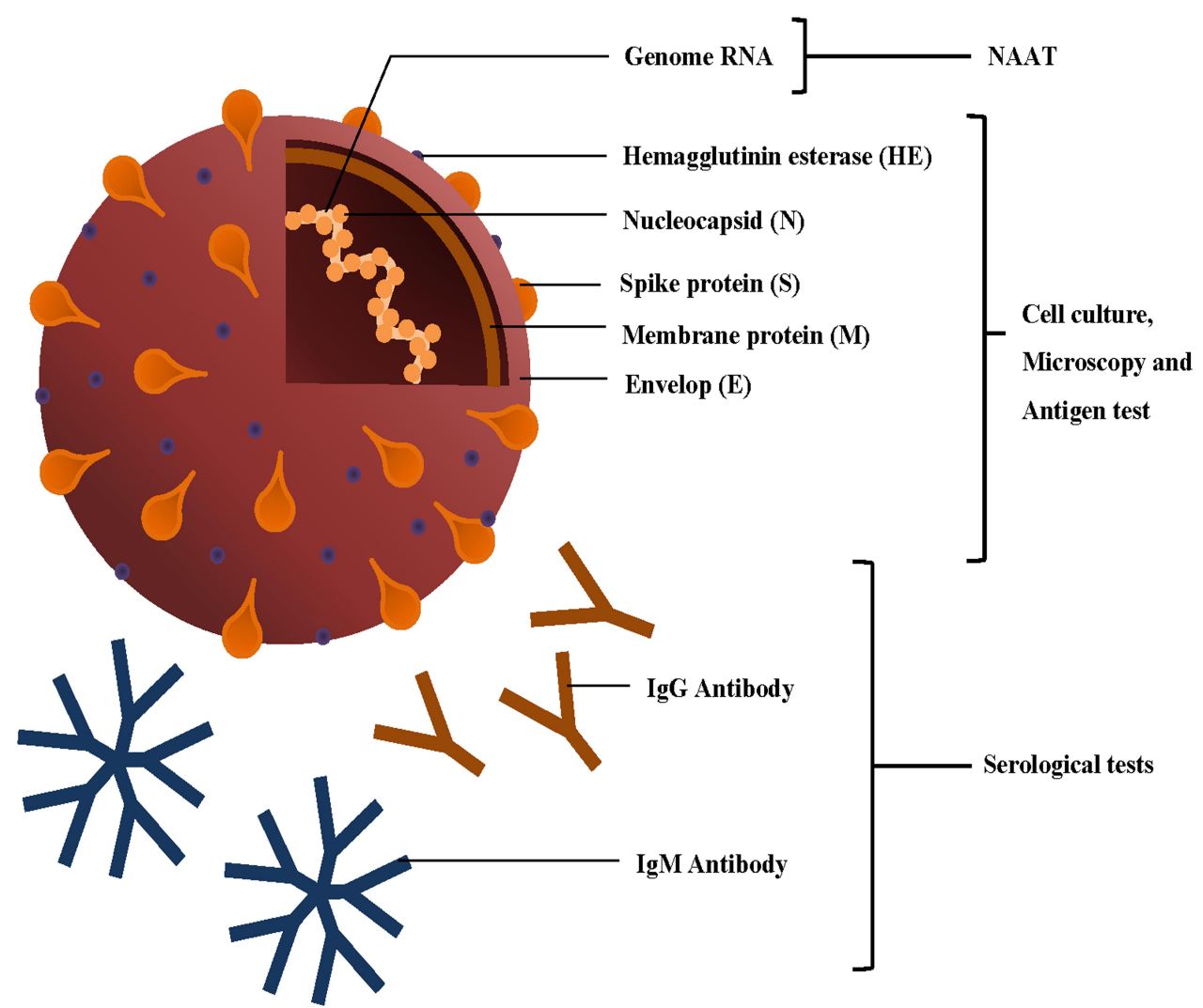

Figure 2 Simplified structure of SARS-CoV-2 and different tests based on viral RNA, proteins, and antibodies (ie, lgM and lgG) against viral antigens.

requiring 1 hour to attain results. ${ }^{106}$ Several studies comparing RT-LAMP with rRT-PCR demonstrated $>90 \%$ sensitivity while being simple, reliable, and high-throughput than conventional rRT-PCR methods. ${ }^{100,107-109}$

\section{Rolling Circle Amplification-Based Method}

Rolling circle amplification (RCA) is another efficient isothermal DNA amplification diagnostic method that employs a target-mediated padlock probe (PLP) and high fidelity DNA polymerase with strand-displacing capacities phi 29 or Bst DNA polymerase. ${ }^{110-112}$ The method is highly sensitive and robust amplifying signals by $10^{9}$ fold for each circle within 90 min. ${ }^{113,114}$ RCA and its variations are combined with different detection systems such as fluorescence detection, colorimetric assay, chemiluminescent assay, or electrical signal for target nucleic acid detection. ${ }^{115,116}$ Its ultrahigh sensitivity at the femtomolar level and specificity discriminating even single-base variants and eliminating complex instruments make it an attractive molecular diagnostic tool. ${ }^{117}$ Previously, RCA was performed in liquid and solid phases for SARS-CoV detection and applied to different biosensors to detect other targets. ${ }^{118-121}$ Recently, the Circular to Circular Amplification (C2CA) strategy, a modification of RCA, has been proposed as a promising technique to detect SARS-CoV-2 viral RNA. The proposed approach claims to achieve the detection limit at the sub-femtomolar level through simplified operation compared to previously reported C2CA-based sensors. ${ }^{122}$

\section{Other Isothermal Amplification Methods}

Other available isothermal amplification techniques include nucleic acid sequence-based amplification (NASBA), recombinase polymerase amplification (RPA), transcription-mediated amplification (TMA), multiple strand displacement amplification (SDA), isothermal helicase-dependent amplification (HDA), all of which can be used for nucleic acid detection. ${ }^{123,124}$ These varieties of testing methodologies are easy to operate, requiring a heatblock or water bath, providing constant temperature. ${ }^{125}$

Nucleic acid sequence-based amplification (NASBA), known as self-sustained sequence replication (3SR), has already been deployed in detecting different bacteria, parasites, and viral agents, including SARS-CoV. ${ }^{124,126-134} \mathrm{~A}$ testing approach has been proposed known as INSIGHT 
(Isothermal NASBA-Sequencing based hIGH-throughput Test) for SARS-CoV-2 detection comprising testing at two stages, Nucleic Acid Sequence-Based Amplification (NASBA) at $41^{\circ} \mathrm{C}$ and Next Generation Sequencing (NGS) technologies. ${ }^{135}$ This technique facilitates rapid fluorescence read-out, or lateral-flow read-out, specific to sequence at the first stage, further ascertained by NGS. This method provides high accuracy, detecting 10-100 copies/reaction in crude saliva lysate. Recently, transcription-mediated amplification (TMA) by Hologic Panther (non-Fusion) Aptima platform demonstrated higher analytical sensitivity (98\%) and specificity (100\%) for SARSCoV-2 detection in nasopharyngeal swab compared to RTPCR. ${ }^{136}$

A diagnostic test based on recombinase polymerase amplification (RPA), named Fast Isothermal Nucleic Acid Detection (FIND), has been developed for COVID19 detection. RPA primers designed against both the $N$ gene and the $S$ gene of SARS-CoV-2 can detect viral RNA as low as two viral particles $/ \mu \mathrm{L} .{ }^{137}$ Another sensitive approach introduced based on RT-RPA is reverse transcription-enzymatic recombinase amplification (RT-ERA) for SARS-CoV-2 identification at a low detection limit of 1 copy. ${ }^{138}$ Recently, RT-RPA assay is reported having a 95\% detection probability being one of the fastest detections by isothermal amplification method. ${ }^{139}$ In addition to all, helicase-dependent isothermal amplification has also been successfully implemented in various diagnosis purposes, implementation of which is yet in its infancy for SARS-CoV-2 detection. ${ }^{140}$

\section{CRISPR-Based Diagnostics}

Clustered regularly interspaced short palindromic repeats (CRISPR) based nucleic acid detection can provide a rapid, inexpensive, ultrasensitive diagnostic tool in point-of-care diagnosis to detect pathogens and monitor the disease. ${ }^{141,142}$ The CRISPR systems proposed in SARS-CoV-2 diagnosis utilize collateral catalytic activity of different Cas enzymes such as Cas 12, Cas-12a, Cas-13, and Cas-9 to detect target RNA. Labeled nucleic acid specifically amplified with conventional PCR or other isothermal amplification act as a substrate for these effector molecules. crRNA guided Cas enzymes, upon target recognition, cleave nucleic acid, and produce detection signals which can be read out through fluorescence visualization. ${ }^{143-147}$

SHERLOCK and DETECTR are two CRISPR-based SARS-CoV-2 commercial kits launched recently. ${ }^{148}$ SHERLOCK (Specific High Sensitivity Enzymatic
Reporter UnLOCKing) technology targets the $S$ and Orflab gene to identify the presence of COVID-19. The system uses Cas 13, catalytically inactive, in the presence of two or more mismatches in the crRNA target duplex. This makes it more specific for the target pathogen and eliminates any possibility of false positivity. ${ }^{147}$ DNA Endonuclease-Targeted CRISPR Trans Reporter (DETECTR) is an assay developed by Mammoth Biosciences. ${ }^{143}$ The gRNA of this system is designed to target the E region of three SARS-like coronaviruses (ie, SARS-CoV-1, SARS-CoV2, and bat SARS-like coronavirus) and the $\mathrm{N}$ region of SARS-CoV-2 specifically to distinguish this virus with no cross-reactivity from others and can detect ten copies of RNA/ $\mu \mathrm{L}$ with $95 \%$ sensitivity and $100 \%$ specificity. ${ }^{143}$ On the other hand, Lucia et al used the same enzyme system targeting $R d R p, O R F 1 b$, and ORF $1 a b$ genes of SARS-CoV-2. ${ }^{149}$ Another CRISPR-Casbased detection system reported is FELUDA, an acronym for FnCas9 Editor Linked Uniform Detection Assay. ${ }^{146,150}$ FnCas9 is an ortholog that can recognize mismatches within DNA with high sensitivity. FELUDA uses this property for identifying conserved regions (NSP8 and Nucleocapsid phosphoprotein) of SARS-CoV-2.

Ding et al described a system that combines a pair of Cas12a-crRNA complexes and RPA amplification components within a single reaction to detect both HIV-1 and SARS-CoV-2, named All-in-One Dual CRISPR-Cas12a (AIOD-CRISPR) Assay. ${ }^{144,151}$ The all-in-one reaction system without the prerequisite preamplification step makes it advantageous over other CRISPR-based detection systems. Another attractive point of this technique is the use of dual CRISPR RNA that enhances assay sensitivity. The test can detect as low as 1.2 copies of DNA targets and 4.6 documents of RNA targets in $40 \mathrm{~min}$. The report claims that AIOD-CRISPR can be developed as one-step RT-AIODCRISPR with the addition of AMV reverse transcriptase to detect RNA targets without cDNA preparation. ${ }^{144}$

\section{Microfluidic Biochip or Lab-on-a-Chip Technology}

Various types of biochip or lab-on-chip-based techniques are used to detect pathogenic bacteria and viruses in POC settings. ${ }^{152}$ Centrifugal microfluidic biochip or centrifugal microfluidic bio disk, a type of lab-on-a-chip technology known as lab-on-a-disc, is a handy diagnostic tool for virus detection. This type of microfluidic biochip can incorporate sample preparation, reactions, and detection 
of nano-size molecules on a micron-scale chip. In this assay, molecules are separated by centrifugal force followed by viral lysis using chemical and physical methods to release genomic and proteomic materials. The viral RNA is then amplified using various amplification methods. Tools interpret results based on binary or quantitative assessment of the genomic contents. A change visualizes the interpretation within the reaction chamber (color change) or electrochemical assessment. ${ }^{153}$ A recent study by Zhuang et al showed Filmarray ${ }^{\circledR}$, a BioFire ${ }^{\mathrm{TM}}$ microfluidic assay device that combines nucleic acid extraction, purification, and PCR amplification a single chip, provide results with precise detections. ${ }^{154}$ Previously, the device was used for Ebola Virus detection. ${ }^{155}$ The FDA recently provided EUA with a COVID-19 test kit based on the microfluidic technology. ${ }^{154}$

Detection of SARS-CoV-2 by microfluidic technology has made significant progress with improved LOD, time, and speed along with high sensitivity and high specificity. ${ }^{156}$ Microfluidic assays' advantages are primarily little reagents, and samples required to quickly obtain precise results, making it suitable for POC. ${ }^{153,154}$ Meticulous sample preparation requiring enrichment and avoidance of contamination for accurate results are the limitations hindering its adaptation. $^{157}$

\section{Immunoassay-Based Detection}

Immunoassay tests detect the presence of a particular antibody or antigen in the biological specimen, such as blood, serum, saliva, urine, sputum, and others from individuals. These tests are of utmost importance in defining a person's immune status (present or past infection) irrespective of symptoms development. ${ }^{158,159}$ Although the ongoing pandemic rRT-PCR is considered the reference standard to diagnose COVID-19, serological analysis is crucial to identify patients with a viral load below the rRT-PCR detection limit. ${ }^{160-163}$ Serosurveillance at the population level is critical for public health response in pandemic situations and the successful implementation of a vaccine program. ${ }^{164}$ Furthermore, in the present pandemic, immunoassays play a pivotal role in measuring immune response, tracing contact transmission, and defining disease burden and disease scope. ${ }^{161,165}$ A rapid antigen test with higher predictive value has been suggested for screening strategy. ${ }^{166}$ Still, indirect diagnosis by antibody testing is more useful in this situation as it provides a more considerable window period than antigen testing in identifying the disease. ${ }^{160}$ The new coronavirus generates specific antibody responses against two major SARSCoV-2 structural proteins: Nucleocapsid (N) protein and Spike (S) protein, subsequently making them important targets for developing serological testing. ${ }^{167,168}$

The spike is a class I glycoprotein, consisting of S1 and $\mathrm{S} 2$ subunit. S1 containing receptor-binding domain (RBD) is responsible for recognizing host ACE-2 receptors, while S2 is responsible for fusion. ${ }^{167}$ Although hACE-2 is the entry receptor for SARS-CoV-2, an array of protease and kinase enzymes such as TMPRSS, TPC2, PIKFYVE, and CTSL are also significant for viral entry. ${ }^{169,170}$ Alternative receptors, such as CD147 and integrins, have been reported as well. ${ }^{160,171}$ Serum antibody response is mainly generated against $\mathrm{N}$ and different spike proteins. ${ }^{160,164}$ The different dynamics of specific $\operatorname{IgA}, \operatorname{IgG}$, and $\operatorname{IgM}$ responses (Figure 3 ) have been reported with a recent study suggesting that IgA dominates early humoral response against SARS-CoV-2 with a significant contribution towards virus neutralization albeit at a low level, decreasing after only one month of presentation. ${ }^{15,158,160,168,172}$ IgG and IgM seroconversions occur in the first week or within 20 days after symptom onset. Three types of seroconversions are observed: (i) $\operatorname{IgG}$ and $\operatorname{IgM}$ develop simultaneously, (ii) IgG comes earlier than IgM, (iii) IgM comes earlier than IgG. ${ }^{158}$ While the IgM level reaches its peak in the second week and goes into decline, IgG continues its increase into the third week, attaining 100\% seroconversion while persisting for three months. ${ }^{160,164,168}$ If combined, IgG and IgM against both spike and nucleocapsid can detect up to $75 \%$ of patients within the first week. ${ }^{168}$

Four major types of immunoassays are utilized for serodiagnoses of SARS-CoV-2 are enzyme-linked immunosorbent assay (ELISA), automated chemiluminescence immunoassay (CLIA), lateral flow immunoassay (LFIA), and the neutralizing antibody assay. These assay methods target a particular protein antigen, total antibody, or all isotypes simultaneously and provide quantitative, qualitative, or semi-qualitative data.

Commercially manufactured serology tests to detect SARS-CoV-2 antibodies are available through healthcare providers and professional laboratories and many of them have been recently certified by the US Food and Drug Administration. EUA issued Anti-SARS-CoV-2 ELISA (IgG) developed by EUROIMMUN US Inc. is a widely used ELISA kit to detect SARS-CoV-2 antigen S1 specific IgG, showed sensitivity $50-100 \%$ sensitivity and $98.5 \%$ specificity. Several other serology tests were approved by FDA like VITROS Immunodiagnostic Products Anti- 


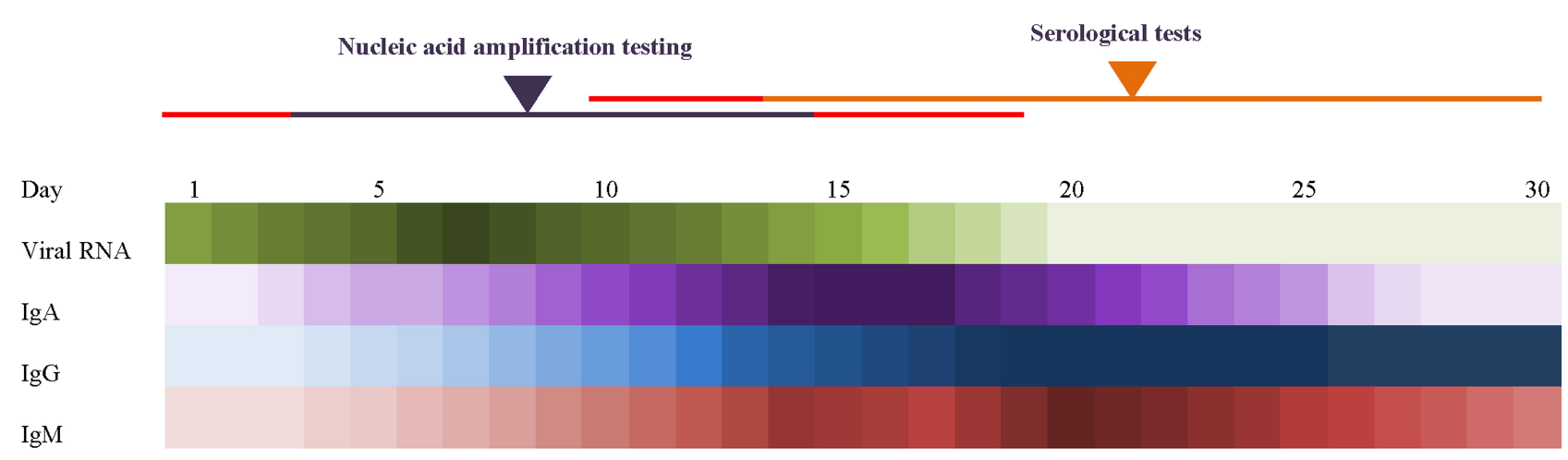

Figure 3 Expression of viral RNA load and antibody titer (IgA, $\lg M$, and $\lg G)$ in patients over 30 days. $^{82,158,172,176,236}$

SARS-CoV-2 IgG Reagent Pack (Ortho Clinical Diagnostics, Inc.) adopting CLIA technique, RapCov Rapid COVID-19 Test (ADVAITE, Inc.) following lateral flow technique, etc. ${ }^{173,174}$

BD Veritor ${ }^{\mathrm{TM}}$ System (Becton, Dickinson, and Company) adopting Chromatographic Digital Immunoassay, LumiraDx SARS-CoV-2 Ag Test (LumiraDx) pursuing microfluidic technique and most widely used Sofia SARS Antigen FIA manufactured by Quidel Corporation following lateral flow assay, are some FDA accredited serological antigen tests. All of them identify SARS-CoV-2 nucleoprotein showing sensitivity $95-100 \%{ }^{173}$

\section{Enzyme-Linked Immunosorbent Assay}

ELISA is broadly used as a serological test to detect COVID19 positive patients. These methods use an antigen-antibodysubstrate binding concept to detect specific $\operatorname{IgA}, \operatorname{IgM}$, and/or IgG against $\mathrm{S}$ (mainly $\mathrm{RBD}$ ) and/or $\mathrm{N}$ viral proteins of SARS-CoV-2 as these are highly immunogenic, being the target of many neutralizing antibodies. ${ }^{175-177}$

Commercial ELISA kits incorporating the double-antibody sandwich immunoassay principle are used to detect SARS-CoV-2 IgM and IgG. ${ }^{176,178}$ Table 4 lists examples of available kits for both research use only (RUO) and invitro diagnostics (IVD). However, only a few have received Emergency Use Authorization (EUA) from the US Food and Drug Administration (FDA). IgG and IgM ELISA kits diagnose the body's immune status and the past infection, respectively, whereas IgA ELISA kits detect early disease. ${ }^{75,163,179}$

In addition to antibody detection kits, many commercial kits for detecting SARS-CoV-2 pathogens have been developed. A commercial ELISA kit designed by Sino Biological for SARS-CoV-2 antigen detection is based on the principle of SARS-CoV-2 Spike RBD protein detection by capturing it with HRP labeled anti-SARS-CoV-2 Spike RBD monoclonal antibody. ${ }^{180,181}$

Serum investigation using ELISA provides convenience for determining the actual morbidity and infection status in the population. Furthermore, the ELISA technique's fast, accurate, and highly sensitive results can also be used to map antibody reaction kinetics against SARSCoV-2. ${ }^{86,182,183}$ Though ELISA kits can test multiple samples in a single run, they lack point-of-care applicability. The nonspecific binding of the antibody or antigen to the plate may lead to false high-positive results. ${ }^{184}$

\section{Chemiluminescence Immunoassay (CLIA)}

CLIA is a variation of enzyme-linked immunosorbent assay employed in serodiagnosis of SARS-CoV-2. Due to its high concordance with ELISA, the capacity to test a large volume of sample, high detection sensitivity (100\%) for total antibody, this automated system is an attractive choice of the assay in outbreak situations. ${ }^{176,185}$ Numerous studies have used CLIA to assess dynamic antibody response against SARS-CoV-2. ${ }^{158,185-193}$ Table 4 lists currently available commercial and laboratory-developed chemiluminescence assays. RBD, $\mathrm{S}, \mathrm{N}, \mathrm{S}+\mathrm{N}$, and $\mathrm{S} 1+\mathrm{S} 2$ are used as capturing agents to detect specific serum antibodies in COVID-19 patients. $^{185,187-195}$ Studies validated and assessed these serological assays' clinical performance by analyzing the humoral response against SARS-CoV-2. Inadequate sample size, the anomaly of sample distribution, lack of data on cross-reactivity, the inconsistent time interval of sample collection is some of the limiting factors of these studies. ${ }^{185,189-191,193}$

Zhang et al used a commercial CLIA to study 736 subjects to observe the rising level of serum immunoglobulins along with disease progression. ${ }^{193}$ Receiver operating 


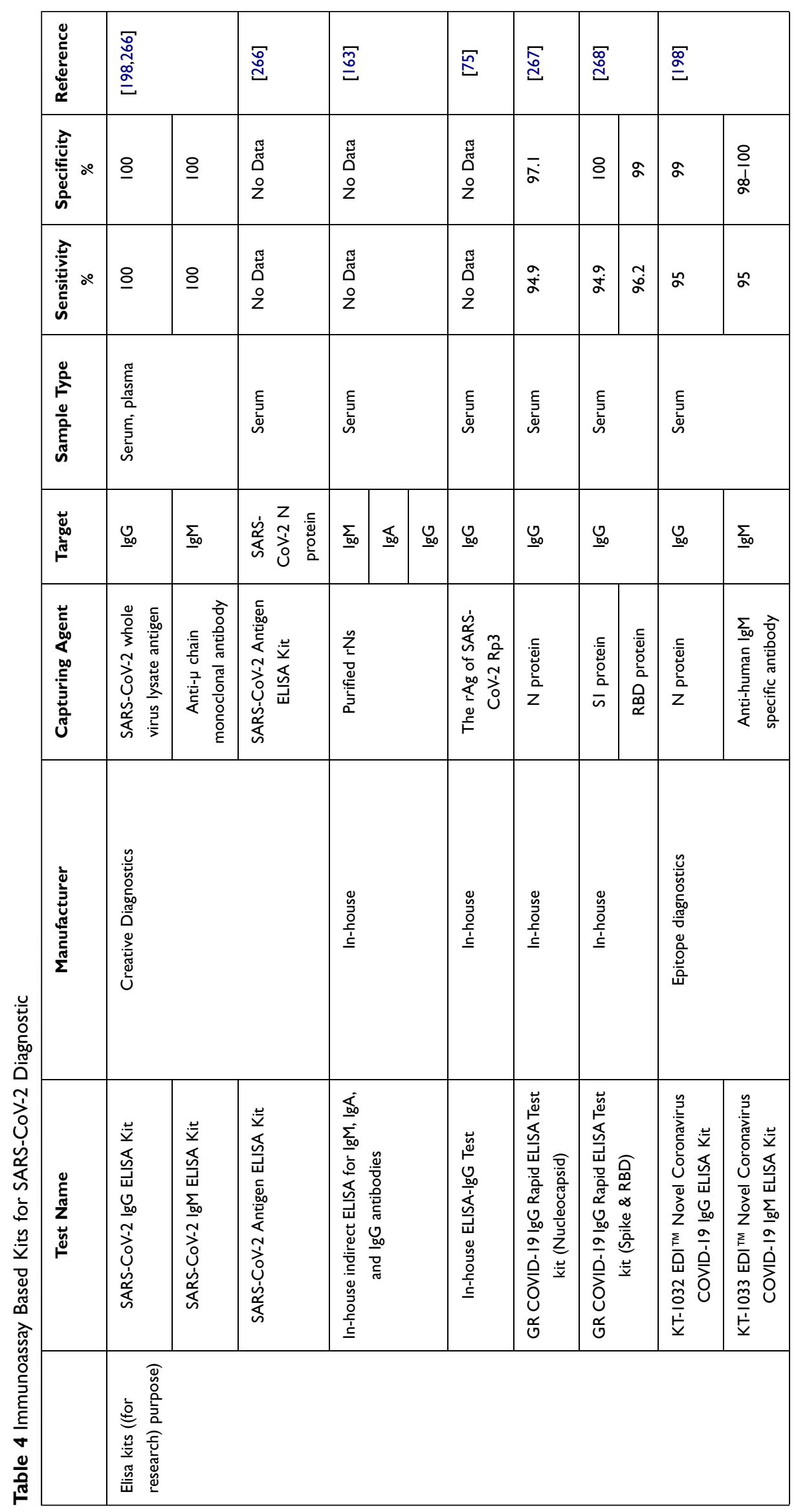




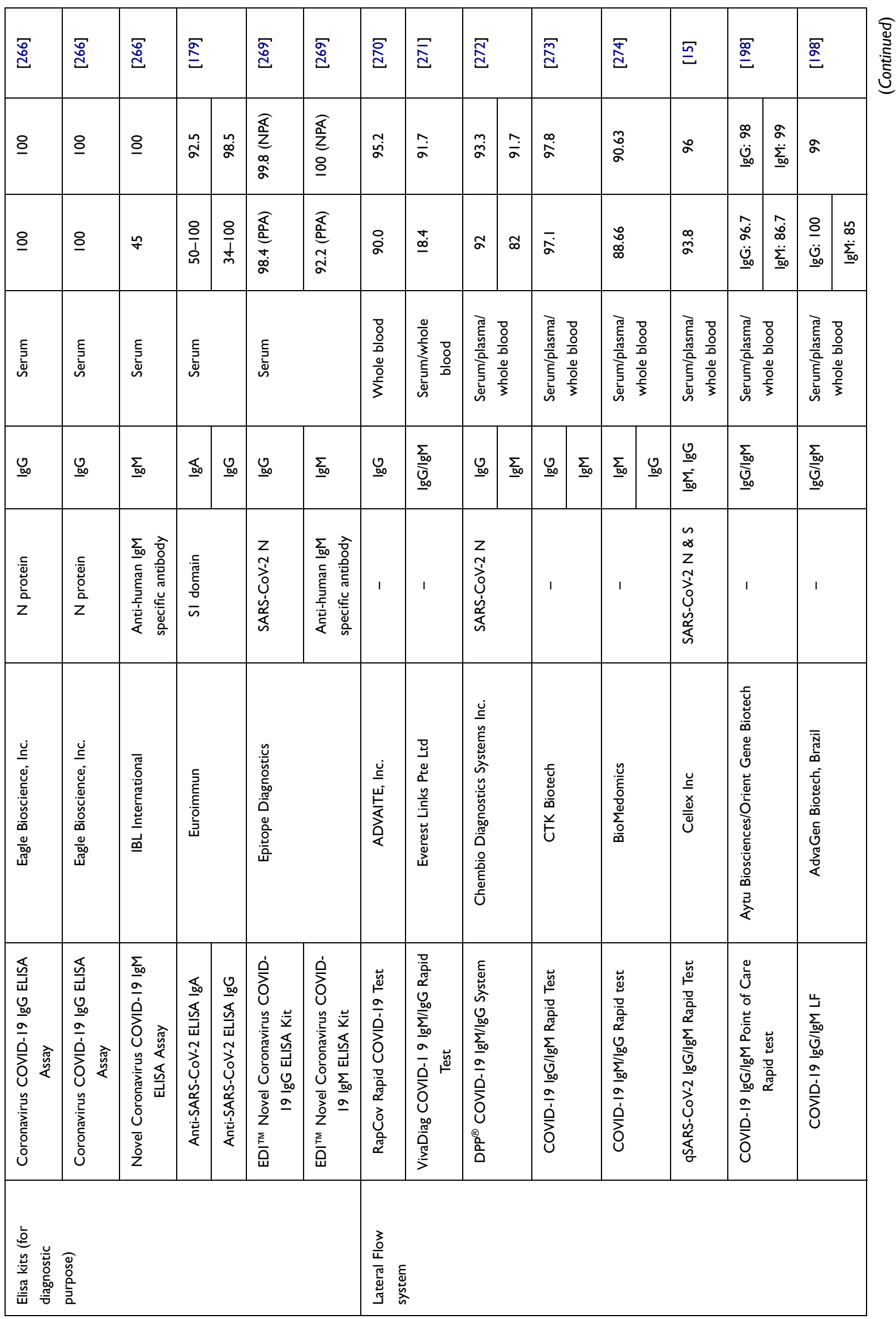




\begin{tabular}{|c|c|c|c|c|c|c|c|c|c|c|c|c|c|c|c|}
\hline \multirow{2}{*}{ 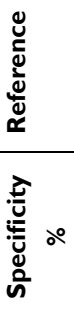 } & \multirow{2}{*}{ 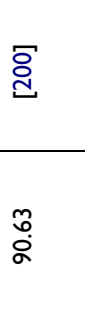 } & \multirow{2}{*}{$\begin{array}{l}\overline{\bar{d}} \\
m \\
\stackrel{m}{\alpha}\end{array}$} & \multicolumn{7}{|l|}{$\begin{array}{l}\frac{5}{\Omega} \\
\stackrel{+5}{\Xi}\end{array}$} & $\stackrel{\Gamma}{\varrho}$ & \multicolumn{2}{|l|}{ 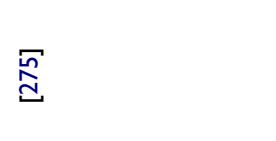 } & \multicolumn{2}{|l|}{ 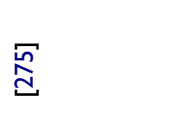 } & \multirow{2}{*}{$\begin{array}{l}\frac{\text { N }}{\Xi} \\
\frac{+}{\sigma}\end{array}$} \\
\hline & & & $\underset{\sim}{\tilde{\sigma}}$ & $\begin{array}{l}\infty \\
\stackrel{1}{0} \\
\dot{0} \\
\underline{\underline{0}}\end{array}$ & 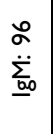 & $\begin{array}{l}\stackrel{\circ}{\ddot{0}} \\
\underline{\underline{0}}\end{array}$ & $\underset{\underline{\underline{\Sigma}}}{\stackrel{8}{\dot{\Sigma}_{0}}}$ & $\S$ & $\stackrel{\circ}{\circ}$ & 으 & \multicolumn{2}{|l|}{ 으 } & 으 & 으 & \\
\hline 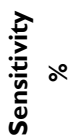 & $\begin{array}{l}\stackrel{\circ}{\infty} \\
\infty \\
\infty\end{array}$ & 으 & 으 & $\begin{array}{l}\sigma \\
\sigma \\
\alpha \\
\hat{\hat{H}} \\
\underline{b}\end{array}$ & 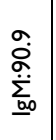 & 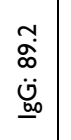 & 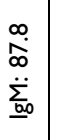 & $\S$ & 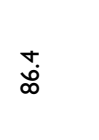 & $a$ & \multicolumn{2}{|l|}{$\underset{\infty}{\stackrel{m}{\infty}}$} & 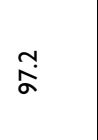 & 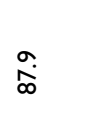 & 으 \\
\hline 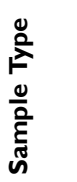 & 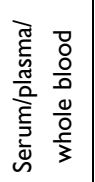 & $\begin{array}{l}\text { 음 } \\
\frac{\circ}{\infty}\end{array}$ & $\begin{array}{l}\text { 음 } \\
\frac{\circ}{\infty}\end{array}$ & $\begin{array}{l}\frac{8}{0} \\
\frac{0}{\infty}\end{array}$ & & $\begin{array}{l}\frac{\mathrm{o}}{0} \\
\frac{\mathrm{o}}{\infty}\end{array}$ & & $\left|\begin{array}{l}\frac{D}{0} \\
\frac{\circ}{\infty}\end{array}\right|$ & $\begin{array}{l}\frac{D}{0} \\
\frac{\circ}{\infty}\end{array}$ & 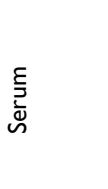 & \multicolumn{2}{|l|}{ 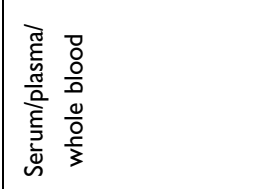 } & \multicolumn{2}{|l|}{ 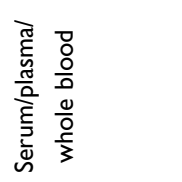 } & \multirow{2}{*}{ 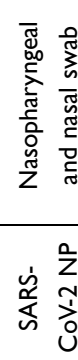 } \\
\hline 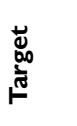 & 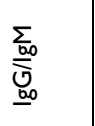 & $\underline{\sum_{0}}$ & $\underline{\sum_{0}}$ & \multicolumn{2}{|l|}{ 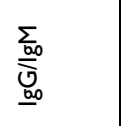 } & \multicolumn{2}{|l|}{$\begin{array}{l}\sum_{000} \\
\bar{N} \\
\underline{b 0}\end{array}$} & 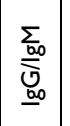 & 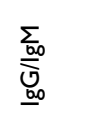 & \begin{tabular}{l|l}
$\Sigma_{\underline{\underline{0}}}$ & $\underline{\underline{0}}$
\end{tabular} & $\begin{array}{l}0 \\
\underline{0}\end{array}$ & $\underline{\sum_{000}}$ & $\underline{\underline{w}}$ & $\underline{\sum_{\underline{0}}}$ & \\
\hline 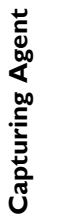 & 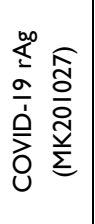 & 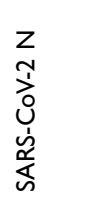 & 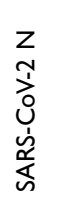 & 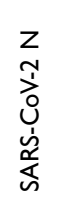 & & 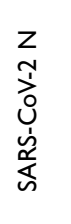 & & 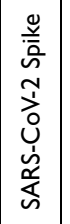 & 1 & 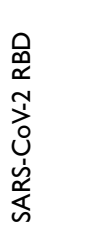 & 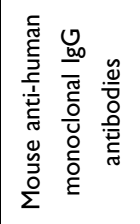 & 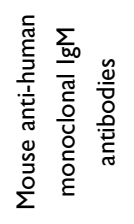 & 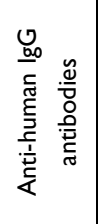 & 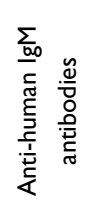 & $\begin{array}{l}\mathbb{J} \\
\text { O̊ } \\
\text { O }\end{array}$ \\
\hline 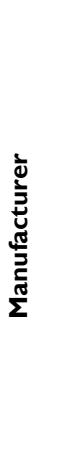 & 趇 & 1 & 1 & 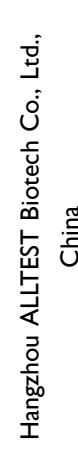 & & 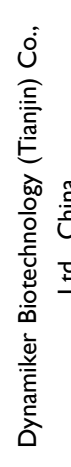 & & 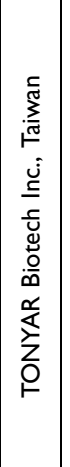 & 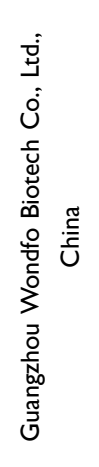 & 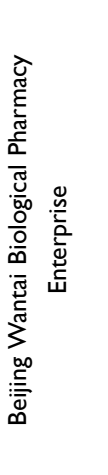 & \multicolumn{2}{|l|}{ 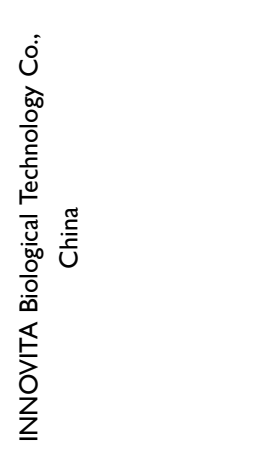 } & \multicolumn{2}{|l|}{ 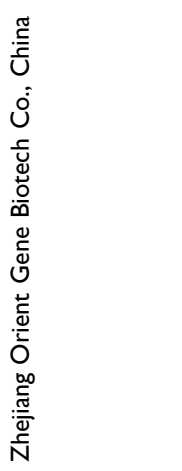 } & 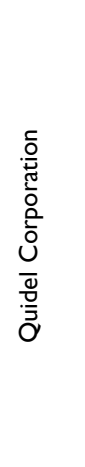 \\
\hline 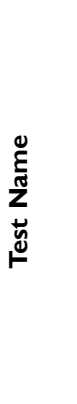 & 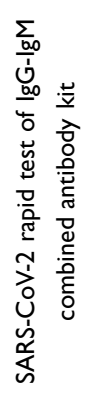 & 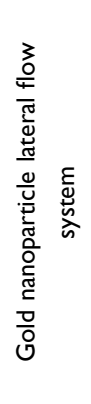 & 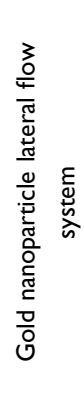 & 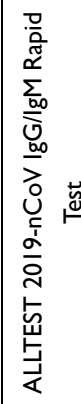 & & 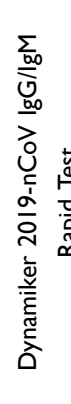 & & 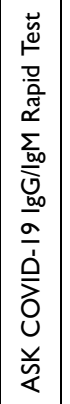 & 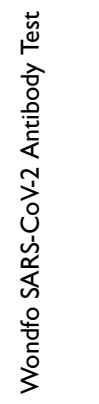 & 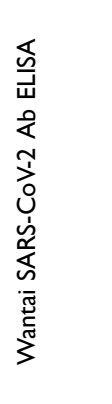 & 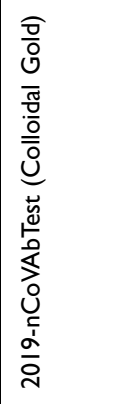 & & 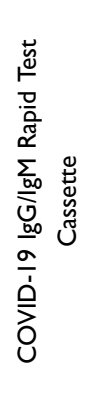 & & 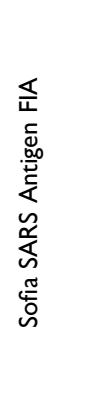 \\
\hline & & & & & & & & & & & & & & & \\
\hline
\end{tabular}




\begin{tabular}{|c|c|c|c|c|c|c|c|c|c|c|c|c|c|c|c|}
\hline $\begin{array}{l}\stackrel{D}{\Xi} \\
\stackrel{\vdots}{ }\end{array}$ & \multicolumn{2}{|l|}{$\underset{\Xi}{\mathbb{D}}$} & \multicolumn{2}{|l|}{$\stackrel{\bar{\sigma}}{\underline{\sigma}}$} & \multicolumn{2}{|l|}{$\stackrel{\Gamma \infty}{\underline{\infty}}$} & \multicolumn{2}{|l|}{$\overline{\bar{\sigma}}$} & \multicolumn{2}{|l|}{$\stackrel{\nwarrow}{\varrho}$} & \multicolumn{2}{|c|}{ 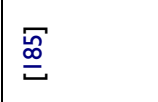 } & \multirow[t]{2}{*}{$\begin{array}{l}\frac{\pi}{\alpha} \\
\sigma \\
\sigma\end{array}$} & \multirow[b]{2}{*}{$\begin{array}{l}\text { no } \\
\frac{\hat{\sigma}}{0} \\
\hat{\lambda} \\
\hat{\alpha} \\
\underline{8}\end{array}$} & \multirow{2}{*}{ 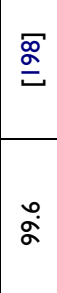 } \\
\hline $\begin{array}{l}\text { âd } \\
\underline{\Lambda} \\
\underline{8}\end{array}$ & $\begin{array}{l}\stackrel{\leftrightarrow}{\infty} \\
\underset{\sigma}{2}\end{array}$ & $\begin{array}{l}\text { హ. } \\
\text { o }\end{array}$ & s & o & 으 & $\bar{a}$ & م & $\alpha$ & $\infty$ & $\infty$ & 吕 & २ & & & \\
\hline $\begin{array}{l}\frac{\pi}{a} \\
0 \\
0 \\
\infty\end{array}$ & ను & œ & $\underline{\text { 음 }}$ & 으 & $\stackrel{\infty}{+}$ & ळ & 으 & 으 & 으 & 으 & 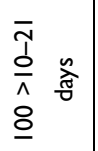 & 8 & 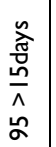 & 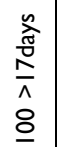 & 으 \\
\hline 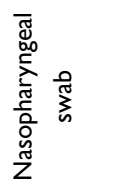 & \multicolumn{2}{|l|}{$\begin{array}{l}\xi \\
\stackrel{\Xi}{\bar{D}} \\
\stackrel{\Phi}{n}\end{array}$} & \multicolumn{13}{|l|}{1} \\
\hline$\stackrel{n}{z}$ & $\underline{\sum_{00}}$ & $\stackrel{\bigcup_{\underline{0}}}{0}$ & $\begin{array}{l}\bigcup_{0} \\
-\end{array}$ & $\sum_{\underline{\underline{\underline{0}}}}$ & $\underline{\sum_{0} 0}$ & $\begin{array}{l}0 \\
\underline{\underline{0}}\end{array}$ & 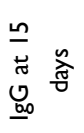 & 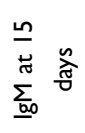 & $\begin{array}{l}0 \\
\underline{\underline{0}}\end{array}$ & $\underline{\Sigma_{0}}$ & $\begin{array}{l}\bigcup_{0} \\
\underline{-1}\end{array}$ & $\sum_{\underline{\underline{0}} 0}$ & $\underset{\mathfrak{g}_{0}}{0}$ & $\begin{array}{l}\bigcup_{0} \\
-\end{array}$ & $\underset{\underline{o}}{\cup}$ \\
\hline 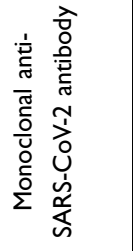 & 1 & 1 & $\begin{array}{l}Z \\
\pm \\
w\end{array}$ & Z & $\begin{array}{l}Z \\
\pm \\
\mathbf{w}\end{array}$ & $\underset{⿱ z}{z}$ & Z & $\begin{array}{l}Z \\
⿱ \\
\text { w }\end{array}$ & 壬 & $\begin{array}{l}Z \\
\pm \\
\text { D }\end{array}$ & 吕 & 壬 & $\begin{array}{l}\tilde{\tilde{t}} \\
\frac{\mathbf{s}}{n}\end{array}$ & $z$ & $z$ \\
\hline 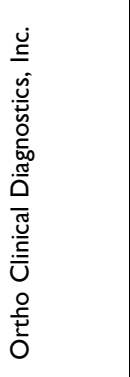 & \multicolumn{2}{|l|}{ 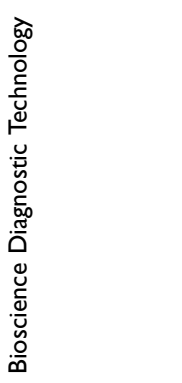 } & 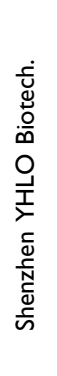 & & 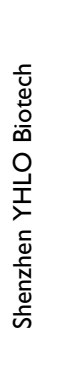 & & 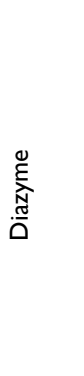 & & $\begin{array}{l}\text { 㟧 } \\
n_{n}\end{array}$ & & 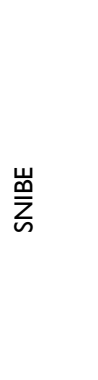 & & 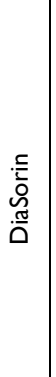 & \multicolumn{2}{|l|}{ 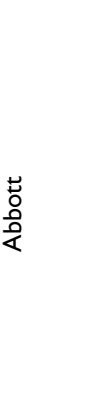 } \\
\hline 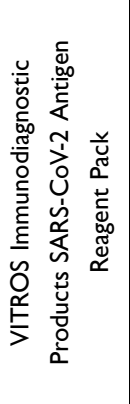 & 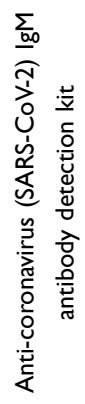 & 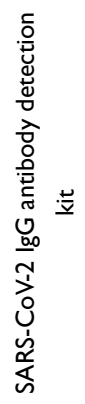 & २ & & $\mathrm{Q}$ & & 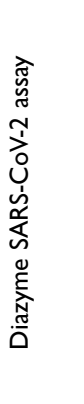 & & 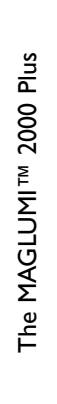 & & 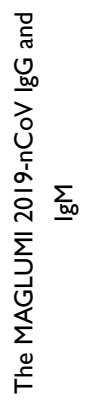 & & 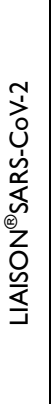 & 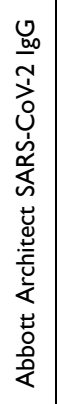 & 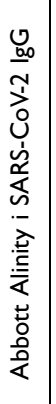 \\
\hline 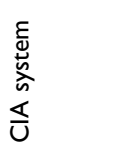 & & & & & & & & & & & & & & & \\
\hline
\end{tabular}




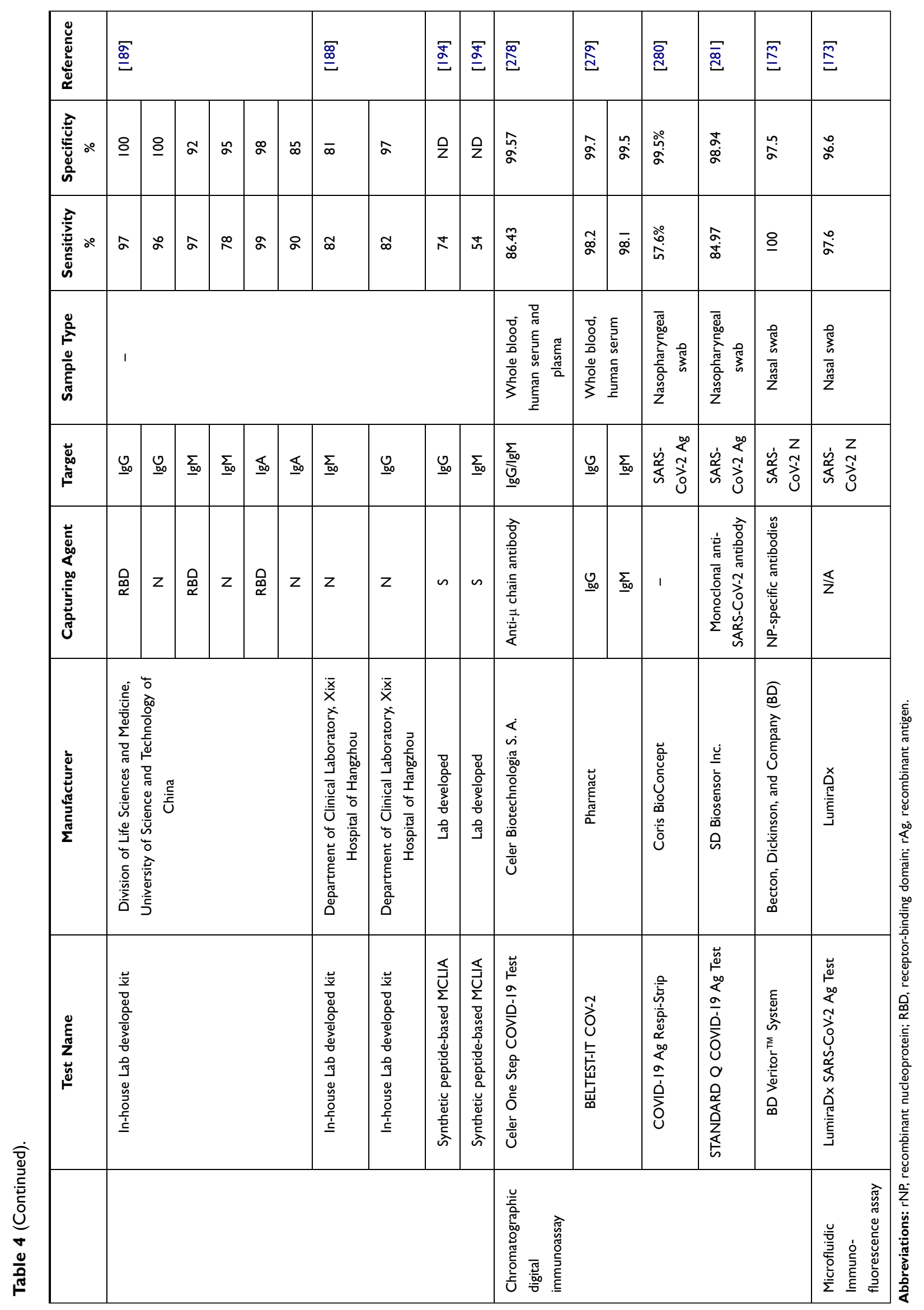


characteristic (ROC) curve analysis gave a value of 0.988 and 1.000 for $\operatorname{IgM}$ and $\operatorname{IgG}$, respectively, indicating higher diagnosis accuracy. The kit detected SARS-CoV-2 with high sensitivity and specificity with no cross-reaction from other respiratory viruses. Suhandynata et al executed a longitudinal study to evaluate Diazyme SARS-CoV-2 assay efficiency to analyze the seroconversion rate of $\operatorname{IgM}$ and $\mathrm{IgG}$ in acutely ill patients. ${ }^{191}$ Seropositivity was observed following confirmed positive PCR results. A low sensitivity was observed in the first week, but a better one (94.4\%) for both immunoglobulins (Ig) was reported in the second week. After 15 days from symptom onset, IgG's sensitivity increased slightly (94.7), and $\mathrm{IgG} / \mathrm{IgM}$ reached $100 \%$, though a reduction was observed for IgM (89\%). The report noted high specificity for three different panels of Ig and no cross-reaction with other pathogens.

Two different studies assessed the SNIBE "MAGLUMI" CLIA System's analytical performance. ${ }^{185,190}$ Padoan et al reported that the assay's reproducibility was not consistent with the manufacturer's claim. Still, detection sensitivity was $100 \%$ and $88 \%$ for $\operatorname{IgG}$ and $\mathrm{IgM}$, respectively, at the later phase of infection ( $>12$ days for IgG). ${ }^{190}$ The study suggests that a cut of value refinement may increase $\operatorname{IgM}$ sensitivity, and $\mathrm{IgG}+\operatorname{IgM}$ combinations may increase detection sensitivity at the early stage of infection. Antibody kinetics was consistent with other data. Lippi et al utilized the same system to perform a comparative analysis between MAGLUMI CLIA and Euroimmun Anti-SARS-CoV-2 IgA and IgG ELISA. ${ }^{185}$ The study reports $90 \%$ similarities between these assays, regardless of using different immunoglobulin targets. Jin et al used CLIA to compare serological and molecular diagnostic values and dynamic variance in serum antibody. ${ }^{187}$ When compared to molecular detection, IgG and $\operatorname{IgM}$ detection specificity was $90 \%$. A combination of serology and molecular diagnosis revealed a dilutive difference in immunoglobulin titer before and after conversion to virus-negative status. Bryan et al did a performance analysis on the Abbott CLIA kit for the Abbott ARCHITECT platform that revealed an optimum threshold index for $100 \%$ sensitivity and specificity for the commercial kit. ${ }^{196}$ A comparative analysis on RBD and $\mathrm{N}$ based CLIA demonstrated that RBD as an immobilized antigen works better than N. ${ }^{189}$ The study insisted on the importance of IgA in the serological analysis of COVID-19. Inclusion of IgA with IgG in serological testing yield a higher accuracy (sensitivity, specificity, and overall agreement elevate to $99.1 \%, 100 \%$, and $99.7 \%$, respectively) than the current reference standard (RT-PCR, $>70 \%$ sensitivity) and the presence of $\operatorname{IgA}$ correlates with severity of the disease. Lin et al used $\mathrm{N}$ antigen-based CLIA to detect $\operatorname{IgM}$ and $\operatorname{IgG}$ reactivity, which showed higher sensitivity $(82 \%)$ than the same N-based ELISA system while the specificity for $\operatorname{IgG}$ and $\operatorname{IgM}$ detection was $98 \%$ and $81 \%$, respectively. ${ }^{188} \mathrm{Cai}$ et al have reported a peptidebased Magnetic Chemiluminescence Enzyme Immunoassay (MCLIA) to detect $\operatorname{IgG}$ and $\operatorname{IgM}$ with a $71 \%$ and $57 \%$ sensitivity, respectively. ${ }^{194}$ If both are combined, detection sensitivity is enhanced to $81 \%$. The study screened 20 different biotinylated synthetic peptides from orfla/b, nucleocapsid $(\mathrm{N})$, and spike $(\mathrm{S})$ proteins and demonstrated a better result for spike antigen. Luciferase immunoprecipitation system (LIPS) assay, a liquid phase immunoassay technique, has also been highly sensitive in detecting the SARS-CoV-2 antibody. The advantage of this assay is that protein remains in its native form. ${ }^{196}$

A chromatographic digital immunoassay was developed to detect SARS-CoV-2 antigen (ie, nucleocapsid proteins) directly from the nasal swab with $96.6 \%$ specificity and $97.6 \%$ sensitivity. ${ }^{197}$ Another FDA-approved kit based on Microfluidic immunofluorescence assay also detects the viral nucleocapsid antigen; however, it cannot differentiate between SARS-CoV and SARS-CoV-2 antigens. $^{198}$

\section{Lateral Flow Assay}

The lateral flow immunoassay technique has been a popular diagnostic tool in recent years for its low-cost, low limit of detection, rapid, sensitive, and specific diagnostic capabilities. ${ }^{199}$ In the rapidly emerging SARS-CoV-2, lateral flow technique can play a crucial role in the faster diagnosis of suspected patients and proper isolation. Thousands of lateral flow assay kits have been developed since the emergence of SARS-CoV-2. Still, critical assessment of the sensitivity and specificity limits their use, as being a POC, false-negative results would augment the catastrophic situation by further disseminating this virus. A lateral flow technique was developed to detect antibodies, eg, both IgM and IgG in whole blood/serum/plasma against the SARS-CoV-2 virus had a sensitivity and $88.66 \%$ specificity $90.63 \%$, respectively. ${ }^{200}$ Another research group developed a lateral flow assay based on colloidal gold nanoparticle to identify human IgM against SARS-CoV-2 infection. The nucleoprotein of SARS-CoV-2 was coated on the device strips, and compared to the rRT-PCR result, the test has a sensitivity of $100 \%$, although the specificity was 93.3\%. Small sample requirements $(10-20 \mu \mathrm{L})$ and the quick result $(15 \mathrm{~min})$ made this technique unique. ${ }^{201} \mathrm{~A}$ 
CRISPR-Cas12 based lateral flow assay was developed, which uses respiratory swab instead of blood. A positive result detects the $N$ gene or $E$ gene in the extracted viral RNA used in this technology. It is a faster visual alternative method to rRT-PCR assay with a 95\% positive and $100 \%$ negative predictive agreement. ${ }^{144}$ Additionally, four different lateral flow techniques (ASK COVID-19 IgG/IgM Rapid Test, ALLTEST 2019-nCoV IgG/IgM Rapid Test, Wondfo SARS-CoV-2 Antibody Test, and Dynamiker 2019-nCoV IgG/IgM Rapid Test) showed 100\% sensitivity and specificity for IgM and IgG antibody against SARSCoV-2 detection after three weeks of symptom onset. ${ }^{174}$

Recently, FDA has approved a few SARS-CoV-2 rapid antigen detection kits such as Sofia SARS Antigen Fluorescent Immunoassay (FIA) for quicker diagnosis of COVID-19. It uses a lateral flow method coupled with an advanced immunofluorescence technique for the detection of SARS-CoV-2 antigen in nasal or nasopharyngeal swabs. Within 15 minutes, the result can be obtained with a $96.7 \%$ favorable percent agreement (PPA) and a 100\% negative percent agreement (NPA). ${ }^{173,202}$

\section{Neutralization Assay}

Neutralization assays can detect antibodies that inhibit viral infection, thus neutralizing them. ${ }^{203}$ The results are observed by detecting the cytopathic effects of viral replication in cell lines. It plays a crucial role in the clinical use of convalescent plasma and, in the long run, vaccine development. Recently two types of neutralization assays have been reported, pseudovirus neutralization assay and micro-neutralization assay for SARS-CoV-2.

\section{Pseudovirus-Based Neutralization Assays (PBNA)}

Pseudoviruses are recombinant viral particles containing the core or backbone and envelope proteins acquired from two different viruses. ${ }^{204}$ They are crucial virologic tools for studying emerging and reemerging viruses. ${ }^{204}$ Pseudotyping involves exchanging a viral attachment protein with a different virus, for example, vesicular stomatitis virus $\mathrm{G}$ glycoprotein (VSV-G), the most common glycoprotein used in the retroviral and lentiviral vectors. Pseudotyping has many advantages: efficient delivery to a wide range of cell types increased vector stability and increased infectious titer. ${ }^{205,206}$ A pseudovirus neutralization assay developed by Nie et al detects SARS-Cov-2 constructed pseudoviruses with spike genes from Wuhan-
Hu-1 (GenBank) strain. The results showed high potency of neutralization against SARS-CoV-2 pseudovirus when the convalescent sera of COVID-19 patients were tested. PBNA are advantageous over the virus-based approaches due to their versatility and safe-handling and easy treatment. The versatility of pseudovirus is accomplished by virus pseudotyping with proteins. ${ }^{204,207}$ PBNA is a sensitive, precise, reproducible, and less labor-intensive method. The result, however, may vary with variation in the pseudovirus inoculum. Fixing the dose of the pseudoviruses is essential to yielding comparable results between different labs. ${ }^{208}$

\section{Microneutralization Assay}

Microneutralization assay is an essential test in the field of immunology, vaccine development, and epidemiological studies. $^{209-211}$ Neutralization assay is one of the most widely used methods for detecting virus-specific neutralizing antibodies. ${ }^{212}$ This assay depends on cell culture, having the ability to detect biologically active antibodies. ${ }^{213}$ SARS-CoV-2 viruses are cultivated in a particular cell line (ie, VERO cell lines, VERO E6 cell lines, and Huh-7 cell line set) heat-inactivated human serum samples of different dilutions are incubated with viruses harvested from those cell lines. ${ }^{211}$ The dilution provides comparability of different sera to neutralize the viruses. The titer of neutralization is expressed as the reciprocal of the highest dilution, which blocks virus infection. The colorimetric analysis is done after three days of incubation. Maximum serum dilution is considered the neutralization titer showed by an optical density (OD) value more significant than the cut-off value. After four days of incubation, CPE (Cytopathic Effect) read-out is taken as the neutralization titer is considered the maximum serum dilution, which protects more than $50 \%$ of CPE cells. Manenti et al and Amanat et al developed micro-neutralization assays to detect SARS-CoV-2 viruses for research purposes. Manenti et al used commercial SARS-CoV-2 antigen for the detection of neutralizing antibodies. On the other hand, Amanat et al used commercial SARS-CoV-2 viruses to establish microneutralization assay. ${ }^{214}$ The assay's main advantage is quantifying the antibody titer that specially neutralizes or blocks the SARS-CoV-2 viruses. ${ }^{215}$ Microneutralization assay's main advantage is to quantify the antibody titer that essentially neutralizes or block the SARS-CoV-2 viruses. ${ }^{211}$ This is also used to produce active and precise neutralizing antibodies at a high concentration and development of the vaccine. The major 
drawback of this method is transfection, which kills the majority of the cell. However, a successful assessment requires $90 \%$ to $95 \%$ viable cells. Moreover, the technique is time-consuming, making it inconvenient to tackle the emergency. $^{215}$

\section{Sequencing-Based Methods}

The advent of Next-generation sequencing (NGS) technologies facilitates effective and high-throughput screening of large numbers of samples. ${ }^{216}$ The technology can identify a diversified array of microbes in a single sample without any previous knowledge. This makes it ideal for the rapid diagnosis of COVID-19 patients by detecting SARS-CoV2 along with background microbiomes. Metagenomic NGS provides a novel solution for detection, typing, mutational analysis, epidemiological and surveillance studies, and comprehension of the host immune response against the SARS-CoV-2. ${ }^{84,216,217}$

MinION based sequencing is being used for the identification of SARS-CoV-2 within 10 hours in nasopharyngeal swabs of infected patients by the ISARIC $4 \mathrm{C}$ consortium. ${ }^{218}$ It employs two complementary techniques, an amplicon-based system and a metagenomic approach, to identify and sequence of SARS-CoV-2. The former method, a set of primers targeting conserved regions, was exploited to amplify the SARS-CoV-2 genome with an approximately 200 base pair overlap allowing sequence assembly for about 1000 base-paired sequential fragments. For the metagenomic approach, amplification by sequence-independent single primer amplification (SISPA) was used. ${ }^{218}$

Illumina has recently devised two methods for the SARS-CoV-2 detection, namely shotgun metagenomics approach and target enrichment approach. The shotgun approach includes sample preparation, library preparation, sequencing, and analysis, while the target enrichment approach is used to reduce the amount of data to be analyzed. The latter can identify coronavirus and other respiratory viruses in a sample using the Respiratory Virus Oligo Panel. ${ }^{219}$ The two approaches mainly differ in the number of reads required per piece for analysis. The former requires a minimum of 10 million reads per sample, while the latter requires 0.5 million reads to achieve acceptable results. $^{219}$

Ion Torrent, a next-generation sequencing developed by ThermoFisher Scientific, based on amplicons ranging from $125 \mathrm{bp}$ to $275 \mathrm{bp}$ in length, is a fast and rapid system circumventing coronavirus typing. ${ }^{220}$ Additionally,
Nanopore technologies provide a platform for metagenomics and meta-transcriptomic analysis of SARS-CoV2 , providing valuable information regarding co-infections that may aggravate the COVID-19 outcomes. These technologies include the base reading of DNA by retrieving changes in current as DNA passes through the tiny, small pores providing robust, fast, and effective diagnosis compared to POC applications. ${ }^{220}$

\section{Forthcoming Technologies Under Development}

\section{Aptamer-Based Detection}

Aptamers have recently been used as targets for rapid viral detection and therapeutic purposes and have been advocated to have great potential in coronavirus pandemic. ${ }^{221,222}$ These short artificial nucleotides can bind to SARS-CoV-2 RBD with high affinity employing an ACE2 competition-based selection strategy. The inhibitory capacity of anti-RBD aptamer has the potential to be a treatment of COVID-19. Furthermore, Chen et al designed a DNA aptamer-based on SARS-CoV nucleoprotein to detect SARS-CoV-2 nucleoprotein. ${ }^{223}$ In the study, the aptamer's binding affinity was evaluated with enzyme-linked aptamer binding assay (ELAA). Though the biomolecule's small size makes it a stable target with minimum cross-reactivity, its diagnostic performance is yet to be evaluated. ${ }^{223}$

Another RNA aptamer-based rapid detection system is SENSR, a ligation-dependent molecular technique utilizing SplintR ligase and T7 RNA polymerase for target RNA amplification and transcript detection by fluorescence read-out. $^{224}$ The method allows detecting a broad range of pathogens, including the novel coronavirus, with a low detection $(0.1 \mathrm{aM})$ in a one-step reaction. ${ }^{224}$

\section{Molecular Imprinting Technology (MIT)- Based Detection}

Molecular imprinting polymer (MIP), which utilizes molecular imprinting technology (MIT), can be employed as a diagnostic tool by binding to predictable structure with high affinity and specificity, analogous to the "Lock and Key" model of enzyme-substrate recognition. ${ }^{225}$ A rapid point-of-care detection kit based on MIP has been proposed, which utilizes a combination of MIP-based sensor and SARS-CoV-2 specific aptamer to detect SARS-CoV-2 with high specificity. ${ }^{225}$ Similarly, Puoci et al also developed a hemocompatible MIP-based "monoclonal type" antibody that can selectively bind with SARS-CoV-2 
RBD, rendering them useful as sensors for COVID-19 diagnosis and therapeutics. ${ }^{226}$

\section{Microarray}

A microarray is a multifunctional tool employed for retrospective Search of SARS-CoV-2 in Human Fecal Metagenomes in diagnostics, research, and epidemiological studies. The technique allows studying the genomic behavior of pathogen, immunogenic response to different disease phases, antigen-antibody interactions, cross-reactivity between species, and target proteins used as biomarkers in a single platform. ${ }^{227-229}$ Wang et al described a proteome microarray that mapped out SARS-CoV-2 specific antibody response at the amino acid level. ${ }^{227}$ Array analysis revealed that commercial antisera against SARS-CoV proteins could be used as a marker for SARS-CoV-2. ${ }^{227}$ A comparative study between respiratory viruses, including SARS CoV-2, used microarray to define the differences in pathogen-specific antibody profile and optimal antigen selection for diagnosis and vaccine development. Cross-reaction with other beta coronaviruses may decrease test specificity when S2 is used as a target antigen but combining S2 with $\mathrm{N}$ enhances its predictive value of diagnosis. ${ }^{229}$

\section{Biosensors}

Biosensors are advanced rapid diagnostic techniques for biomolecules, such as protein, glucose, and other analytes or pathogens, detection. ${ }^{230}$ These are highly portable, simple, and of low cost. ${ }^{230}$ Several studies provided evidence for the convenience of the technology in SARS-CoV-2 detection. Field-effect transistors (FET) are such devices fabricated as a biosensing detector of SARS-CoV-2. ${ }^{231}$ The device's surface was primarily coated with graphene and then conjugated with the anti-spike antibody of SARSCoV-2 via a molecular probe linker (eg, 1-pyrene butyric acid $N$-hydroxysuccinimide ester). This could successfully detect $1 \mathrm{fg} / \mathrm{mL}$ and $100 \mathrm{fg} / \mathrm{mL}$ of SARS-CoV-2 spike protein in phosphate buffer saline and clinical transport medium, respectively. The device had a limit of detection (LOD) of $1.6 \times 10^{1} \mathrm{pfu} / \mathrm{mL}$ and $2.42 \times 10^{2}$ copies $/ \mathrm{mL}$, respectively.

Similarly, another research group developed a biosensor technique to detect SARS-CoV-2 spike protein (S1) based on bioelectric recognition assay. ${ }^{232}$ This novel biosensor detected SARS-CoV-2 within 3 min with a LOD of approximately $1 \mathrm{fg} / \mathrm{mL}$, without any cross-reactivity to SARS-CoV-2 nucleocapsid protein. The portable read-out system of this ready-to-use biosensor platform can be controlled with a smartphone or tablet. Murugan et al proposed another portable field-deployable biosensor based on plasmonic fiber-optic absorbance. The design demonstrated a wash free, one-step detection of SARSCoV-2 proteins using saliva samples where the LOD was $10^{-18} \mathrm{M}$ (attomolar). ${ }^{233}$ SARS-CoV-2 can be efficiently diagnosed using the Fiber Optic Surface Plasmon Resonance (FO-SPR) biosensor system. The FO-SPR, employs both immunoassay and aptamer-based strategy to the biosensor-based technique.

\section{Other/Combined Diagnostic Methods}

Rocca et al detected SARS-CoV-2 from nasopharyngeal swabs by combining multivariate analysis to MALDITOF Mass Spectrometry. It can be used as a complementary detection tool. ${ }^{234}$ A surface-enhanced Raman scattering (SERS) based diagnosis combined with multivariate analysis was studied. ${ }^{235}$ The method includes silver nanorods, which were functionalized on a silicon surface, and angiotensin-converting enzyme 2 (ACE2) was conjugated over the silver-nanorod SERS (SNSERS) decorated as ACE2@SN-SERS array. The binding of the spike protein RBD of SARS-CoV-2 with the surface ACE2 ultimately generates SERS signals. SARS-CoV-2 was detected by identifying a potential spectral intensity where most peaks interestingly show a shift from 1189 to $1182 \mathrm{~cm}^{-1.235}$ These technologies (Table 5) thus hold a promising opportunity to explore the impediments faced in detecting SARS-CoV-2.

\section{Summary and Future Perspective}

Present worldwide circumstance draws attention to the fact that laboratory diagnosis is crucial in public health response to curb SARS-CoV-2 infection which has been continuously emphasized by the health authorities around the world. Various testing systems have been developed, compared and contrasted to assess the test eligibility for successful disease control, but a single quick, accurate and cost-effective method with adequate sensitivity has been difficult to ascertain with all benefits and drawbacks of each strategy. The current review looks at the diagnostic technologies that either have already been implemented or are under development. COVID-19 diagnostic systems are based on four major principles: Cell culture and microscopy, imaging 
Table 5 Proposed Technologies Under Development for SARS-CoV-2 Diagnosis

\begin{tabular}{|c|c|c|c|c|}
\hline Technology & Manufacturer & Capturing Agent & Target & Reference \\
\hline \multirow[t]{3}{*}{ Aptamer based detection } & \multirow[t]{3}{*}{ Laboratory developed } & Anti-RBD aptamer & RBD & [282] \\
\hline & & DNA aptamer & $\mathrm{N}$ & [223] \\
\hline & & RNA aptamer & RNA transcript & [224] \\
\hline Molecular Imprinting Technology & Laboratory developed & Plastic monoclonal type antibody & Spike protein & [283] \\
\hline \multirow[t]{2}{*}{ Microarray } & \multirow[t]{2}{*}{ Laboratory developed } & SARS-CoV 2 proteome & $\lg G+\lg M$ & [227] \\
\hline & & Coronavirus + respiratory virus antigen & $\lg G / \lg A$ & [229] \\
\hline \multirow[t]{3}{*}{ Biosensor } & \multirow[t]{3}{*}{ Laboratory developed } & Cell-based biosensor + Spike SI antibody & SI & [232] \\
\hline & & FET + Anti-spike protein & Spike protein & [23I] \\
\hline & & $\mathrm{P}-\mathrm{FAB}+$ anti-N protein & $\mathrm{N}$ protein & [233] \\
\hline Surface-enhanced Raman scattering (SERS) & Laboratory developed & SN-SERS+ ACE2 & RBD & [235] \\
\hline
\end{tabular}

Abbreviations: FET, field effect transistor; P-FAB, plasmonic fiber optic absorbance biosensor; ACE 2, angiotensin-converting enzyme-2.

systems, nucleic acid-based detection, and immunoassay, though each has its advantages and disadvantages (Table-6). While cell culture and microscopy are important for a deeper understanding of the evolving novel coronavirus and its relationship with the host cell, these systems entail expensive criteria, which hardly makes it an optimal cost-effective diagnostic method. Imaging examinations have been very useful at the onset of the pandemic in detecting unknown pneumonia, but common respiratory viral pneumonia features make this a conditional approach for determining disease seriousness rather than a standard diagnostic method. Most commercial systems for COVID-19 detection are mainly based on the molecular and immunological techniques, with rRT-PCR being used in the front line. rRT-PCR is a very sensitive and specific technique that can identify viral RNA from very small sized sample input. But expensive instruments and facilities, trained human resources and a definite window period to achieve accurate results make it a little disadvantageous for an emergency situation. In contrast, isothermal NAATs and CRISPR technologies are getting utilized for advancement of rapid, POC testing that may reduce the dependency on rRT-PCR tests. Immunoassays are the other diagnostic tools that are dominating the COVID-19 diagnostic market after the gold standard rRT-PCR. Numerous commercial and laboratory-based immunoassays have been reported, but many of these reports lack the relevant validation data, which is critical for defining test sensitivity and specificity. Despite the drawbacks, immunoassays offer a powerful tool for dramatically reducing COVID-19 cases. It has the advantage of identifying both symptomatic and asymptomatic patients. Therefore, it can be used in conjunction with or complementary to RNAbased tests to increase diagnostic sensitivity. Moreover, immunoassays can be useful for contact tracing, studying seroprevalence and dynamics of an immune response against the virus. The world has moved toward vaccination, and more than four vaccines have already been in clinical use. Immunoassays will be required to evaluate these vaccine's effectiveness. Hence, it is essential to assess these immunoassay kits properly before approving for a community. Besides these conventional methods, microarray, aptamer, MIP and biosensor-based methods still under development should be evaluated to determine their effectiveness in urgent conditions. Even though vaccination programs have started, and reports have shown a slight reduction in disease severity, SARS-CoV-2 being a positive-strand RNA virus creates the continuing possibility of a recurrence of the previous situation. Before an efficient, commercially viable vaccine is successfully introduced, rapid POC tests based on molecular and immunoassay are still of great importance to deal with the challenges of COVID-19 disease containment. Further insights are yet to be addressed to unveil the epidemiological, immunological, genomic, 


\begin{tabular}{|c|c|c|c|c|c|c|c|}
\hline 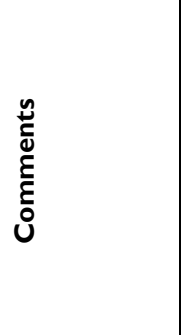 & 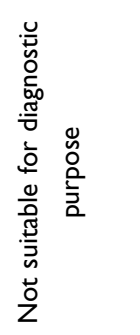 & 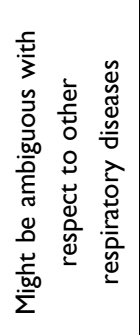 & 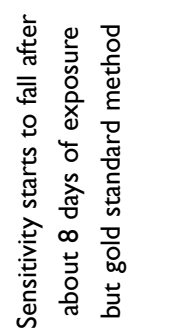 & 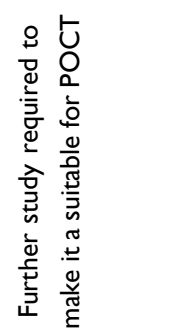 & 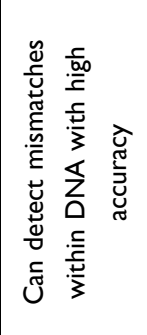 & 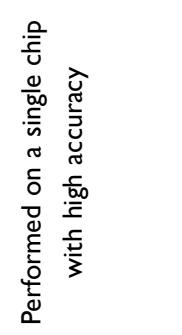 & 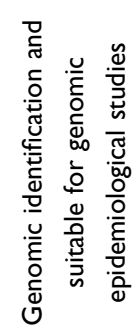 \\
\hline 离 & 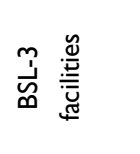 & 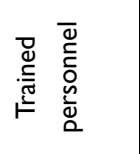 & 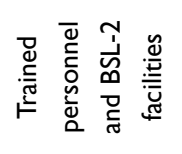 & 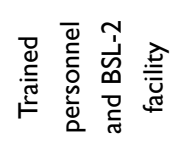 & $\begin{array}{l}5 \\
0 \\
0\end{array}$ & $\begin{array}{l}5 \\
0\end{array}$ & 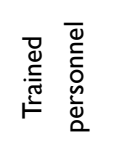 \\
\hline 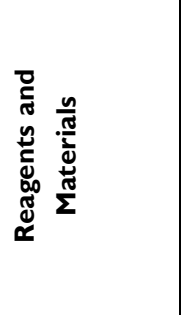 & 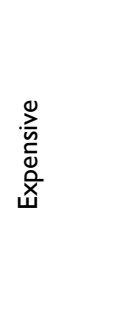 & 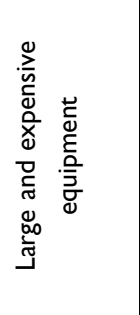 & 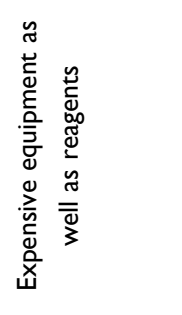 & 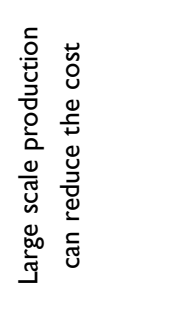 & 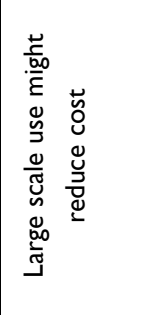 & 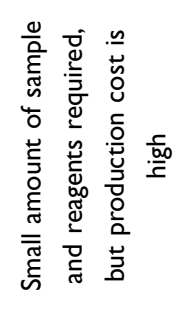 & 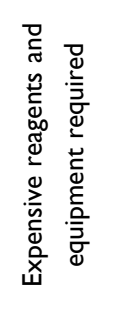 \\
\hline 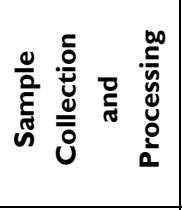 & : & $\lesssim$ & 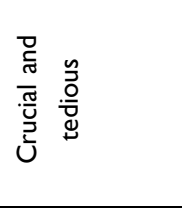 & 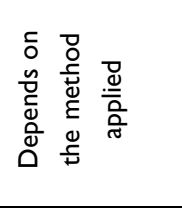 & 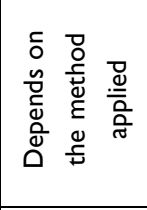 & 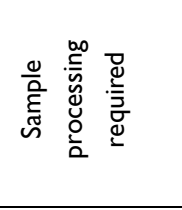 & $\begin{array}{l}\stackrel{n}{0} \\
\stackrel{0}{\overline{0}} \\
\vdash\end{array}$ \\
\hline 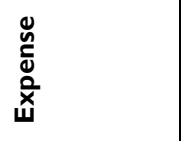 & $\begin{array}{l}+ \\
+ \\
+\end{array}$ & + & $\stackrel{+}{+}$ & + & + & $\begin{array}{l}+ \\
+ \\
+\end{array}$ & $\stackrel{+}{+}+$ \\
\hline 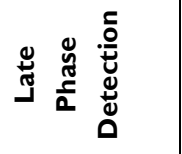 & + & + & +1 & +1 & +1 & +1 & 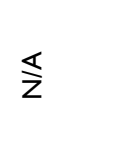 \\
\hline 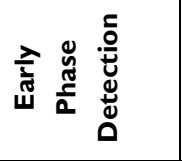 & $\stackrel{+}{+}$ & 1 & $\stackrel{+}{\ddagger}+$ & $\stackrel{+}{+}$ & $\stackrel{+}{+}$ & + & 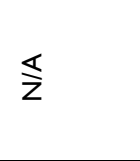 \\
\hline 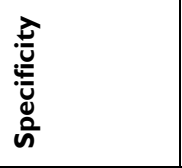 & $\begin{array}{l}+ \\
+\end{array}$ & +1 & $\begin{array}{l}+ \\
+\end{array}$ & $\stackrel{+}{+}$ & $\stackrel{+}{+}$ & $\begin{array}{l}+ \\
+ \\
+\end{array}$ & $\begin{array}{l}+ \\
+ \\
+ \\
+\end{array}$ \\
\hline 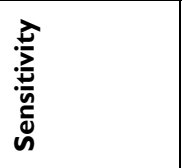 & $\begin{array}{l}+ \\
+ \\
+\end{array}$ & +1 & $\begin{array}{l}+ \\
+ \\
+\end{array}$ & $\stackrel{+}{\ddagger}+$ & $\stackrel{+}{\ddagger}$ & $\begin{array}{l}+ \\
+ \\
+\end{array}$ & $\stackrel{+}{+}+$ \\
\hline 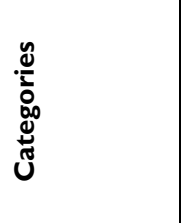 & 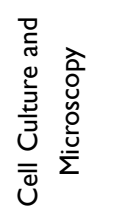 & 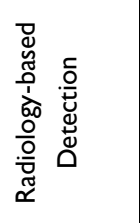 & 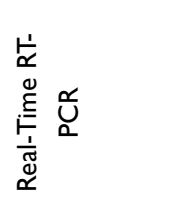 & 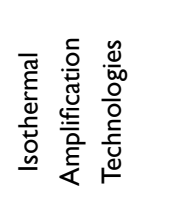 & 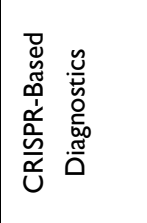 & 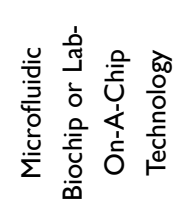 & 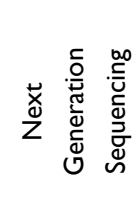 \\
\hline & 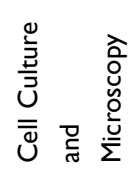 & 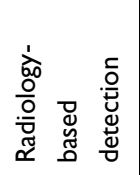 & \multicolumn{5}{|l|}{ 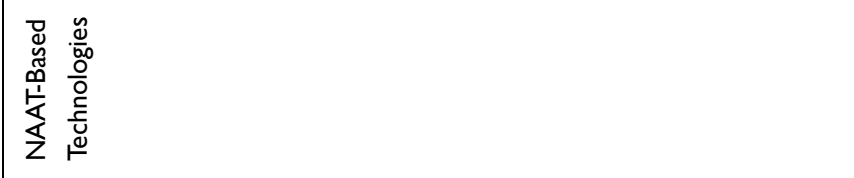 } \\
\hline
\end{tabular}




\begin{tabular}{|c|c|c|c|c|c|c|}
\hline 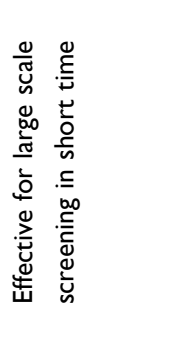 & 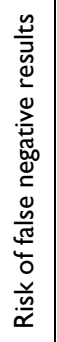 & 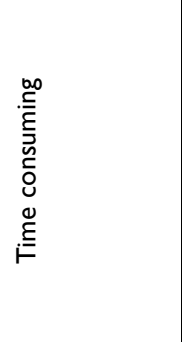 & 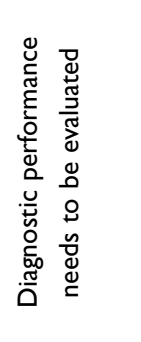 & 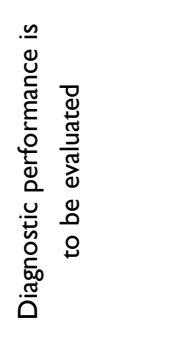 & 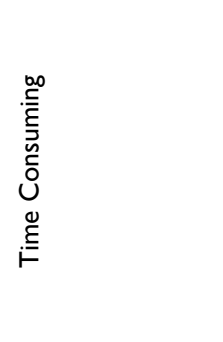 & 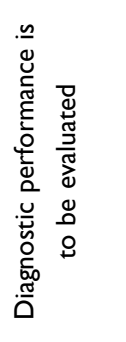 \\
\hline 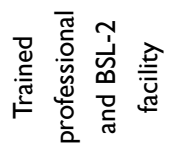 & $\stackrel{\leftarrow}{\circ}$ & 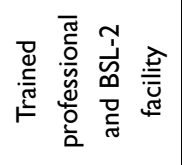 & 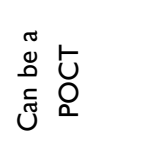 & 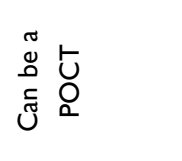 & 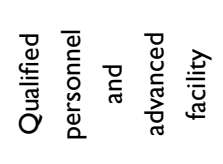 & 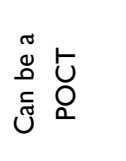 \\
\hline 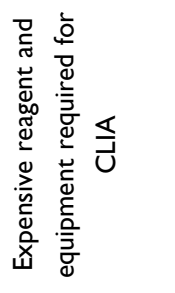 & 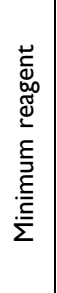 & 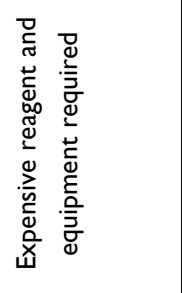 & 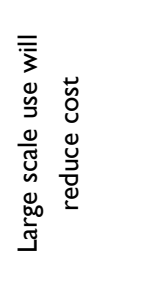 & 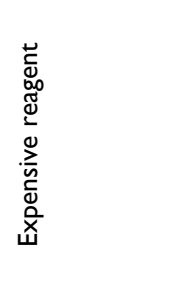 & 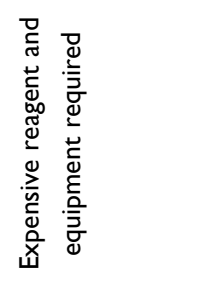 & 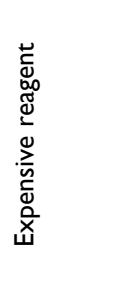 \\
\hline 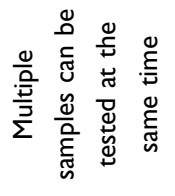 & 志 & 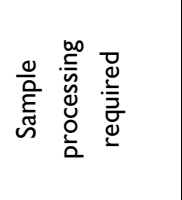 & 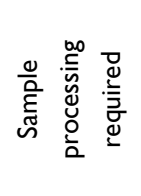 & 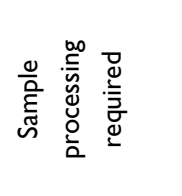 & 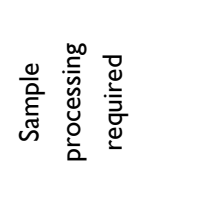 & 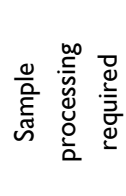 \\
\hline$\ddagger$ & + & 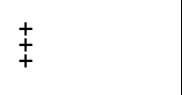 & +1 & 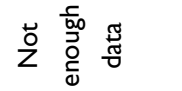 & 1 & + \\
\hline+1 & 1 & +1 & 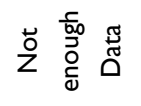 & 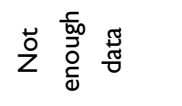 & 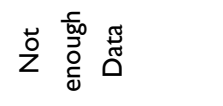 & 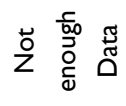 \\
\hline$\stackrel{+}{+}$ & + & $\stackrel{+}{+}$ & 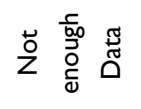 & 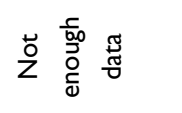 & 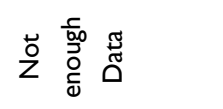 & 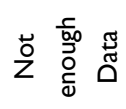 \\
\hline$\stackrel{+}{\ddagger}$ & $\begin{array}{l}+ \\
+ \\
+\end{array}$ & $\stackrel{+}{+}+$ & $\ddagger$ & + & $\stackrel{+}{+}$ & $\ddagger$ \\
\hline$\ddagger$ & + & $\begin{array}{l}+ \\
+ \\
+\end{array}$ & + & + & + & $\ddagger$ \\
\hline 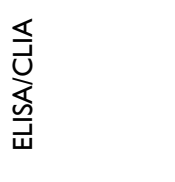 & 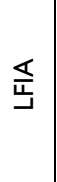 & 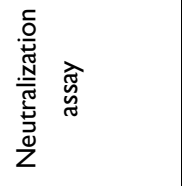 & 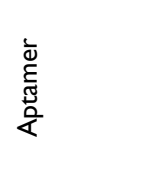 & 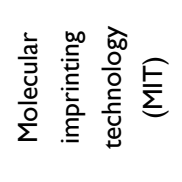 & 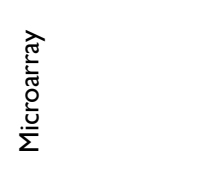 & 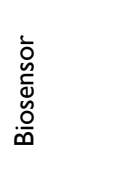 \\
\hline \multicolumn{3}{|l|}{ 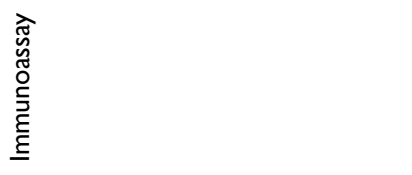 } & \multicolumn{4}{|l|}{ 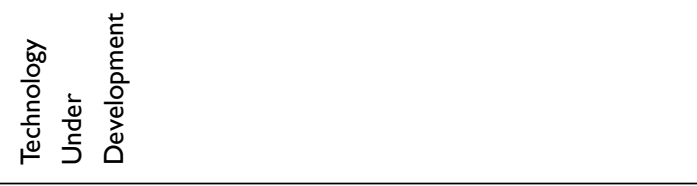 } \\
\hline
\end{tabular}


and proteomic features of the novel virus that might bolster the implementation of techniques under development for COVID-19 diagnosis.

\section{Article Highlights}

- Multi-faceted pathophysiologic behavior of SARSCoV-2 makes it difficult for the physicians to draw a universal outline to manage the patients with COVID19.

- Early diagnosis and isolation of the carriers from their neighbor are believed to flatten the disease mortality curve.

- Choosing rapid and accurate diagnostic kits, and their widespread implementation is critical for policymakers to rein in the pandemic as long as an effective and safe vaccine has not been established and provided to the masses.

- In this COVID-19 outbreak, initial detection and characterization were performed in cell culture laboratories followed by whole genome sequencing, but according to WHO, culturing of SARS-CoV-2 has only been approved in BSL-III laboratories, making cell culture-based detection mostly impractical and expensive, prohibiting its implementation in resource lacking countries.

- Radiological tools such as X-ray, CT-scan are effective for the diagnosis as well as prognosis.

- Nucleic acid amplification tests (NAATs), such as rRtPCR, isothermal amplification techniques, CRISPR-Cas, and micro-fluidic systems, on the other hand, are considered the most convenient tools for diagnostic purposes.

- The advantage of immunoassay kits is that they can cover both the patient and viral windows using antibody and antigen tests.

- Prospective techniques such as aptamer, biosensors, microarrays, MALDI-TOFs, and others, alone or in combination, show promising outcomes in COVID-19 diagnosis.

\section{Acknowledgment}

The authors are grateful to Prof. Mohammed S. Razzaque, MBBS, Ph.D. of Lake Erie College of Osteopathic Medicine (Pennsylvania, USA), for reading the manuscript and providing useful suggestions.

\section{Author Contributions}

All authors made a significant contribution to the work reported, whether that is in the conception, study design, execution, acquisition of data, analysis, and interpretation, or in all these areas; took part in drafting, revising, or critically reviewing the article; gave final approval of the version to be published; have agreed on the journal to which the article has been submitted; and agreed to be accountable for all aspects of the work.

\section{Disclosure}

Mr Md. Ahsanul Haq reports a patent 10202006327W pending; Prof. Dr. Bijon Kumar Sil report a patent 10202006327W pending; Dr Mohd. Raeed Jamiruddin reports a patent $10202006327 \mathrm{~W}$ pending to Intellectual Property Office of Singapore; Dr Nihad Adnan report a patent $10202006327 \mathrm{~W}$ pending; The authors report no other conflicts of interest in this work.

\section{References}

1. Munster VJ, Feldmann F, Williamson BN, et al. Respiratory disease in rhesus macaques inoculated with SARS-CoV-2. Nature. 2020;585(7824):268-272. doi:10.1038/s41586-020-23 24-7

2. Shang J, Ye G, Shi K, et al. Structural basis of receptor recognition by SARS-CoV-2. Nature. 2020;581(7807):221-224. doi:10. 1038/s41586-020-2179-y

3. Wu Y, Ho W, Huang Y, et al. SARS-CoV-2 is an appropriate name for the new coronavirus. Lancet. 2020;395(10228):949950. doi:10.1016/S0140-6736(20)30557-2

4. Morawska L, Cao J. Airborne transmission of SARS-CoV-2: the world should face the reality. Environ Int. 2020;139:105730. doi:10.1016/j.envint.2020.105730

5. Cascella M, Rajnik M, Cuomo A, Dulebohn SC, Di Napoli R. Features, evaluation, and treatment of coronavirus. In: StatPearls. Treasure Island (FL); 2020.

6. Vogel L. Feds update immunization advice with Moderna vaccine approval. CMAJ. 2021;193(3):E108-E109. doi:10.1503/cmaj.109 5914

7. Ledford H. Moderna COVID vaccine becomes second to get US authorization. Nature. 2020. doi:10.1038/d41586-020-03593-7

8. Tanne JH. Covid-19: FDA panel votes to approve Pfizer BioNTech vaccine. BMJ. 2020;371:m4799. doi:10.1136/bmj. m4799

9. Mahase E. Covid-19: UK approves Moderna vaccine to be given as two doses 28 days apart. $B M J .2021 ; 372: \mathrm{n} 74$. doi:10.1136/bmj. $\mathrm{n} 74$

10. Mahase E. Covid-19: reports from Israel suggest one dose of Pfizer vaccine could be less effective than expected. BMJ. 2021;372:n217. doi:10.1136/bmj.n217

11. Mahase E. Covid-19: UK approves Pfizer and BioNTech vaccine with rollout due to start next week. BMJ. 2020;371:m4714. doi:10.1136/bmj.m4714

12. Pan Y, Zhang D, Yang P, Poon LLM, Wang Q. Viral load of SARS-CoV-2 in clinical samples. Lancet Infect Dis. 2020;20 (4):411-412. doi:10.1016/S1473-3099(20)30113-4

13. Nayak S, Blumenfeld NR, Laksanasopin T, Sia SK. Point-of-care diagnostics: recent developments in a connected age. Anal Chem. 2017;89(1):102-123. doi:10.1021/acs.analchem.6b04630

14. Yuce M, Filiztekin E, Ozkaya KG. COVID-19 diagnosis -A review of current methods. Biosens Bioelectron. 2021;17 2:112752. doi:10.1016/j.bios.2020.112752 
15. Ravi N, Cortade DL, Ng E, Wang SX. Diagnostics for SARSCoV-2 detection: a comprehensive review of the FDA-EUA COVID-19 testing landscape. Biosens Bioelectron. 2020;16 5:112454. doi:10.1016/j.bios.2020.112454

16. Wang W, Xu Y, Gao R, et al. Detection of SARS-CoV-2 in different types of clinical specimens. JAMA. 2020;323 (18):1843-1844. doi:10.1001/jama.2020.3786

17. Jalandra R, Yadav AK, Verma D, et al. Strategies and perspectives to develop SARS-CoV-2 detection methods and diagnostics. Biomed Pharmacother. 2020;129:110446. doi:10.1016/j.biopha. 2020.110446

18. Chua KB, Goh KJ, Wong KT, et al. Fatal encephalitis due to Nipah virus among pig-farmers in Malaysia. Lancet. 1999;354 (9186):1257-1259.

19. Ksiazek TG, Erdman D, Goldsmith CS, et al. A novel coronavirus associated with severe acute respiratory syndrome. $N$ Engl J Med. 2003;348(20):1953-1966. doi:10.1056/NEJMoa030781

20. Reed KD, Melski JW, Graham MB, et al. The detection of monkeypox in humans in the Western Hemisphere. $N$ Engl J Med. 2004;350(4):342-350. doi:10.1056/NEJMoa032299

21. Yu XJ, Liang MF, Zhang SY, et al. Fever with thrombocytopenia associated with a novel bunyavirus in China. $N$ Engl $\mathrm{J} \mathrm{Med}$. 2011;364(16):1523-1532. doi:10.1056/NEJMoa1010095

22. Farkash EA, Wilson AM, Jentzen JM. Ultrastructural evidence for direct renal infection with SARS-CoV-2. J Am Soc Nephrol. 2020;31(8):1683-1687. doi:10.1681/ASN.2020040432

23. Harcourt J, Tamin A, Lu X, et al. Severe acute respiratory syndrome Coronavirus 2 from patient with coronavirus disease, United States. Emerg Infect Dis. 2020;26(6):1266-1273. doi:10. 3201/eid2606.200516

24. Lin Y, Yan X, Cao W, et al. Probing the structure of the SARS coronavirus using scanning electron microscopy. Antivir Ther. 2004;9(2):287-289.

25. Prasad S, Potdar V, Cherian S, Abraham P, Basu A; Team I-NN. Transmission electron microscopy imaging of SARS-CoV-2. Indian J Med Res. 2020;151(2 \& 3):241-243. doi:10.4103/ijmr. IJMR_577_20

26. Algarroba GN, Rekawek P, Vahanian SA, et al. Visualization of severe acute respiratory syndrome coronavirus 2 invading the human placenta using electron microscopy. Am $J$ Obstet Gynecol. 2020;223(2):275-278. doi:10.1016/j.ajog.2020.05.023

27. Chu H, Chan JF, Yuen TT, et al. Comparative tropism, replication kinetics, and cell damage profiling of SARS-CoV-2 and SARS$\mathrm{CoV}$ with implications for clinical manifestations, transmissibility, and laboratory studies of COVID-19: an observational study. Lancet Microb. 2020;1(1):e14-e23. doi:10.1016/S2666-5247(20) 30004-5

28. Zhu N, Zhang D, Wang $\mathrm{W}$, et al. A novel coronavirus from patients with pneumonia in China, 2019. $N$ Engl J Med. 2020;382(8):727-733. doi:10.1056/NEJMoa2001017

29. Zhou P, Yang XL, Wang XG, et al. A pneumonia outbreak associated with a new coronavirus of probable bat origin. Nature. 2020;579 (7798):270-273. doi:10.1038/s41586-020-2012-7

30. Calderaro A, Arcangeletti MC, De Conto F, et al. SARS-CoV-2 infection diagnosed only by cell culture isolation before the local outbreak in an Italian seven-week-old suckling baby. Int $J$ Infect Dis. 2020;96:387-389. doi:10.1016/j.ijid.2020.05.035

31. Hui KPY, Cheung MC, Perera R, et al. Tropism, replication competence, and innate immune responses of the coronavirus SARS-CoV-2 in human respiratory tract and conjunctiva: an analysis in ex-vivo and in-vitro cultures. Lancet Respir Med. 2020;8(7):687-695. doi:10.1016/S2213-2600(20)30193-4

32. WHO. Country \& Technical Guidance - Coronavirus disease (COVID-19); 2020. Available from: https://www.who.int/emer gencies/diseases/novel-coronavirus-2019/technical-guidance. Accessed February 15, 2021.
33. Cozzi D, Albanesi M, Cavigli E, et al. Chest X-ray in new Coronavirus Disease 2019 (COVID-19) infection: findings and correlation with clinical outcome. Radiol Med. 2020;125(8):730737. doi:10.1007/s11547-020-01232-9

34. Jacobi A, Chung M, Bernheim A, Eber C. Portable chest X-ray in coronavirus disease-19 (COVID-19): a pictorial review. Clin Imaging. 2020;64:35-42. doi:10.1016/j.clinimag.2020.04.001

35. Narin A, Kaya C, Pamuk Z Automatic detection of coronavirus disease (covid-19) using x-ray images and deep convolutional neural networks. arXiv preprint arXiv:200310849; 2020.

36. Vancheri SG, Savietto G, Ballati F, et al. Radiographic findings in 240 patients with COVID-19 pneumonia: time-dependence after the onset of symptoms. Eur Radiol. 2020;30(11):6161-6169. doi:10.1007/s00330-020-06967-7

37. Wong HYF, Lam HYS, Fong AH, et al. Frequency and distribution of chest radiographic findings in patients positive for COVID-19. Radiology. 2020;296(2):E72-E78. doi:10.1148/ radiol.2020201160

38. Xu B, Xing Y, Peng J, et al. Chest CT for detecting COVID-19: a systematic review and meta-analysis of diagnostic accuracy. Eur Radiol. 2020;30(10):5720-5727. doi:10.1007/s00330-02006934-2

39. Yang W, Sirajuddin A, Zhang X, et al. The role of imaging in 2019 novel coronavirus pneumonia (COVID-19). Eur Radiol. 2020;30(9):4874-4882. doi:10.1007/s00330-020-06827-4

40. Li Y, Xia L. Coronavirus disease 2019 (COVID-19): role of chest $\mathrm{CT}$ in diagnosis and management. AJR Am $J$ Roentgenol. 2020;214(6):1280-1286. doi:10.2214/AJR.20.22954

41. Ye Z, Zhang Y, Wang Y, Huang Z, Song B. Chest CT manifestations of new coronavirus disease 2019 (COVID-19): a pictorial review. Eur Radiol. 2020;30(8):4381-4389. doi:10.1007/s00330020-06801-0

42. Pan Y, Guan H, Zhou S, et al. Initial CT findings and temporal changes in patients with the novel coronavirus pneumonia (2019nCoV): a study of 63 patients in Wuhan, China. Eur Radiol. 2020;30(6):3306-3309. doi:10.1007/s00330-020-06731-X

43. $\mathrm{Xu} \mathrm{X}, \mathrm{Yu} \mathrm{C}, \mathrm{Qu}$ J, et al. Imaging and clinical features of patients with 2019 novel coronavirus SARS-CoV-2. Eur J Nucl Med Mol Imaging. 2020;47(5):1275-1280. doi:10.1007/s00259-020-04735-9

44. Liu J, Yu H, Zhang S. The indispensable role of chest CT in the detection of coronavirus disease 2019 (COVID-19). Eur J Nucl Med Mol Imaging. 2020;47(7):1638-1639. doi:10.1007/s00259020-04795-x

45. Li X, Zeng W, Li X, et al. CT imaging changes of corona virus disease 2019 (COVID-19): a multi-center study in Southwest China. J Transl Med. 2020;18(1):154. doi:10.1186/s12967-02002324-w

46. Bosso G, Allegorico E, Pagano A, et al . Lung ultrasound as diagnostic tool for SARS-CoV-2 infection. Intern Emerg Med. 2020. doi:10.1007/s11739-020-02512-y

47. Sorlini C, Femia M, Nattino G, et al. The role of lung ultrasound as a frontline diagnostic tool in the era of COVID-19 outbreak. Intern Emerg Med. 2020. doi:10.1007/s11739-020-02524-8

48. Li B, Li X, Wang Y, et al. Diagnostic value and key features of computed tomography in Coronavirus disease 2019. Emerg Microbes Infect. 2020;9(1):787-793. doi:10.1080/22221751.20 20.1750307

49. Sun Z, Zhang N, Li Y, Xu X. A systematic review of chest imaging findings in COVID-19. Quant Imaging Med Surg. 2020;10(5):1058-1079.

50. Radiology ACo. ACR recommendations for the use of chest radiography and computed tomography (CT) for suspected COVID-19 infection; 2020. Available from: https://www.acr.org/ Advocacy-and-Economics/ACR-Position-Statements/ Recommendations-for-Chest-Radiography-and-CT-forSuspected-COVID19-Infection. Accessed February 15, 2021. 
51. FDA. Coronavirus testing basics; 2020. Available from: https:// www.fda.gov/consumers/consumer-updates/coronavirus-testingbasics. Accessed February 15, 2021.

52. Wang AM, Doyle MV, Mark DF. Quantitation of mRNA by the polymerase chain reaction. Proc Natl Acad Sci U S A. 1989;86 (24):9717-9721. doi:10.1073/pnas.86.24.9717

53. FDA. Coronavirus Disease 2019 (COVID-19); 2019. Available from: https://www.fda.gov/emergency-preparedness-andresponse/counterterrorism-and-emerging-threats/coronavirus-dis ease-2019-covid-19. Accessed February 15, 2021.

54. Wang X, Seed B. High-throughput primer and probe design. In: Dorak MT. editor. Real-Time PCR. Vol. 1, 1st ed. London: Taylor \& Francis; 2006:93-106

55. VanGuilder HD, Vrana KE, Freeman WM. Twenty-five years of quantitative PCR for gene expression analysis. Biotechniques. 2008;44(5):619-626. doi:10.2144/000112776

56. Overbergh L, Giulietti A-P, Valckx D, Mathieu C. Real-time polymerase chain reaction. In: Patrinos GP, Ansorge WJ, editors. Molecular Diagnostics. Elsevier/Academic Press:London, United Kingdom; 2010:87-105.

57. Yip CC, Ho CC, Chan JF, et al. Development of a novel, genome subtraction-derived, SARS-CoV-2-specific COVID-19-nsp2 realtime RT-PCR assay and its evaluation using clinical specimens. Int J Mol Sci. 2020;21(7).

58. Bustin SA, Nolan T. RT-qPCR testing of SARS-CoV-2: a primer. Int J Mol Sci. 2020;21(8):3004. doi:10.3390/ijms21083004

59. Battaglia M, Pedrazzoli P, Palermo B, et al. Epithelial tumour cell detection and the unsolved problems of nested RT-PCR: a new sensitive one step method without false positive results. Bone Marrow Transplant. 1998;22(7):693-698. doi:10.1038/sj.bmt.1701405

60. Wong ML, Medrano JF. Real-time PCR for mRNA quantitation. Biotechniques. 2005;39(1):75-85. doi:10.2144/05391RV01

61. Park M, Won J, Choi BY, Lee CJ. Optimization of primer sets and detection protocols for SARS-CoV-2 of coronavirus disease 2019 (COVID-19) using PCR and real-time PCR. Exp Mol Med. 2020;52(6):963-977. doi:10.1038/s12276-020-0452-7

62. Corman VM, Landt O, Kaiser M, et al. Detection of 2019 novel coronavirus (2019-nCoV) by real-time RT-PCR. Euro Surveill. 2020;25(3):2000045.

63. Chu DKW, Pan Y, Cheng SMS, et al. Molecular diagnosis of a novel coronavirus (2019-nCoV) causing an outbreak of pneumonia. Clin Chem. 2020;66(4):549-555. doi:10.1093/clinchem/hvaa029

64. Niu P, Lu R, Zhao L, et al. Three novel real-time RT-PCR assays for detection of COVID-19 virus. China CDC Weekly. 2020:1-5.

65. Lu X, Wang L, Sakthivel SK, et al. US CDC real-time reverse transcription PCR panel for detection of severe acute respiratory syndrome coronavirus 2. Emerg Infect Dis. 2020;26(8):1654. doi:10.3201/eid2608.201246

66. Organization WH. Protocol: Real-Time RT-PCR Assays for the Detection of SARS-CoV-2 Institut Pasteur. Paris: World Health Organization; 2020.

67. Poon L, Chu D, Peiris M. Detection of 2019 Novel Coronavirus (2019-nCoV) in Suspected Human Cases by RT-PCR. Hong Kong: School of Public Health, The University of Hong Kong; 2020.

68. Naganori Nao KS, Katano H, Matsuyama S, Takeda M. Detection of second case of 2019-nCoV infection in Japan; 2020. Available from: https:/www.who.int/docs/default-source/coronaviruse/method-niid20200123-2.pdf?sfvrsn=fbf75320_7. Accessed February 15, 2021.

69. Chen W, Lan Y, Yuan X, et al. Detectable 2019-nCoV viral RNA in blood is a strong indicator for the further clinical severity. Emerg Microbes Infect. 2020;9(1):469-473. doi:10.1080/222217 51.2020.1732837

70. Peng L, Liu J, Xu W, et al. SARS-CoV-2 can be detected in urine, blood, anal swabs, and oropharyngeal swabs specimens. $J$ Med Virol. 2020.
71. Liu R, Han H, Liu F, et al. Positive rate of RT-PCR detection of SARSCoV-2 infection in 4880 cases from one hospital in Wuhan, China, from Jan to Feb 2020. Clin Chim Acta. 2020;505:172-175.

72. Wang M, Wu Q, Xu W, et al. Clinical diagnosis of 8274 samples with 2019-novel coronavirus in Wuhan. medRxiv. 2020.

73. Li Y, Yao L, Li J, et al. Stability issues of RT-PCR testing of SARS-CoV-2 for hospitalized patients clinically diagnosed with COVID-19. J Med Virol. 2020;92(7):903-908. doi:10.1002/ jmv.25786

74. LeBlanc JJ, Heinstein C, MacDonald J, Pettipas J, Hatchette TF, Patriquin G. A combined oropharyngeal/nares swab is a suitable alternative to nasopharyngeal swabs for the detection of SARSCoV-2. J Clin Virol. 2020;128:104442. doi:10.1016/j.jcv.2020. 104442

75. Zhang W, Du RH, Li B, et al. Molecular and serological investigation of 2019-nCoV infected patients: implication of multiple shedding routes. Emerg Microbes Infect. 2020;9(1):386-389. doi:10.1080/22221751.2020.1729071

76. Mohammadi A, Esmaeilzadeh E, Li Y, Bosch RJ, Li JZ. SARSCoV-2 detection in different respiratory sites: a systematic review and meta-analysis. EBioMedicine. 2020;59:102903. doi:10.1016/ j.ebiom.2020.102903

77. Azzi L, Carcano G, Gianfagna F, et al. Saliva is a reliable tool to detect SARS-CoV-2. J Infect. 2020;81(1):e45-e50. doi:10.1016/j. jinf.2020.04.005

78. Torres I, Albert E, Navarro D. Pooling of nasopharyngeal swab specimens for SARS-CoV-2 detection by RT-PCR. J Med Virol. 2020;92(11):2306-2307. doi:10.1002/jmv.25971

79. Tahamtan A, Ardebili A. Real-time RT-PCR in COVID-19 detection: issues affecting the results. Expert Rev Mol Diagn. 2020;20 (5):453-454. doi:10.1080/14737159.2020.1757437

80. Li D, Wang D, Dong J, et al. False-negative results of real-time reverse-transcriptase polymerase chain reaction for severe acute respiratory syndrome coronavirus 2: role of deep-learning-based CT diagnosis and insights from two cases. Korean J Radiol. 2020;21(4):505-508. doi:10.3348/kjr.2020.0146

81. Xu J, Wu R, Huang H, et al. Computed tomographic imaging of 3 patients with coronavirus disease 2019 pneumonia with negative virus real-time reverse-transcription polymerase chain reaction test. Clin Infect Dis. 2020;71(15):850-852. doi:10.1093/cid/ ciaa207

82. Kucirka LM, Lauer SA, Laeyendecker O, Boon D, Lessler J. Variation in false-negative rate of reverse transcriptase polymerase chain reaction-based SARS-CoV-2 tests by time since exposure. Ann Intern Med. 2020;173(4):262-267. doi:10.7326/M201495

83. Wikramaratna P, Paton RS, Ghafari M, Lourenco J. Estimating false-negative detection rate of SARS-CoV-2 by RT-PCR. medRxiv. 2020.

84. Peddu V, Shean RC, Xie H, et al. Metagenomic analysis reveals clinical SARS-CoV-2 infection and bacterial or viral superinfection and colonization. Clin Chem. 2020;66(7):966-972. doi:10.10 93/clinchem/hvaa106

85. Lippi G, Simundic A-M, Plebani M. Potential preanalytical and analytical vulnerabilities in the laboratory diagnosis of coronavirus disease 2019 (COVID-19). Clin Chem Lab Med. 2020;1.

86. Amanat F, Stadlbauer D, Strohmeier S, et al. A serological assay to detect SARS-CoV-2 seroconversion in humans. Nat Med. 2020;26(7):1033-1036. doi:10.1038/s41591-020-0913-5

87. Luo Z, Chen L, Liang C, Wei Q, Chen Y, Wang J. Porous carbon films decorated with silver nanoparticles as a sensitive SERS substrate, and their application to virus identification. Microchim Acta. 2017;184(9):3505-3511. doi:10.1007/s00604-017-2369-y

88. Dong L, Zhou J, Niu C, et al. Highly accurate and sensitive diagnostic detection of SARS-CoV-2 by digital PCR. medRxiv. 2020 . 
89. CDC. CDC 2019-novel coronavirus (2019-nCoV) real-time RTPCR diagnostic panel. Services USDoHaH, editor. Centers for Disease Control and Prevention; 2020.

90. James AS, Alwneh JI. COVID-19 infection diagnosis: potential impact of isothermal amplification technology to reduce community transmission of SARS-CoV-2. Diagnostics. 2020;10(6):399. doi:10.3390/diagnostics 10060399

91. Osterdahl MF, Lee KA, Lochlainn MN, et al. Detecting SARSCoV-2 at point of care: preliminary data comparing loopmediated isothermal amplification (LAMP) to polymerase chain reaction (PCR). BMC Infect Dis. 2020;20(1):783. doi:10.1186/ s12879-020-05484-8

92. Teoh BT, Sam SS, Tan KK, et al. Detection of dengue viruses using reverse transcription-loop-mediated isothermal amplification. BMC Infect Dis. 2013;13:387. doi:10.1186/1471-2334-13387

93. Lu R, Wu X, Wan Z, Li Y, Jin X, Zhang C. A novel reverse transcription loop-mediated isothermal amplification method for rapid detection of SARS-CoV-2. Int J Mol Sci. 2020;21(8):2826. doi:10.3390/ijms21082826

94. Yu L, Wu S, Hao X, et al. Rapid colorimetric detection of COVID-19 coronavirus using a reverse transcriptional loopmediated isothermal amplification (RT-LAMP) diagnostic platform: iLACO. medRxiv. 2020.

95. Shen M, Zhou Y, Ye J, et al. Recent advances and perspectives of nucleic acid detection for coronavirus. J Pharm Anal. 2020;10 (2):97-101. doi:10.1016/j.jpha.2020.02.010

96. Mori Y, Nagamine K, Tomita N, Notomi T. Detection of loopmediated isothermal amplification reaction by turbidity derived from magnesium pyrophosphate formation. Biochem Biophys Res Commun. 2001;289(1):150-154. doi:10.1006/bbrc.2001.5921

97. Shirato K, Semba S, El-Kafrawy SA, et al. Development of fluorescent reverse transcription loop-mediated isothermal amplification (RT-LAMP) using quenching probes for the detection of the Middle East respiratory syndrome coronavirus. J Virol Methods. 2018;258:41-48. doi:10.1016/j.jviromet.2018.05.006

98. Tanner NA, Zhang Y, Evans TC Jr. Visual detection of isothermal nucleic acid amplification using $\mathrm{pH}$-sensitive dyes. Biotechniques. 2015;58(2):59-68. doi:10.2144/000114253

99. Park GS, Ku K, Baek SH, et al. Development of reverse transcription loop-mediated isothermal amplification assays targeting severe acute respiratory syndrome coronavirus 2 (SARS-CoV-2). J Mol Diagn. 2020;22(6):729-735. doi:10.1016/j.jmoldx.2020. 03.006

100. Yu L, Wu S, Hao X, et al. Rapid detection of COVID-19 Coronavirus using a reverse transcriptional loop-mediated isothermal amplification (RT-LAMP) diagnostic platform. Clin Chem. 2020;66(7):975-977. doi:10.1093/clinchem/hvaa102

101. Baek YH, Um J, Antigua KJC, et al. Development of a reverse transcription-loop-mediated isothermal amplification as a rapid early-detection method for novel SARS-CoV-2. Emerg Microbes Infect. 2020;9(1):998-1007. doi:10.1080/22221751.2020.1756 698

102. Yan C, Cui J, Huang L, et al. Rapid and visual detection of 2019 novel coronavirus (SARS-CoV-2) by a reverse transcription loopmediated isothermal amplification assay. Clin Microbiol Infect. 2020;26(6):773-779. doi:10.1016/j.cmi.2020.04.001

103. Lamb LE, Bartolone SN, Ward E, Chancellor MB. Rapid detection of novel coronavirus/severe acute respiratory syndrome coronavirus 2 (SARS-CoV-2) by reverse transcription-loop-mediated isothermal amplification. PLoS One. 2020;15(6):e0234682. doi:10.1371/journal.pone.0234682

104. Zhang Y, Odiwuor N, Xiong J, et al. Rapid molecular detection of SARS-CoV-2 (COVID-19) virus RNA using colorimetric LAMP. medRxiv. 2020.
105. Thi VLD, Herbst K, Boerner K, et al. A colorimetric RT-LAMP assay and LAMP-sequencing for detecting SARS-CoV-2 RNA in clinical samples. Sci Transl Med. 2020;12(556).

106. Zhu X, Wang X, Han L, et al. Multiplex reverse transcription loop-mediated isothermal amplification combined with nanoparticle-based lateral flow biosensor for the diagnosis of COVID-19. Biosens Bioelectron. 2020;166:112437. doi:10.1016/j.bios.20 20.112437

107. Kitagawa Y, Orihara Y, Kawamura R, et al. Evaluation of rapid diagnosis of novel coronavirus disease (COVID-19) using loopmediated isothermal amplification. $J$ Clin Virol. 2020;12 9:104446. doi:10.1016/j.jcv.2020.104446

108. Kashir J, Yaqinuddin A. Loop mediated isothermal amplification (LAMP) assays as a rapid diagnostic for COVID-19. Med Hypotheses. 2020;141:109786. doi:10.1016/j.mehy.2020.109786

109. Jiang M, Pan W, Arastehfar A, et al. Development and validation of a rapid single-step reverse transcriptase loop-mediated isothermal amplification (RT-LAMP) system potentially to be used for reliable and high-throughput screening of COVID-19. medRxiv. 2020 .

110. Goo N-I, Kim D-E. Rolling circle amplification as isothermal gene amplification in molecular diagnostics. Biochip J. 2016;10 (4):262-271. doi:10.1007/s13206-016-0402-6

111. Nilsson M, Malmgren H, Samiotaki M, Kwiatkowski M, Chowdhary BP, Landegren U. Padlock probes: circularizing oligonucleotides for localized DNA detection. Science. 1994;265 (5181):2085-2088. doi:10.1126/science.7522346

112. Nilsson M. Lock and roll: single-molecule genotyping in situ using padlock probes and rolling-circle amplification. Histochem Cell Biol. 2006;126(2):159-164. doi:10.1007/s00418-006-0213-2

113. Wang W-K, Fang C-T, Chen H-L, et al. Detection of severe acute respiratory syndrome coronavirus RNA in plasma during the course of infection. $J$ Clin Microbiol. 2005;43(2):962-965. doi:10.1128/JCM.43.2.962-965.2005

114. Xu M, Ye J, Yang D, et al. Ultrasensitive detection of miRNA via one-step rolling circle-quantitative PCR (RC-qPCR). Anal Chim Acta. 2019;1077:208-215. doi:10.1016/j.aca.2019.05.028

115. Sun Y, Gregory KJ, Chen NG, Golovlev V. Rapid and direct microRNA quantification by an enzymatic luminescence assay. Anal Biochem. 2012;429(1):11-17. doi:10.1016/j.ab.2012.06.021

116. Hamidi SV, Ghourchian H. Colorimetric monitoring of rolling circle amplification for detection of H5N1 influenza virus using metal indicator. Biosens Bioelectron. 2015;72:121-126. doi:10.1016/j.bios.2015.04.078

117. Gu L, Yan W, Liu L, Wang S, Zhang X, Lyu M. Research progress on rolling circle amplification (RCA)-based biomedical sensing. Pharmaceuticals. 2018;11(2):35. doi:10.3390/ph110 20035

118. Wang B, Potter SJ, Lin Y, et al. Rapid and sensitive detection of severe acute respiratory syndrome coronavirus by rolling circle amplification. $J$ Clin Microbiol. 2005;43(5):2339-2344. doi:10.1128/JCM.43.5.2339-2344.2005

119. Huang J, Li X-Y, Du Y-C, et al. Sensitive fluorescent detection of DNA methyltransferase using nicking endonuclease-mediated multiple primers-like rolling circle amplification. Biosens Bioelectron. 2017;91:417-423. doi:10.1016/j.bios.2016.12.061

120. Li B, Yin H, Zhou Y, Wang M, Wang J, Ai S. Photoelectrochemical detection of miRNA-319a in rice leaf responding to phytohormones treatment based on $\mathrm{CuO}-\mathrm{CuWO} 4$ and rolling circle amplification. Sens Actuators B Chem. 2018;255:1744-1752. doi:10.1016/j.snb.2017.08.192

121. Zhao X, Luo C, Mei Q, et al. Aptamer-cholesterol-mediated proximity ligation assay for accurate identification of exosomes. Anal Chem. 2020;92(7):5411-5418. doi:10.1021/acs.analchem. $0 \mathrm{c} 00141$ 
122. Tian B, Gao F, Fock J, Dufva M, Hansen MF. Homogeneous circle-to-circle amplification for real-time optomagnetic detection of SARS-CoV-2 RdRp coding sequence. Biosens Bioelectron. 2020;165:112356. doi:10.1016/j.bios.2020.112356

123. Vincent $\mathrm{M}, \mathrm{Xu} \mathrm{Y}$, Kong H. Helicase-dependent isothermal DNA amplification. EMBO Rep. 2004;5(8):795-800. doi:10.1038/sj. embor.7400200

124. Keightley MC, Sillekens P, Schippers W, Rinaldo C, George KS. Real-time NASBA detection of SARS-associated coronavirus and comparison with real-time reverse transcription-PCR. J Med Virol. 2005;77(4):602-608. doi:10.1002/jmv.20498

125. Kumar S, Kumar A, Venkatesan G. Isothermal nucleic acid amplification system: an update on methods and applications. $J$ Genet Genom. 2018;2(112):2.

126. Costa AM, Lamb D, Garland SM, Tabrizi SN. Evaluation of LightCycler as a platform for nucleic acid sequence-based amplification (NASBA) in real-time detection of enteroviruses. Curr Microbiol. 2008;56(1):80-83. doi:10.1007/s00284-007-9043-2

127. Lau LT, Feng XY, Lam TY, Hui HK, Yu ACH. Development of multiplex nucleic acid sequence-based amplification for detection of human respiratory tract viruses. J Virol Methods. 2010;168(12):251-254. doi:10.1016/j.jviromet.2010.04.027

128. Forbi JC, Gabadi S, Iperepolu HO, Esona MD, Agwale SM. Quantification of human immunodeficiency virus-1 viral load using nucleic acid sequence-based amplification (NASBA) in north central Nigeria. Niger J Clin Pract. 2010;13(3):284-287.

129. Fukuda S, Sasaki Y, Seno M. Rapid and sensitive detection of norovirus genomes in oysters by a two-step isothermal amplification assay system combining nucleic acid sequence-based amplification and reverse transcription-loop-mediated isothermal amplification assays. Appl Environ Microbiol. 2008;74 (12):3912-3914. doi:10.1128/AEM.00127-08

130. Jean J, Blais B, Darveau A, Fliss I. Rapid detection of human rotavirus using colorimetric nucleic acid sequence-based amplification (NASBA)-enzyme-linked immunosorbent assay in sewage treatment effluent. FEMS Microbiol Lett. 2002;210(1):143-147.

131. Lamhoujeb S, Charest H, Fliss I, Ngazoa S, Jean J. Real-time molecular beacon NASBA for rapid and sensitive detection of norovirus GII in clinical samples. Can J Microbiol. 2009;55 (12):1375-1380. doi:10.1139/W09-105

132. Churruca E, Girbau C, Martinez I, Mateo E, Alonso R, FernandezAstorga A. Detection of Campylobacter jejuni and Campylobacter coli in chicken meat samples by real-time nucleic acid sequence-based amplification with molecular beacons. Int J Food Microbiol. 2007;117 (1):85-90. doi:10.1016/j.ijfoodmicro.2007.02.007

133. Mollasalehi H, Yazdanparast R. Development and evaluation of a novel nucleic acid sequence-based amplification method using one specific primer and one degenerate primer for simultaneous detection of Salmonella Enteritidis and Salmonella Typhimurium. Anal Chim Acta. 2013;770:169-174. doi:10.1016/j.aca.2013.01.053

134. van der Meide WF, Schoone GJ, Faber WR, et al. Quantitative nucleic acid sequence-based assay as a new molecular tool for detection and quantification of Leishmania parasites in skin biopsy samples. J Clin Microbiol. 2005;43(11):5560-5566. doi:10.1128/JCM.43.11.5560-5566.2005

135. Wu Q, Suo C, Brown T, Wang T, Teichmann SA, Bassett AR. INSIGHT: a scalable isothermal NASBA-based platform for COVID-19 diagnosis. bioRxiv. 2020.

136. Gorzalski AJ, Tian H, Laverdure C, et al. High-throughput transcription-mediated amplification on the Hologic Panther is a highly sensitive method of detection for SARS-CoV-2. J Clin Virol. 2020;129:104501. doi:10.1016/j.jcv.2020.104501

137. Qian J, Boswell SA, Chidley C, et al. An enhanced isothermal amplification assay for viral detection. bioRxiv. 2020. doi:10. $1101 / 2020.05 .28 .118059$
138. Xia S, Chen X. Single-copy sensitive, field-deployable, and simultaneous dual-gene detection of SARS-CoV-2 RNA via modified RT-RPA. Cell Discov. 2020;6:37. doi:10.1038/s41421-0200175-x

139. Behrmann O, Bachmann I, Spiegel M, et al. Rapid detection of SARS-CoV-2 by low volume real-time single tube reverse transcription recombinase polymerase amplification using an exo probe with an internally linked quencher (Exo-IQ). Clin Chem. 2020;66(8):1047-1054. doi:10.1093/clinchem/hvaa116

140. Barreda-Garcia S, Miranda-Castro R, De-los-santos-alvarez N, Miranda-Ordieres AJ, Lobo-Castanon MJ. Helicase-dependent isothermal amplification: a novel tool in the development of molecularbased analytical systems for rapid pathogen detection. Anal Bioanal Chem. 2018;410(3):679-693. doi:10.1007/s00216-017-0620-3

141. Gootenberg JS, Abudayyeh OO, Lee JW, et al. Nucleic acid detection with CRISPR-Cas13a/C2c2. Science. 2017;356 (6336):438-442. doi:10.1126/science.aam9321

142. Myhrvold C, Freije CA, Gootenberg JS, et al. Field-deployable viral diagnostics using CRISPR-Cas13. Science. 2018;360 (6387):444-448. doi:10.1126/science.aas8836

143. Broughton JP, Deng X, Yu G, et al. CRISPR-Cas12-based detection of SARS-CoV-2. Nat Biotechnol. 2020;38(7):870-874. doi:10.1038/s41587-020-0513-4

144. Ding X, Yin K, Li Z, et al. Ultrasensitive and visual detection of SARS-CoV-2 using all-in-one dual CRISPR-Cas12a assay. Nat Commun. 2020;11(1):4711. doi:10.1038/s41467-020-18575-6

145. Rauch JN, Valois E, Solley SC, et al. A scalable, easy-to-deploy, protocol for Cas13-based detection of SARS-CoV-2 genetic material. bioRxiv. 2020.

146. Azhar M, Phutela R, Ansari AH, et al. Rapid, field-deployable nucleobase detection and identification using FnCas9. bioRxiv. 2020.

147. Won J, Lee S, Park M, et al. Development of a laboratory-safe and low-cost detection protocol for SARS-CoV-2 of the Coronavirus disease 2019 (COVID-19). Exp Neurobiol. 2020;29 (2):107-119. doi:10.5607/en20009

148. Emergency Use Authorization (EUA) F. Emergency use authorization (EUA) information, and list of all current EUAs; 2020. Available from: https://www.fda.gov/emergency-preparednessand-response/mcm-legal-regulatory-and-policy-framework/emer gency-use-authorization. Accessed February 15, 2021.

149. Lucia C, Federico PB, Alejandra GC. An ultrasensitive, rapid, and portable coronavirus SARS-CoV-2 sequence detection method based on CRISPR-Cas12. bioRxiv. 2020. doi:10.1101/ 2020.02.29.971127

150. Mukama $\mathrm{O}, \mathrm{Wu}$ J, Li Z, et al. An ultrasensitive and specific pointof-care CRISPR/Cas 12 based lateral flow biosensor for the rapid detection of nucleic acids. Biosens Bioelectron. 2020;159:112143. doi:10.1016/j.bios.2020.112143

151. Ding X, Yin K, Li Z, Liu C. All-in-one dual CRISPR-cas12a (AIOD-CRISPR) assay: a case for rapid, ultrasensitive and visual detection of novel coronavirus SARS-CoV-2 and HIV virus. bioRxiv. 2020.

152. Nasseri B, Soleimani N, Rabiee N, Kalbasi A, Karimi M, Hamblin MR. Point-of-care microfluidic devices for pathogen detection. Biosens Bioelectron. 2018;117:112-128. doi:10.1016/ j.bios.2018.05.050

153. Basha IHK, Ho ETW, Yousuff CM, Hamid NHB. Towards multiplex molecular diagnosis-A review of microfluidic genomics technologies. Micromachines. 2017;8(9):266.

154. Zhuang J, Yin J, Lv S, Wang B, Mu Y. Advanced "lab-on-a-chip" to detect viruses-current challenges and future perspectives. Biosens Bioelectron. 2020;163:112291. doi:10.1016/j.bios.2020.112291

155. Magro L, Jacquelin B, Escadafal C, et al. based RNA detection and multiplexed analysis for Ebola virus diagnostics. Sci Rep. 2017;7(1):1-9. doi:10.1038/s41598-017-00758-9 
156. Blacksell SD. Commercial dengue rapid diagnostic tests for point-of-care application: recent evaluations and future needs? Biomed Res Int. 2012;2012.

157. Kuehn BM. Genetic analysis tracks SARS-CoV-2 mutations in human hosts. JAMA. 2020;323(23):2363.

158. Long Q-X, Liu B-Z, Deng H-J, et al. Antibody responses to SARS-CoV-2 in patients with COVID-19. Nat Med. 2020:1-4.

159. Haveri A, Smura T, Kuivanen S, et al. Serological and molecular findings during SARS-CoV-2 infection: the first case study in Finland, January to February 2020. Eurosurveillance. 2020;25(11):2000266. doi:10.2807/1560-7917.ES.2020.25.11.2 000266

160. To KK-W, Tsang OT-Y, Leung W-S, et al. Temporal profiles of viral load in posterior oropharyngeal saliva samples and serum antibody responses during infection by SARS-CoV-2: an observational cohort study. Lancet Infect Dis. 2020;20(5):565-574. doi:10.1016/S1473-3099(20)30196-1

161. Xu Y, Xiao M, Liu X, et al. Significance of serology testing to assist timely diagnosis of SARS-CoV-2 infections: implication from a family cluster. Emerg Microbes Infect. 2020;9(1):924 927. doi:10.1080/22221751.2020.1752610

162. Krsak M, Johnson SC, Poeschla EM. COVID-19 serosurveillance may facilitate return-to-work decisions. Am J Trop Med Hyg. 2020;102(6):1189-1190. doi:10.4269/ajtmh.20-0302

163. Guo L, Ren L, Yang S, et al. Profiling early humoral response to diagnose novel coronavirus disease (COVID-19). Clin Infect Dis. 2020;71(15):778-785. doi:10.1093/cid/ciaa310

164. Yin S, Tong X, Huang A, et al. Longitudinal anti-SARS-CoV-2 antibody profile and neutralization activity of a COVID-19 patient. $J$ Infect. 2020;81(3):e31-e32. doi:10.1016/j.jinf.2020. 06.076

165. Yong SEF, Anderson DE, Wei WE, et al. Connecting clusters of COVID-19: an epidemiological and serological investigation. Lancet Infect Dis. 2020.

166. Peto J, Alwan NA, Godfrey KM, et al. Universal weekly testing as the UK COVID-19 lockdown exit strategy. Lancet. 2020;395 (10234):1420-1421. doi:10.1016/S0140-6736(20)30936-3

167. Wrapp D, Wang N, Corbett KS, et al. Cryo-EM structure of the 2019-nCoV spike in the prefusion conformation. Science. 2020;367(6483):1260-1263. doi:10.1126/science.abb2507

168. Sun B, Feng Y, Mo X, et al. Kinetics of SARS-CoV-2 specific IgM and IgG responses in COVID-19 patients. Emerg Microbes Infect. 2020;1-36.

169. Ou X, Liu Y, Lei X, et al. Characterization of spike glycoprotein of SARS-CoV-2 on virus entry and its immune cross-reactivity with SARS-CoV. Nat Commun. 2020;11(1):1-12. doi:10.1038/ s41467-020-15562-9

170. Hoffmann M, Kleine-Weber H, Schroeder S, et al. SARS-CoV-2 cell entry depends on ACE2 and TMPRSS2 and is blocked by a clinically proven protease inhibitor. Cell. 2020;181(2):271-280. doi:10.1016/j.cell.2020.02.052

171. Sigrist CJ, Bridge A, Le Mercier P. A potential role for integrins in host cell entry by SARS-CoV-2. Antiviral Res. 2020;177:104759. doi:10.1016/j.antiviral.2020.104759

172. Sterlin D, Mathian A, Miyara M, et al. IgA dominates the early neutralizing antibody response to SARS-CoV-2. medRxiv. 2020.

173. U.S.FDA. In vitro diagnostics EUAs; 2020. Available from: https:/www.fda.gov/medical-devices/coronavirus-disease-2019covid-19-emergency-use-authorizations-medical-devices/vitrodiagnostics-euas. Accessed February 15, 2021.

174. Wu J-L, Tseng W-P, Lin C-H, et al. Four point-of-care lateral flow immunoassays for diagnosis of COVID-19 and for assessing dynamics of antibody responses to SARS-CoV-2. J Infect. 2020;81(3):435-442. doi:10.1016/j.jinf.2020.06.023

175. Lassaunière R, Frische A, Harboe ZB, et al. Evaluation of nine commercial SARS-CoV-2 immunoassays. Medrxiv. 2020.
176. Lou B, Li T-D, Zheng S-F, et al. Serology characteristics of SARS-CoV-2 infection after exposure and post-symptom onset. Eur Respir J. 2020;56(2):2000763. doi:10.1183/13993003.007632020

177. Zhang B, Zhou X, Zhu C, et al. Immune phenotyping based on neutrophil-to-lymphocyte ratio and $\mathrm{IgG}$ predicts disease severity and outcome for patients with COVID-19. medRxiv. 2020.

178. Liu R, Liu X, Han H, et al. The comparative superiority of IgMIgG antibody test to real-time reverse transcriptase PCR detection for SARS-CoV-2 infection diagnosis. medRxiv. 2020.

179. Beavis KG, Matushek SM, Abeleda APF, et al. Evaluation of the EUROIMMUN Anti-SARS-CoV-2 ELISA Assay for detection of IgA and IgG antibodies. J Clin Virol. 2020;129:104468. doi:10.1016/j.jcv.2020.104468

180. Biological S. SARS-CoV-2 serological analysis kit; 2020. Available from: https:/www.sinobiological.com/research/virus/ sars-cov-2-antigen-detection-assay. Accessed February 15, 2021.

181. Biological S. SARS-CoV-2 (2019-nCoV) antigen reagents; 2020. Available from: https:/www.sinobiological.com/research/virus/ 2019-ncov-antigen. Accessed February 15, 2021.

182. Liu W, Liu L, Kou G, et al. Evaluation of nucleocapsid and spike protein-based enzyme-linked immunosorbent assays for detecting antibodies against SARS-CoV-2. J Clin Microbiol. 2020;58(6). doi:10.1128/JCM.00461-20.

183. Schoeler L, Le-trilling VTK, Eilbrecht M, et al. A novel in-cell ELISA assay allows rapid and automated quantification of SARSCoV-2 to analyse neutralizing antibodies and antiviral compounds. bioRxiv. 2020.

184. Gan SD, Patel KR. Enzyme immunoassay and enzyme-linked immunosorbent assay. $J$ Invest Dermatol. 2013;133(9):e12. doi:10.1038/jid.2013.287

185. Lippi G, Salvagno GL, Pegoraro M, et al. Assessment of immune response to SARS-CoV-2 with fully automated MAGLUMI 2019-nCoV IgG and IgM chemiluminescence immunoassays. Clin Chem Lab Med. 2020;1.

186. Bonelli F, Sarasini A, Zierold C, et al. Clinical and analytical performance of an automated serological test that identifies S1/S2 neutralizing IgG In covid-19 patients semiquantitatively. bioRxiv. 2020.

187. Jin Y, Wang M, Zuo Z, et al. Diagnostic value and dynamic variance of serum antibody in coronavirus disease 2019. Int $J$ Infect Dis. 2020;94:49-52. doi:10.1016/j.ijid.2020.03.065

188. Lin D, Liu L, Zhang M, et al. Evaluations of the serological test in the diagnosis of 2019 novel coronavirus (SARS-CoV-2) infections during the COVID-19 outbreak. Eur J Clin Microbiol Infect Dis. 2020:1-7.

189. Ma H, Zeng W, He H, et al. Serum IgA, IgM, and IgG responses in COVID-19. Cell Mol Immunol. 2020;17(7):773-775. doi:10.1038/s41423-020-0474-z

190. Padoan A, Cosma C, Sciacovelli L, Faggian D, Plebani M. Analytical performances of a chemiluminescence immunoassay for SARS-CoV-2 IgM/IgG and antibody kinetics. Clin Chem Lab Med. 2020;1.

191. Suhandynata RT, Hoffman MA, Kelner MJ, McLawhon RW, Reed SL, Fitzgerald RL. Longitudinal monitoring of SARSCoV-2 IgM and IgG seropositivity to detect COVID-19. J Appl Lab Med. 2020;5(5):908-920.

192. Tre-Hardy M, Wilmet A, Beukinga I, Dogne JM, Douxfils J, Blairon L. Validation of a chemiluminescent assay for specific SARS-CoV-2 antibody. Clin Chem Lab Med. 2020;58(8):13571364. doi:10.1515/cclm-2020-0594

193. Zhang J, Zhang X, Liu J, et al. Serological detection of 2019$\mathrm{nCoV}$ respond to the epidemic: a useful complement to nucleic acid testing. Int Immunopharmacol. 2020:106861. doi:10.1016/j. intimp.2020.106861 
194. Cai X-F, Chen J, Long Q-X, et al. A peptide-based magnetic chemiluminescence enzyme immunoassay for serological diagnosis of coronavirus disease 2019. J Infect Dis. 2020;222(2):189193. doi:10.1093/infdis/jiaa243

195. Bonelli F, Sarasini A, Zierold C, et al. Clinical and analytical performance of an automated serological test that identifies S1/ S2-neutralizing IgG in COVID-19 patients semiquantitatively. $J$ Clin Microbiol. 2020;58:9. doi:10.1128/JCM.01224-20

196. Bryan A, Pepper G, Wener MH, et al. Performance characteristics of the Abbott architect SARS-CoV-2 IgG assay and seroprevalence in Boise, Idaho. J Clin Microbiol. 2020. doi:10.1128/ JCM.00941-20

197. Kohmer N, Toptan T, Pallas C, et al. The comparative clinical performance of Four SARS-CoV-2 rapid antigen tests and their correlation to infectivity in vitro. J Clin Med. 2021;10(2). doi:10.3390/jcm10020328.

198. U.S.FDA. FDA combating COVID-19 with medical devices; 2020. Available from: https://www.fda.gov/media/136702/down load. Accessed February 15, 2021.

199. Quesada-González D, Merkoçi A. Nanoparticle-based lateral flow biosensors. Biosens Bioelectron. 2015;73:47-63. doi:10.1016/j. bios.2015.05.050

200. Li Z, Yi Y, Luo X, et al. Development and clinical application of a rapid IgM-IgG combined antibody test for SARS-CoV-2 infection diagnosis. J Med Virol. 2020.

201. Huang C, Wen T, Shi FJ, Zeng XY, Jiao YJ. Rapid detection of IgM antibodies against the SARS-CoV-2 virus via colloidal gold nanoparticle-based lateral-flow assay. ACS Omega. 2020;5 (21):12550-12556. doi:10.1021/acsomega.0c01554

202. Quidel. Sofia, SARS antigen FIA; 2020. Available from: https:// www.quidel.com/immunoassays/rapid-sars-tests/sofia-sars-anti gen-fia. Accessed February 15, 2021.

203. Monto AS, Cowling BJ, Peiris JSM. Coronaviruses. In: Kaslow RA, Stanberry LR, LeDuc JW, editors. Viral Infections of Humans. 5th ed. Springer Science \& Business Media; 2014:199-223.

204. Li Q, Liu Q, Huang W, Li X, Wang Y. Current status on the development of pseudoviruses for enveloped viruses. Rev Med Virol. 2018;28(1):e1963. doi:10.1002/rmv.1963

205. Sanders DA. No false start for novel pseudotyped vectors. Curr Opin Biotechnol. 2002;13(5):437-442. doi:10.1016/S0958-1669 (02)00374-9

206. Hwang B-Y, Schaffer DV. Engineering a serum-resistant and thermostable vesicular stomatitis virus $\mathrm{G}$ glycoprotein for pseudotyping retroviral and lentiviral vectors. Gene Ther. 2013;20 (8):807-815. doi:10.1038/gt.2013.1

207. Nie J, Huang W, Liu Q, Wang Y. HIV-1 pseudoviruses constructed in China regulatory laboratory. Emerg Microbes Infect. 2020;9(1):32-41. doi:10.1080/22221751.2019.1702479

208. Nie J, Li Q, Wu J, et al. Establishment and validation of a pseudovirus neutralization assay for SARS-CoV-2. Emerg Microbes Infect. 2020;9(1):680-686. doi:10.1080/22221751.20 20.1743767

209. Haralambieva IH, Ovsyannikova IG, Vierkant RA, Poland GA. Development of a novel efficient fluorescence-based plaque reduction microneutralization assay for measles virus immunity. Clin Vaccine Immunol. 2008;15(7):1054-1059. doi:10.1128/ CVI.00008-08

210. Carpp LN, Fong Y, Bonaparte M, et al. Microneutralization assay titer correlates analysis in two Phase 3 trials of the CYD-TDV tetravalent dengue vaccine in Asia and Latin America. PLoS One. 2020;15(6):e0234236

211. Manenti A, Maggetti M, Casa E, et al. Evaluation of SARS-CoV2 neutralizing antibodies using a CPE-based colorimetric live virus micro-neutralization assay in human serum samples. $J$ Med Virol. 2020;92(10):2096-2104. doi:10.1002/jmv.25986
212. Zielinska E, Liu D, Wu HY, Quiroz J, Rappaport R, Yang DP. Development of an improved microneutralization assay for respiratory syncytial virus by automated plaque counting using imaging analysis. Virol J. 2005;2:84. doi:10.1186/1743-422X-2-84

213. Casals J. Immunological techniques for animal viruses. In: Maramorosch K, Koprowski H, editors. Methods in Virology. Vol. 3. Elsevier; 1967:113-198.

214. Amanat F, White KM, Miorin L, et al. An in vitro microneutralization assay for SARS-CoV-2 serology and drug screening. Curr Protoc Microbiol. 2020;58(1):e108. doi:10.1002/cpmc.108

215. Stadlbauer D, Amanat F, Chromikova V, et al. SARS-CoV-2 seroconversion in humans: a detailed protocol for a serological assay, antigen production, and test setup. Curr Protoc Microbiol. 2020;57(1):e100. doi:10.1002/cpmc.100

216. Reuter JA, Spacek DV, Snyder MP. High-throughput sequencing technologies. Mol Cell. 2015;58(4):586-597. doi:10.1016/j. molcel.2015.05.004

217. Blanco-Suarez A, Perez-Jove P, Escribano-Castillejo N, Ballestero-Tellez M. Retrospective search of SARS-CoV-2 in respiratory samples in Valles Occidental (Barcelona, Spain) before the first case was reported. Enferm Infecc Microbiol Clin. 2020;38(10):511-512. doi:10.1016/j.eimc.2020.05.019

218. Hourdel V, Kwasiborski A, Baliere C, et al. Rapid genomic characterization of SARS-CoV-2 by direct amplicon-based sequencing through comparison of MinION and Illumina iSeq100(TM) system. Front Microbiol. 2020;11:571328. doi:10.3389/fmicb.2020.571328

219. Illumina. Comprehensive workflow for detecting coronavirus using Illumina benchtop systems; 2020. Available from: https:// www.illumina.com/content/dam/illumina-marketing/documents/ products/appnotes/ngs-coronavirus-app-note-1270-2020-001.pdf. Accessed February 15, 2021.

220. ThermoFisher. Targeted NGS for SARS-CoV-2 viral typing, discovery, and epidemiology; 2020. Available from: https://www. thermofisher.com/bd/en/home/life-science/sequencing/dna-sequen cing/microbial-sequencing/microbial-identification-ion-torrentnext-generation-sequencing/viral-typing/coronavirus-research. html. Accessed February 15, 2021.

221. Zou X, Wu J, Gu J, Shen L, Mao L. Application of aptamers in virus detection and antiviral therapy. Front Microbiol. 2019;10:1462. doi:10.3389/fmicb.2019.01462

222. Torabi R, Ranjbar R, Halaji M, Heiat M. Aptamers, the bivalent agents as probes and therapies for coronavirus infections: a systematic review. Mol Cell Probes. 2020;53:101636. doi:10.1016/j. mcp.2020.101636

223. Chen Z, Wu Q, Chen J, Ni X, Dai J. A DNA aptamer based method for detection of SARS-CoV-2 nucleocapsid protein. Virol Sin. 2020;1.

224. Woo CH, Jang S, Shin G, Jung GY, Lee JW. Sensitive fluorescence detection of SARS-CoV-2 RNA in clinical samples via one-pot isothermal ligation and transcription. Nat Biomed Eng. 2020;4(12):1168-1179. doi:10.1038/s41551-020-00617-5

225. Chatterjee TN, Bandyopadhyay R. A molecularly imprinted polymer-based technology for rapid testing of COVID-19. Trans Indian Natl Acad Eng. 2020:1-4.

226. Puoci F, Parisi OI, Dattilo M, et al. "Monoclonal-type" plastic antibodies for SARS-CoV-2 based on molecularly imprinted polymers. BioRxiv. 2020.

227. Wang $\mathrm{H}$, Hou $\mathrm{X}, \mathrm{Wu} \mathrm{X}$, et al. SARS-CoV-2 proteome microarray for mapping COVID-19 antibody interactions at amino acid resolution. bioRxiv. 2020.

228. Okba NM, Müller MA, Li W, et al. Severe acute respiratory syndrome coronavirus 2- specific antibody responses in coronavirus disease patients. Emerg Infect Dis. 2020;26(7):1478. doi:10.3201/eid2607.200841 
229. De Assis RR, Jain A, Nakajima R, et al. Analysis of SARS-CoV2 Antibodies in COVID-19 convalescent plasma using a coronavirus antigen microarray. BioRxiv. 2020.

230. Goode J, Rushworth J, Millner P. Biosensor regeneration: a review of common techniques and outcomes. Langmuir. 2015;31(23):6267-6276. doi:10.1021/1a503533g

231. Seo G, Lee G, Kim MJ, et al. Rapid detection of COVID-19 causative virus (SARS-CoV-2) in human nasopharyngeal swab specimens using field-effect transistor-based biosensor. ACS Nano. 2020;14(4):5135-5142. doi:10.1021/acsnano.0c02823

232. Mavrikou S, Moschopoulou G, Tsekouras V, Kintzios S. Development of a portable, ultra-rapid and ultra-sensitive cell-based biosensor for the direct detection of the SARS-CoV-2 S1 spike protein antigen. Sensors. 2020;20(11):3121. doi:10.3390/s20113121

233. Murugan D, Bhatia H, Sai V, Satija J. P-FAB: a fiber-optic biosensor device for rapid detection of COVID-19. Trans Indian Natl Acad Eng. 2020:1-5.

234. Rocca MF, Zintgraff JC, Dattero ME, et al. A combined approach of MALDI-TOF mass spectrometry and multivariate analysis as a potential tool for the detection of SARS-CoV-2 virus in nasopharyngeal swabs. J Virol Methods. 2020;286:113991.

235. Zhang D, Zhang X, Ma R, et al. Ultra-fast and onsite interrogation of severe acute respiratory syndrome coronavirus 2 (SARSCoV-2) in environmental specimens via surface enhanced Raman scattering (SERS). medRxiv. 2020

236. Younes N, Al-Sadeq DW, Al-Jighefee H, et al. Challenges in laboratory diagnosis of the novel coronavirus SARS-CoV-2. Viruses. 2020;12(6):582. doi:10.3390/v12060582

237. Wu J, Liu J, Li S, et al. Detection and analysis of nucleic acid in various biological samples of COVID-19 patients. Travel Med Infect Dis. 2020;37:101673. doi:10.1016/j.tmaid.2020.101673

238. Liu Y, Yan L-M, Wan L, et al. Viral dynamics in mild and severe cases of COVID-19. Lancet Infect Dis. 2020.

239. Zhang H, Chen M, Zhang Y, et al. The yield and consistency of the detection of SARS-CoV-2 in multiple respiratory specimens. Open Forum Infect Dis. 2020;7(10):ofaa379. doi:10.1093/ofid/ofaa379

240. Pasomsub E, Watcharananan SP, Watthanachockchai T, et al. Saliva sample pooling for the detection of SARS-CoV-2. J Med Virol. 2020. doi:10.1002/jmv.26460

241. Mittal A, Gupta A, Kumar S, et al. Gargle lavage as a viable alternative to swab for detection of SARS-CoV-2. Indian J Med Res. 2020

242. Walsh KA, Jordan K, Clyne B, et al. SARS-CoV-2 detection, viral load and infectivity over the course of an infection: SARS-CoV-2 detection, viral load and infectivity. J Infect. 2020;81(3):357-371. doi:10.1016/j.jinf.2020.06.067

243. Vogels CB, Brackney D, Wang J, et al. SalivaDirect: simple and sensitive molecular diagnostic test for SARS-CoV-2 surveillance. medRxiv. 2020.

244. Inc. B. Biomeme SARS-CoV-2 Real-Time RT-PCR Test; 2020 Available from: https://www.fda.gov/media/141052/download. Accessed January 25, 2021.

245. Laboratory GWUPH. Emergency use authorization (EUA) summary GWU COVID-19 RT-PCR test; 2020. Available from: https://www. fda.gov/media/140980/download. Accessed February 15, 2021.

246. W1 LLC. Accelerated emergency use authorization (EUA) summary WREN laboratories COVID-19 PCR Test; 2020. Available from: https://www.fda.gov/media/140776/download. Accessed February 15, 2021.

247. Creager HM, Cabrera B, Schnaubelt A, et al. Clinical evaluation of the BioFire(R) respiratory panel 2.1 and detection of SARS-CoV-2. J Clin Virol. 2020;129:104538. doi:10.1016/j.jcv.2020.104538

248. Eckbo EJ, Locher K, Caza M, Li L, Lavergne V, Charles M. Evaluation of the BioFire(R) COVID-19 test and respiratory panel 2.1 for rapid identification of SARS-CoV-2 in nasopharyngeal swab samples. Diagn Microbiol Infect Dis. 2020;99 (3):115260. doi:10.1016/j.diagmicrobio.2020.115260
249. Mostafa HH, Carroll KC, Hicken R, et al. Multi-center evaluation of the Cepheid Xpert(R) Xpress SARS-CoV-2/Flu/RSV Test. $J$ Clin Microbiol. 2020. doi:10.1128/JCM.02955-20

250. Fournier PE, Zandotti C, Ninove L, et al. Contribution of VitaPCR SARS-CoV-2 to the emergency diagnosis of COVID19. J Clin Virol. 2020;133:104682. doi:10.1016/j.jcv.2020.104682

251. Quidel. Lyra SARS-CoV-2 assay; 2020. Available from: https:// www.quidel.com/sites/default/files/product/documents/Lyra_ BRM120002EN00.pdf. Accessed January 21, 2021.

252. DiaSorin. Simplexa ${ }^{\mathrm{TM}}$ COVID-19 direct kit. Available from: https://molecular.diasorin.com/international/kit/simplexa-covid19-direct-kit/. Accessed January 21, 2021.

253. Hologic. Panther Fusion ${ }^{\mathrm{TM}}$ SARS-CoV-2; 2020. Available from: https://www.hologic.com/sites/default/files/2020-05/AW-21388001_002_01.pdf. Accessed January 24, 2021.

254. LabCorp. LabCorp COVID-19 RT-PCR test; 2020. Available from: https://files.labcorp.com/labcorp-d8/2020-04/LabCorpCOVID-EUAsum3.pdf. Accessed January 24, 2021.

255. Tanida K, Koste L, Koenig C, Wenzel W, Fritsch A, Frickmann H. Evaluation of the automated cartridge-based ARIES SARSCoV-2 Assay (RUO) against automated Cepheid Xpert Xpress SARS-CoV-2 PCR as gold standard. Eur J Microbiol Immunol (Bp). 2020;10(3):156-164. doi:10.1556/1886.2020.00017

256. Das Mukhopadhyay C, Sharma P, Sinha K, Rajarshi K. Recent trends in analytical and digital techniques for the detection of the SARS-Cov-2. Biophys Chem. 2020;270:106538. doi:10.1016/j. bpc. 2020.106538

257. Hogan CA, Garamani N, Lee AS, et al. Comparison of the Accula SARS-CoV-2 test with a laboratory-developed assay for detection of SARS-CoV-2 RNA in clinical nasopharyngeal specimens. $J$ Clin Microbiol. 2020;58(8). doi:10.1128/JCM.01072-20.

258. MIRXES. MiRXES fortitude COVID-19 RT-PCR test; 2020. Available from: https://mirxes.com/wp-content/uploads/2021/01/ LB-261US-MiRXES-Fortitude-Kit-3.0_r02-IFU-EUA.pdf. Accessed January 24, 2021.

259. Visseaux B, Le Hingrat Q, Collin G, et al. Evaluation of the QIAstat-Dx respiratory SARS-CoV-2 panel, the first rapid multiplex PCR commercial assay for SARS-CoV-2 detection. J Clin Microbiol. 2020;58(8). doi:10.1128/JCM.00630-20.

260. Poljak M, Korva M, Knap Gasper N, et al. Clinical evaluation of the cobas SARS-CoV-2 test and a diagnostic platform switch during 48 hours in the Midst of the COVID-19 pandemic. $J$ Clin Microbiol. 2020;58(6). doi:10.1128/JCM.00599-20.

261. Li M, Zhao Y, Li Y, et al. Development and evaluation of a Novel RT-PCR system for reliable and rapid SARS-CoV-2 screening of blood donations. Transfusion. 2020;60(12):2952-2961. doi:10.11 $11 /$ trf. 16049

262. Biosensor S. STANDARD M nCoV real-time detection kit; 2020. Available from: https:/www.fda.gov/media/137302/download. Accessed January 24, 2021.

263. Garg A, Ghoshal U, Patel SS, et al. Evaluation of seven commercial RT-PCR kits for COVID-19 testing in pooled clinical specimens. J Med Virol. 2020. doi:10.1002/jmv.26691

264. Hur KH, Park K, Lim Y, Jeong YS, Sung H, Kim MN. Evaluation of four commercial kits for SARS-CoV-2 real-time reverse-transcription polymerase chain reaction approved by emergency-useauthorization in Korea. Front Med (Lausanne). 2020;7:521. doi:10.3389/fmed.2020.00521

265. Diagnostics VEC. Viracor SARS-CoV-2 assay; 2020. Available from: https://www.fda.gov/media/143069/download. Accessed January 24, 2021.

266. Rastawicki W, Rokosz-Chudziak N. Characteristics and assessment of the usefulness of serological tests in the diagnostic of infections caused by coronavirus SARS-CoV-2 on the basis of available manufacturer's data and literature review. Przegl Epidemiol. 2020;74(1):49-68. doi:10.32394/pe.74.11 
267. Sil BK, Jahan N, Haq MA, Oishe MJ, Ali T, Khandker SS, Kobatake E, Mie M, Khondoker MU, Jamiruddin MR, Adnan N. Development and performance evaluation of a rapid in-house ELISA for retrospective serosurveillance of SARS-CoV-2. PLoS One. 2021;16(2):e0246346. doi:10.1371/journal.pone.0246346.

268. Sil BK, Adnan N, Oishee MJ, et al. Development and evaluation of two rapid indigenous IgG-ELISA immobilized with ACE-2 binding peptides for detection neutralizing antibodies against SARS-CoV-2. medRxiv. 2020

269. Bundschuh C, Egger M, Wiesinger K, et al. Evaluation of the EDI enzyme linked immunosorbent assays for the detection of SARSCoV-2 IgM and IgG antibodies in human plasma. Clin Chim Acta. 2020;509:79-82. doi:10.1016/j.cca.2020.05.047

270. Inc. A. Serology test evaluation report for "Advaite RapCovRapid COVID-19 test" from Advaite Inc; 2020. Available from: https:// rapcov.com/wp-content/uploads/2021/01/EUA202686NCI Report2Nov19Finalized.pdf. Accessed January 24, 2021.

271. Cassaniti I, Novazzi F, Giardina F, et al. Performance of VivaDiag COVID-19 IgM/IgG Rapid Test is inadequate for diagnosis of COVID-19 in acute patients referring to emergency room department. J Med Virol. 2020;92(10):1724-1727. doi:10.1002/jmv.25800

272. Rikhtegaran Tehrani Z, Saadat S, Saleh E, et al. Performance of nucleocapsid and spike-based SARS-CoV-2 serologic assays. PLoS One. 2020;15(11):e0237828. doi:10.1371/journal.pone.0237828

273. Biotech C. COVID-19 IgG/IgM Rapid Test; 2020. Available from: https://ctkbiotech.com/product/onsite-covid-19-igg-igmrapid-test/. Accessed January 24, 2021.

274. Biomedomics. Serology test evaluation report for "COVID-19 IgM-IgGRapid Test kit" from Biomedomics; 2020. Available from: https://www.accessdata.fda.gov/cdrh_docs/presentations/ maf/maf3248-a001.pdf. Accessed January 24, 2021.

275. Nagasawa M, Yamaguchi $Y$, Furuya $M$, et al. Investigation of Anti-SARS-CoV-2 IgG and IgM Antibodies in the patients with COVID-19 by three different ELISA test kits. SN Compr Clin Med. 2020:1-5.
276. Diagnostics O-C. VITROS immunodiagnostic products SARSCoV-2 antigen; 2020. Available from: https://www.fda.gov/ media/145073/download. Accessed January 24, 2021.

277. Wan Y, Li Z, Wang K, Li T, Liao P. Performance verification of anti-SARS-CoV-2-specific antibody detection by using four chemiluminescence immunoassay systems. Ann Clin Biochem. 2020;57(6):429-434. doi:10.1177/0004563220963847

278. Biotechnologia C. Celer one step COVID-19 test; 2020. Available from: https://celer.ind.br/wp-content/uploads/2020/04/Instrucaode-Uso-One-Step-COVID-2019-Test_Rev02_informativo.pdf. Accessed January 24, 2021.

279. Pharmact. BELTEST-IT COV-2; 2020. Available from: http:// afrikbiosa.com/wp-content/uploads/2020/04/200414_BfArM Sonderzulassung_Anschreiben_V1.04_Full-Document_sign.pdf. Accessed January 24, 2021.

280. Mertens P, De Vos N, Martiny D, et al. Development and potential usefulness of the COVID-19 ag respi-strip diagnostic assay in a pandemic context. Front Med (Lausanne). 2020;7:225. doi:10. 3389/fmed.2020.00225

281. Biosensor S Standard Q COVID-19 Ag; 2020. Available from: http://sdbiosensor.com/xe/product/7672. Accessed January 24, 2021.

282. Song Y, Song J, Wei X, et al. Discovery of aptamers targeting receptor-binding domain of the SARS-CoV-2 spike glycoprotein. Anal Chem. 2020;92(14):9895-9900. doi:10.1021/acs.analchem. 0c01394

283. Puoci F. "Monoclonal-Type" plastic antibodies for COVID-19 treatment: what Is the Idea? J Funct Biomater. 2020;11(2):43. doi: $10.3390 /$ jfb 11020043
Infection and Drug Resistance

\section{Publish your work in this journal}

Infection and Drug Resistance is an international, peer-reviewed openaccess journal that focuses on the optimal treatment of infection (bacterial, fungal and viral) and the development and institution of preventive strategies to minimize the development and spread of resistance. The journal is specifically concerned with the epidemiology of

\section{Dovepress}

antibiotic resistance and the mechanisms of resistance development and diffusion in both hospitals and the community. The manuscript management system is completely online and includes a very quick and fair peerreview system, which is all easy to use. Visit http://www.dovepress.com/ testimonials.php to read real quotes from published authors. 